\title{
Dam busy: beavers and their influence on the structure and function of river corridor hydrology, geomorphology, biogeochemistry and ecosystems
}

\author{
Annegret Larsen ${ }^{1,2^{*}}$, Joshua Larsen ${ }^{3,4^{*}}$, Stuart N. Lane ${ }^{5}$ \\ 1 Soil Geography and Landscape group, Wageningen University, Droevendaalsesteeg 3, \\ 6708 PB Wageningen, The Netherlands, annegret.larsen@wur.nl (corresponding author) \\ 2 The University of Manchester, Oxford Rd, Manchester, M13 9PL, United Kingdom \\ 3 School of Geography, Earth and Environmental Sciences, University of Birmingham, \\ United Kingdom \\ $4 \quad$ Birmingham Institute of Forestry Research (BIFoR), University of Birmingham, United \\ Kingdom \\ 5 Institute of Earth Surface Dynamics, Université de Lausanne, 1015 Lausanne, Switzerland \\ *these authors have contributed equally to this work
}

This manuscript has been submitted for publication in the journal Earth Science Reviews. Please note that the manuscript is currently under peer-review, and has yet to be accepted for publication. Subsequent versions of this manuscript may have slightly different content. If accepted, the final version of the manuscript will be available via the peerreview DOI link on the right-hand side of the webpage. Please feel free to contact any of the authors, we welcome feedback.

\section{Keywords}

Beaver, hydrology, geomorphology, biogeochemistry, water quality, carbon, ecosystem, disturbance, river restoration, ecosystem engineering, keystone species

\section{Abstract}

Beavers (castor fiber, castor canadensis) are the most influential mammalian ecosystem engineer, heavily modifying river corridors and influencing hydrology, geomorphology, nutrient cycling, and ecosystems. As an agent of disturbance, they achieve this first and foremost through dam construction, which impounds flow and increases the extent of open water, and from which all other landscape and ecosystem impacts follow. After a long period of local and regional eradication, beaver populations have been recovering and expanding throughout Europe and North America, as well as an introduced species in South America, prompting a need to comprehensively review the current state of knowledge 
on how beavers influence the structure and function of river corridors. Here, we synthesize the overall impacts on hydrology, geomorphology, biogeochemistry, and aquatic and terrestrial ecosystems. Our key findings are that a complex of beaver dams can increase surface and subsurface water storage, modify the reach scale partitioning of water budgets, allow site specific flood attenuation, alter low flow hydrology, increase evaporation, increase water and nutrient residence times, increase geomorphic heterogeneity, delay sediment transport, increase carbon, nutrient and sediment storage, expand the extent of anaerobic conditions and interfaces, increase the downstream export of dissolved organic carbon and ammonium, decrease the downstream export of nitrate, increase lotic to lentic habitat transitions and aquatic primary production, induce 'reverse' succession in riparian vegetation assemblages, and increase habitat complexity and biodiversity on reach scales. We then examine the key feedbacks and overlaps between these changes caused by beavers, where the decrease in longitudinal hydrologic connectivity create ponds and wetlands, transitions between lentic to lotic ecosystems, increase vertical hydraulic exchange gradients, and biogeochemical cycling per unit stream length, while increased lateral connectivity will determine the extent of open water area and wetland and littoral zone habitats, and induce changed in aquatic and terrestrial ecosystem assemblages. However, the extent of these impacts depends firstly on the hydro-geomorphic landscape context, which determines the extent of floodplain inundation, a key driver of subsequent changes to hydrologic, geomorphic, biogeochemical, and ecosystem dynamics. Secondly, it depends on the length of time beavers can sustain disturbance at a given site, which is constrained by top down (e.g. predation) and bottom up (e.g. competition) feedbacks, and ultimately determines the pathways of river corridor landscape and ecosystem succession following beaver abandonment. This outsized influence of beavers on river corridor processes and feedbacks is also fundamentally distinct from what occurs in their absence. Current river management and restoration practices are therefore open to reexamination in order to account for the impacts of beavers, both positive and negative, such that they can potentially accommodate and enhance the ecosystem engineering services they provide. It is hoped that our synthesis and holistic framework for evaluating beaver impacts can be used in this endeavor by river scientists and managers into the future as beaver populations continue to expand in both numbers and range.

\section{Contents}

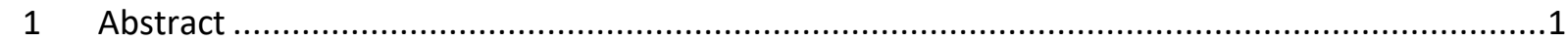

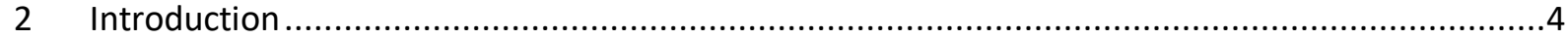

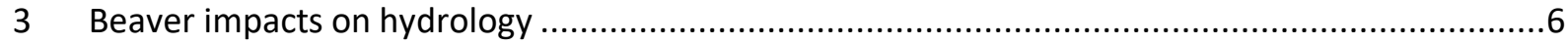

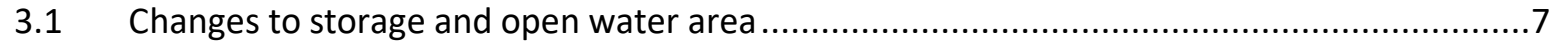

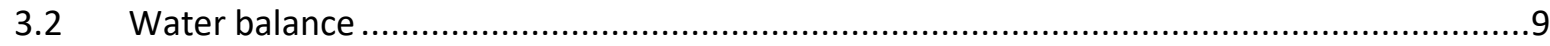

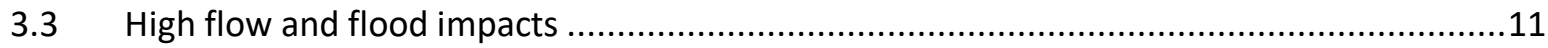

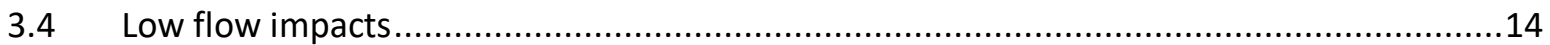

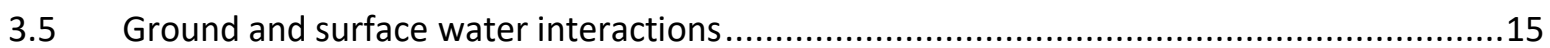

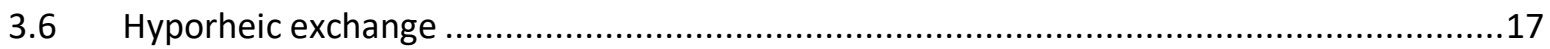

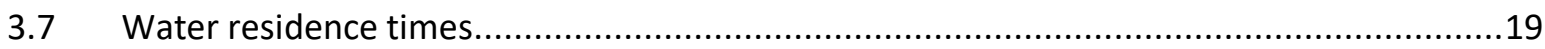


3.8 Water temperature

4 The influence of beavers on river-floodplain Geomorphology ..............................................21

4.1 Sediment transport and deposition in beaver systems ..................................................22

4.2 Erosion in beaver systems.

4.3 The role of beaver channels, burrows and dams in the hydro-geomorphology of rivers and floodplains

4.4 Decadal to millennial valley formation mediated by beavers.

5 Changes in biogeochemistry, carbon and nutrient cycling, and water quality ..... .30

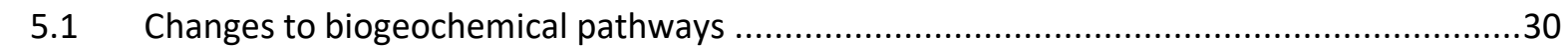

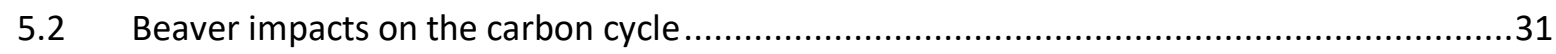

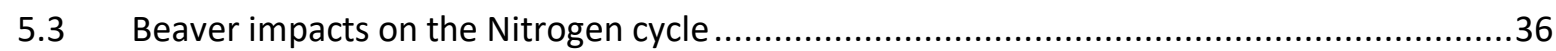

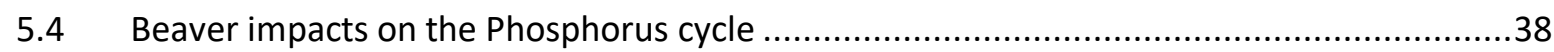

5.5 Impacts on iron cycling, mercury, and additional contaminants ......................................39

5.6 Impacts on source vs sink behavior, and the evolution of overall water quality and its

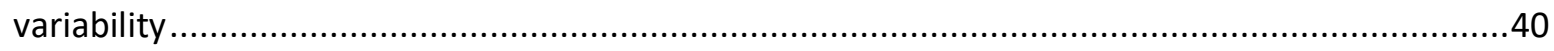

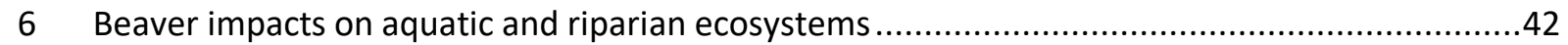

6.1 Creating a mix of lotic and lentic environments, disruptions to the river continuum, and changes to aquatic ecosystem productivity.

6.2 Beaver impacts on ecosystem biodiversity and functioning: Macro-Invertebrates .............44

6.3 Beaver impacts on ecosystem biodiversity and functioning: Fish....................................45

6.4 Beaver impacts on ecosystem biodiversity and functioning: Other fauna ..........................48

6.5 Beaver impacts on ecosystem biodiversity and functioning: Vegetation.

7 Interconnections and feedbacks between the hydrology, geomorphology, biogeochemistry and ecosystems of beaver impacted streams.

7.1 Initial and shorter-term impacts: the importance of floodplain inundation and disturbance 52

7.2 Longer-term impacts: Perpetual succession of landscapes and ecosystems, and feedbacks driving carbon sequestration potential.

8 Do beaver impacts promote alternate stable states for river corridor landscapes and ecosystems?

9 Natural landscapes, perception, and the role of beavers in stream management and rehabilitation....

9.1 What is natural, and what might the future hold?

9.2 Insufficient context can skew the interpretation of beaver impacts ..................................59

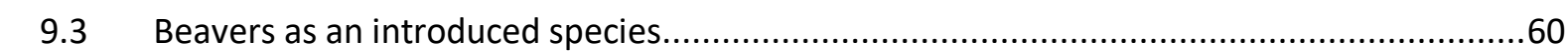

9.4 Beavers as ecosystem engineers and their role in river restoration and rehabilitation .......61 
11311 Conclusion...

\section{Introduction}

Beavers (Castor fiber, Castor canadensis) are semiaquatic mammals partial to freshwater environments. They have the somewhat unique ability to create their own ecological niche at relatively large scales by actively engineering their habitat through dam construction. They get busy doing this most effectively in smaller channels, either of lower order streams and their associated floodplains, or in floodplain and side channels of larger rivers (Butler and Malanson, 2005; Gurnell, 1998; Laland and Boogert, 2010; Westbrook et al., 2013). This dam construction has the potential to alter the hydrology, geomorphology, biogeochemistry, and ecosystems of river corridors and the feedbacks between them, thus the beaver is also increasingly recognized as an 'ecosystem engineer' (e.g. Jones et al. (1996), Wright et al. (2002)). Both species of beaver can have environmental impacts across wide swaths of the Northern Hemisphere, and following a long history of eradication and now partial recovery (Halley et al., 2012), their (re)-introduction is increasingly being advocated for in many cases to aid ecosystem restoration in regions once part of their historical range (Andersen and Shafroth, 2010; Macdonald et al., 1995; Pollock et al., 2014; Rosell et al., 2005) (Figure 1). Whilst some differences in litter size (Parker et al., 2012) and dam building frequency (Whitfield et al., 2015) may exist between the two species, for the purpose of this review, which focuses on landscape and ecosystem process impacts, and given the highly inconclusive data on the biological and ecological differences, we make no further distinctions between them. Although beavers occupy a range of habitats by burrowing (e.g. on large rivers and lakes (Bashinskiy, 2020), it is their unique ability to construct dams within river corridors and the consequences for landscape and ecosystem process that forms the focus of this review. Beavers build dams to help engineer their food supply of riparian and wetland vegetation, to create water bodies sufficiently deep that do not completely freeze during winter in higher latitudes, and as a protection from potential predators. The sound of running water is also apparently sufficient stimulation to trigger the busy dam repair behavior (Müller-Schwarze, 2011). The size of individual beaver dams can be large, especially across floodplain and wetland habitats, however within free flowing river reaches it appears beavers generally prefer to build across river widths of $4-6 \mathrm{~m}$ or less (Hartmann and Törnlöv, 2006) (Suzuki and McComb, 1998) and lower slope gradients (Suzuki and McComb, 1998, Pollock et al. 2003), but also with relatively wide river valleys (e.g. valleys width $>4$ stream widths) (Suzuki and McComb, 1998, Pollock et al. 2003) where beaver meadows can also develop (Figure $2 \mathrm{~b}$ ). In addition, a single dam may not be built in isolation, with multiple dams over a reach termed a beaver dam cascade, and in this case lower peak discharges and higher river valley slope appear to be more important in allowing higher dam numbers to be constructed per cascade (Neumayer et al., 2020) (Figure 2a). This is not to say beavers do not construct dams outside these ranges (Pinto et al., 2009), or that other habitat factors such as vegetation (see section 6.5) are not important, only that they appear to be the preferred conditions for dam construction within a wide distribution of activity. Once constructed, dams may be actively maintained for years to decades, 
become abandoned, breached by floods, filled with sediment, or modified by human activity (James and Lanman, 2012; Johnston, 2015). Whatever their fate, both species of beaver have an amazing capacity to engineer streams across a wide spectrum of environmental gradients, which also shapes a range of positive and negative perceptions concerning their influence. On the one hand beavers may be perceived as undermining existing river engineering schemes and current land use activities, and thus creating conflict (Andersen and Shafroth, 2010). On the other hand, beavers may be seen as an alternative to traditional 'hard' engineering in river restoration (Polvi and Wohl, 2013), with their presence potentially improving river restoration success (Mika et al., 2010).

Recognizing the ever increasing interest in beavers and their works (Goldfarb, 2018), their increasing population numbers and range (Halley et al., 2012), and especially their capacity to shape the river corridor landscape (Naiman and Rogers, 1997), the aim of this paper is to synthesize our current understanding on the process controls and impacts of beavers on river corridor hydrology, geomorphology, biogeochemistry and ecosystems, as well as the feedbacks between them. This is structured using seven sections: The first four deal with the primary impacts of beavers on processes and dynamics: (3) hydrology; (4) geomorphology; (5) biogeochemistry; and (6) stream and riparian ecosystems. In section (7) we integrate the knowledge gained from these separate areas to explore the feedbacks between them, in section (8) we discuss the idea that beavers can promote alternate stable states for river corridor ecosystems, and in section (9) we discuss the interpretation and perception of natural landscapes and beaver impacts, as well as the role of beavers in stream management and rehabilitation. A concise overview of these findings along with selected references is provided in Table 1. Finally, in section (10) we use the outcomes of our synthesis to develop a holistic framework in which beaver impacts can be evaluated as the hydrological and geomorphic contexts of the river system change. 


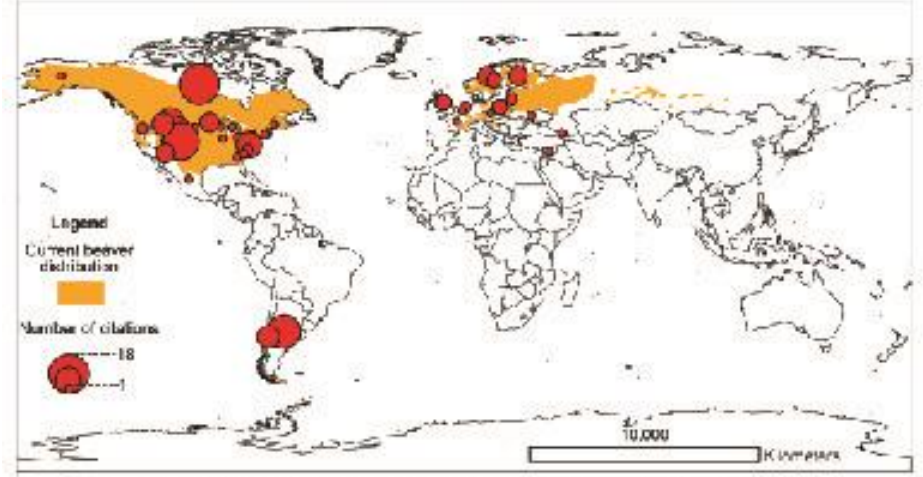

Figure 1_Number of publications on beaver-ecosystem feedbacks in peer-review joumals per country (USA: states).
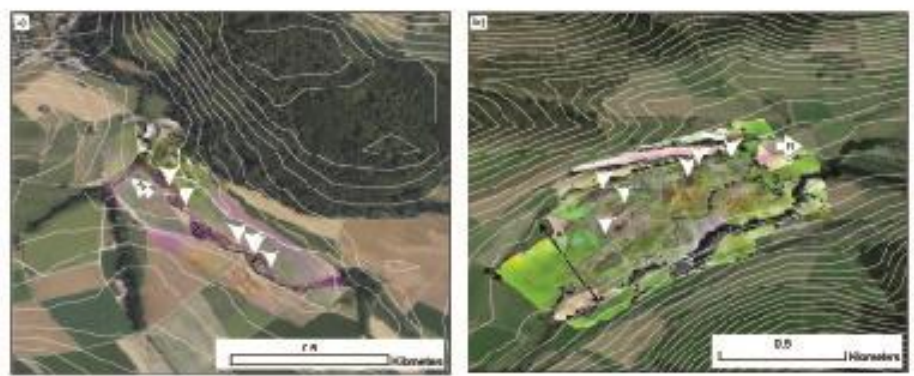

Figure 2_Landscape context of a typical beaver cascade (a) and beaver meadow (b).

Figure 3_Photos of beaver ponds across a wide spectrum of flow regimes
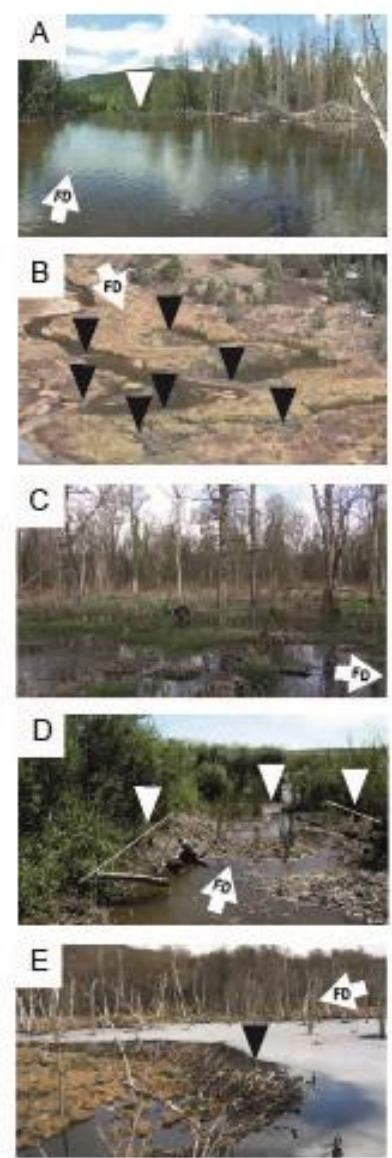

\section{Beaver impacts on hydrology}

179 Beavers first impact the overall water balance, and through this downstream flow regimes. Beavers build dams, and the initial hydrological impact of beaver dam construction is a reduction in water velocity and local increase of the in-channel water level, creating a beaver 'pond', with backwater effects on the inflowing channel (Figure 4,). These ponds can be spatially extensive, grade into wetlands and meadows, and can be relatively shallow in less confined rivers and floodplains (Chaubey and Ward, 2006; Naiman et al., 1988), and vice versa in steeper and more confined river sections. Through flow diversion of stream water (Figure 4) and the accompanying rise in groundwater levels (Figure $9 \mathrm{~b}, \mathrm{c}$ ), floodplain inundation can also be far more extensive than would otherwise occur without beaver dams, especially during flood events (Westbrook et al., 2006). In a semi- or unconfined valley river-floodplain system, beaver dam complexes (Figure 5 b) are likely to create more spatially complex flow networks when compared to the river without beaver dams (Figure 5 a) (Green and Westbrook, 2009). In areas with exceptionally low relief, beaver damming may even divert channels across watershed divides (Westbrook et al., 2013). These observations suggest that the impact of beaver dams on the hydrology of river systems varies widely, according to the processes that determine the relative change in water level, water storage, and subsequent water redistribution within the landscape that beaver dams come to occupy. These processes are discussed below. 


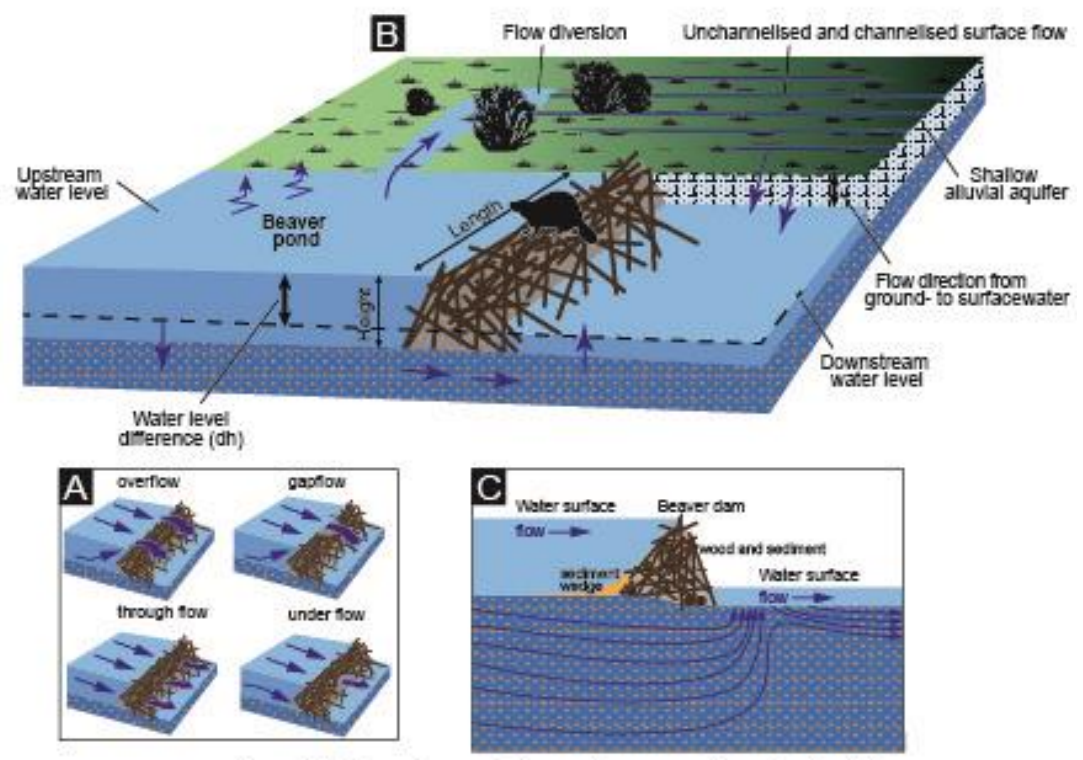

Figure 4_Conceptual model of the influence of beaver dams on (sub)surface hydrology
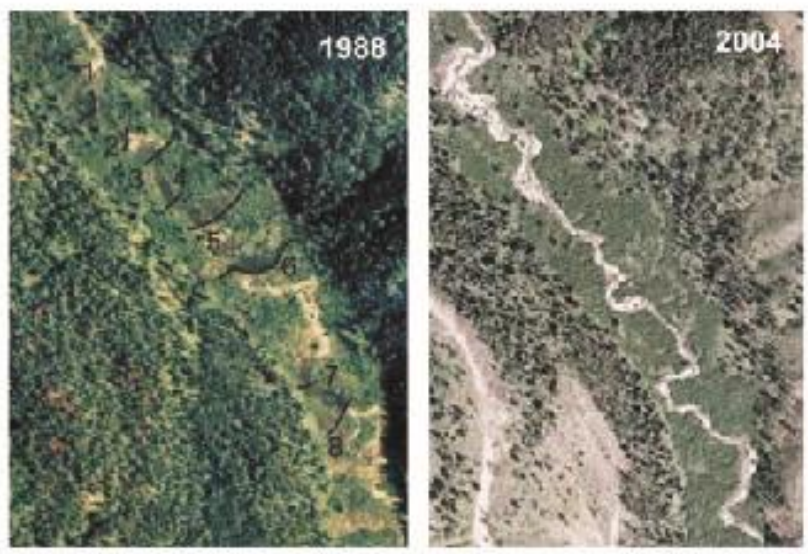

Figure 5_Beaver dam complexes geate more spatially complex flow networks in semi- or unconfined river-floodplain system (from Green and Westbrook (2009))

\subsection{Changes to storage and open water area}

197 A change in water storage capacity is the key hydrological modification from which other impacts follow. Analogous to artificial reservoirs, beaver dams create additional surface water storage whose magnitude depends on whether the rise in water level behind the dam (to create a beaver pond) remains confined to the channel. Examples of confined ponds include incised channels, or where the channel is very large relative to dam size. If this is the case, then the surface storage impacts of beaver dams are related only to the channel volumes, which can in itself be significant (Jin et al., 2009). If the channel water level exceeds the local floodplain height, either permanently or on a seasonal or event basis, the floodplain will be inundated to some extent and create larger areas of ponded and slowly flowing water. This increases the frequency of channel-floodplain connectivity and provide access to greater floodplain spaces to store and move water. Changes to energy losses and stream slope will also be important as these will control the partitioning of discharge rises between increases in velocity and increases in depth for in-channel flow and hence the ease of connection between river and floodplain. Thus, the stream-valley morphology is also a critical determinant of the potential hydrological impacts of beaver dams. Depending on these geomorphic and hydrologic conditions, the increase in water storage is usually most clearly manifest as an increase in the areal extent of open 
surface water, which have been measured to be up to $9-12$ times the pre-beaver open water extent (Hood and Bayley, 2008; Hood and Larson, 2015; Johnston, 2001; Johnston and Naiman, 1990b; Majerova et al., 2015; Morrison et al., 2015; Puttock et al., 2017) (Figure 6). These increases in inundation extent can be profound over long (e.g., 50 - 60 year) time periods (Figure 6a, b), with Hood and Bayley (2008) finding a 9-fold increase in water surface area over this time in Alberta (Canada). They can also be profound within a single reach as dam densities increase (Figure $6 \mathrm{c}$ ), and even seasonally within a single pond and wetland complex (Figure $6 \mathrm{~d}$ ). This increase in open water area with reduced turbulence is therefore an important hydrological consequence of beaver dam construction in river systems, and can have profound implications for the water balance, biogeochemical processes, and ecosystems.

Floodplain storage capacity may be further enhanced as beavers modify their habitat, for example through the excavation of small floodplain channel networks and ponds (Johnston and Naiman, 1990; Stocker, 1985). Although the surface storage capacity of individual beaver dams (pond and floodplain) is small relative to artificial reservoirs, the cumulative surface storages of multiple dams within a beaver dam cascade may significantly increase their hydrological impact (Figure 6a and b) (Puttock et al., 2017, Nyssen et al., 2011). Published dam density estimates range between less than 1 (e.g. 0.1) to $>70$ dams per km of river reach (Gurnell, 1998; Zavyalov, 2014, Pollock et al., 2003), although considerably lower density estimates were compiled by Johnston (2017). At high densities, even small individual dam storage capacities $\left(\mathrm{L}^{3}\right)$ relative to inflow rates $\left(\mathrm{L}^{3} \mathrm{~T}^{-1}\right)$ can in the aggregate substantially modify water balances, water residence times, and flow regimes. These topics will be discussed in the following sections.

There are at least four ways in which the comparison between beaver dams and artificial reservoirs or weirs diverge, with important implications for the interpretation of storage dynamics. First, the dam structure itself is permeable (Burchsted et al., 2010), and will make a largely unknown contribution to outflow rates (discussed in the section below). Second, the relatively low dam height compared to valley width results in very high surface area to volume ratios which can enhance losses to infiltration and evaporation. Third, beaver dams are typically constructed within alluvial valleys of moderate to low stream power (Pollock et al., 2003; Suzuki and McComb, 1998), conditions that are favorable to higher hydraulic connectivity between the surface and shallow alluvial aquifers. This means that the subsurface storage volume changes have the potential to be comparable to, if not larger than, the surface storage volume changes, a point discussed in more detail in the surface - groundwater connectivity section 3.5. Finally, the physical location of beaver dams can be highly dynamic in space and time, adding significant complexity to how storage changes evolve within river reaches, especially those with multiple dams over short distances. All these processes can change the water storage dynamics in catchments and have important implications for the way the hydrological cycle is balanced over a range of timescales. 

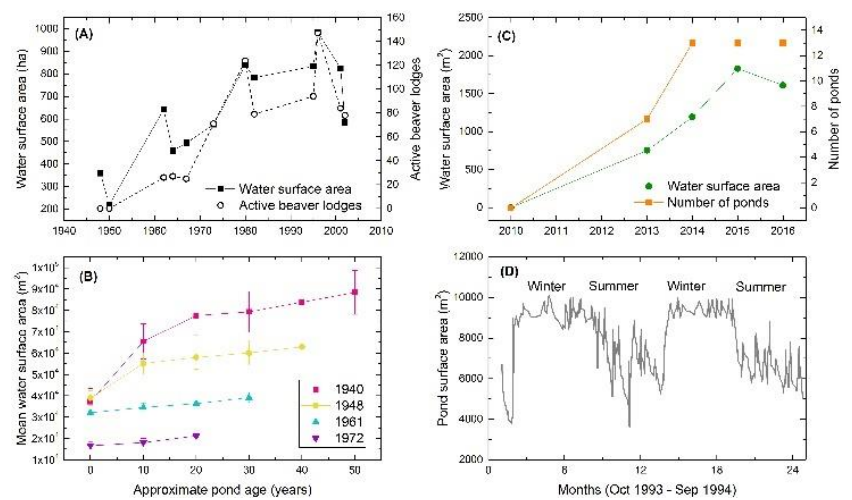

Figure_6: Changes in open water area and number of beaver ponds over time (from Hood and Bayley (2008), Puttock et al. (2017), Johnston and Naiman (1990))

\subsection{Water balance}

The water balance from the perspective of the storage influenced by a beaver dam (e.g. a pond) can be written as

$$
\frac{d S}{d t}=Q_{\text {in }}-E T-Q_{o u t}
$$

where $d S / d t$ is the change in total storage created by damming over the timescale of interest, $Q_{i n}$ is the inflowing discharge, ET is the evaporation from the beaver modified system, and $Q_{\text {out }}$ is the outflowing discharge (Figure 4). The units for the terms on the right-hand side can be volumetric fluxes $\left(\mathrm{L}^{3} \mathrm{~T}^{-1}\right)$, or rates normalized to the area occupied by the beaver dam system $\left(\mathrm{LT}^{-1}\right) . Q_{\text {in }}$ and $Q_{\text {out }}$ are integrated totals, comprising both surface and subsurface flux contributions. It may be especially important to tease out these different contributions to $Q_{o u t}$, where downstream groundwater gradients and floodplain return flow can provide important flux contributions (e.g. Westbrook et al. (2006)), and may be missed if only surface discharge immediately downstream of the dam is considered, thus

$$
Q_{o u t}=Q_{f p}+Q_{d a m}+Q_{g w}
$$

where $Q_{f p}$ is the discharge contributed via return flow from the floodplain downstream of the dam, $Q_{d a m}$ is discharge released via the dam structure itself, and $Q_{g w}$ is groundwater flow into the channel downstream of the dam in the case of gaining conditions. In the case of losing conditions, $Q_{g w}$ becomes a loss term in Equation 2. $Q_{i n}$ in Equation 1 is the product of the upstream catchment water balance. Discharge contributions from $Q_{d a m}$ can occur via some combination of four main mechanisms (inset in Figure 3) (Woo and Waddington, 1990): (1) overflow (or overtopping), the flux flowing over the top of the dam; (2) gap-flow, a concentrated spill flux flowing through open gaps or notches from the surface of the dam; (3) throughflow, the flux distributed across the dam surface generated by its permeability; and 4) underflow, the flux seeping below the dam structure based on the nature of contact between the dam base and the substrate, not including subsurface flow $\left(Q_{g w}\right)$. These mechanisms of $Q_{d a m}$ loss may also vary with dam age and level of maintenance by beaver populations (Woo and Waddington, 1990). A survey of 51 beaver dams of varying age in Germany found gapflow 
was by far the dominant mechanism of $Q_{d a m}$ water release (Neumayer et al., 2020). Crucially, these observations suggest that the quantification of the hydraulics of beaver dams is difficult when based upon analogies with human-engineered instream structures (e.g. broad-crested weirs), particularly if their hydraulic impacts are to be modelled, emphasizing the need for more detailed studies of beaver dam hydraulics (Feng and Molz, 1997).

As mentioned in the previous section, it may be conceptually useful in the case of beaver dam systems to separate the total storage into surface and subsurface terms, noting the likely interaction between them:

$$
d S=d S_{\text {surf }}+d S_{g w}
$$

where $d S_{\text {surf }}$ is the change in surface storage, and $d S_{g w}$ is the change in groundwater storage. $d S_{\text {surf }}$ is also further divisible into the beaver pond (water impounded behind the dam) and water diverted onto the floodplain.

Over shorter timescales (i.e. sub-annual), changes in the total storage term can have significant hydrological impacts and are discussed in the next sections in terms of flow regimes. However, over annual and longer timescales, this change in storage should be largely balanced by the outflow terms (i.e. $Q$ and $E T$ ), assuming regional groundwater flow remains minor relative to the surface fluxes. If the partitioning between $Q_{\text {out }}$ and $E T$ remains the same following beaver dam construction, then the storage changes have had negligible impact on the overall water balance. However, if the partitioning between $Q_{o u t}$ and $E T$ changes following beaver dam construction (e.g. an increase in $E T$ and decrease in $\left.Q_{\text {out }}\right)$, then the changes in the way water is stored will also likely impact the water balance. There are very few quantitative analyses of beaver dam impacts on all components of the water balance at the annual scale (but see: Chaubey and Ward, 2006; Johnston, 2017; Woo and Waddington, 1990), highlighting a clear and profound knowledge gap in how beavers may impact hydrology. In a beaverdammed sub-arctic catchment, Woo and Waddington (1990) found total $Q$ was reduced relative to a paired non-beaver impacted catchment, suggesting that storage changes are capable of increasing $E T$ fluxes (c. 40\%) at the expense of $Q_{\text {out }}$ at the annual scale. In a boreal environment, (Johnston, 2017) also found $Q_{\text {out }}$ was diminished at the expense of increasing $E T$ and groundwater recharge. Correll et al. (2000) also compared annual $Q$ changes in a beaver impacted and control watershed within the Atlantic Coastal Plain (USA), and found a reduction in $Q_{\text {out }}$ presumed to be at the expense of increasing $E T$, however, the full water balance comparison was not reported in this study. In the seasonally dry coastal plain of Alabama (USA), Chaubey and Ward (2006) also found a large increase in ET due to a single beaver dam. However, because of the large increase in wetland and pond surface area at this site relative to the catchment area, the increase in $E T$ was largely subsidized by an increase in direct rainfall on the wetland rather than as a loss to $Q_{\text {out }}$. It is also worth noting that Devito and Dillon (1993) constructed full seasonal and annual water balances for a beaver pond in central Ontario, Canada, however no comparison with pre- or non-beaver impacted sites were made. In any case, there is a consistent message from a small number of studies $(n=8)$ that $Q$ tends to diminish downstream of beaver dam complexes (Figure 16e).

The mechanisms by which beaver dam systems can increase total ET may involve some combination of: modification of vegetation type and extent, or an increase in the open water area which, as already mentioned, creates a high area to volume ratio of the surface water storage zones (Hood and Bayley, 2008; Johnston and Naiman, 1990; Morrison et al., 2015; Puttock et al., 2017). In addition, there can 
be even larger increases in floodplain open water extent downstream of dams due to substantial flow diversion during flood events, inundations which can persist for weeks to months (Levine and Meyer, 2014; Westbrook et al., 2006). This increase in open water extent is likely to be a fairly common feedback affecting the partitioning of $Q$ and $E T$ across all beaver impacted systems, and potentially also the local climate (Hood and Bayley, 2008), yet the feedbacks remain poorly understood. Burns and McDonnell (1998) also found overall streamflow was reduced in a beaver impacted catchment and attributed this to increased ET. Although this was not quantified at annual timescales, the influence of increased evaporation was evident in the clear offset of streamflow stable isotopes from the local meteoric water line in water samples collected downstream of the beaver dam complex (Burns and McDonnell, 1998). Thus, given beaver dams lead to a greater exposure of open water area, it is reasonable to expect an overall increase in ET fluxes from river corridors at the annual time scale.

Apart from increases in open water area, there are also likely to be feedbacks in the rate at which ET occurs that are, as yet, poorly understood. For example, the documented ET increase in the study of Woo and Waddington (1990) may be the result of combined changes to both rate and extent of open water evaporation. In this case, under sub-arctic energy-limited conditions, evaporation rates may have also increased due to the decline in aerodynamic roughness as riparian vegetation is replaced by open water. The degree to which beavers promote open water versus a mix of open water and wetland vegetation will also influence evaporative losses depending on the vegetation conditions they replace. Although not yet examined in beaver impacted systems, evaporation from wetlands with a mix of open water and wetland vegetation can be extremely complex and may be higher or lower than the open water rate depending on how the local atmospheric demand influences stomatal conductance (Anderson and Idso, 1987; Wetzel, 2001). It is clear though that for an equivalent surface area and atmospheric conditions, the rate of ET losses should be higher where wetland vegetation cover is greater than unobstructed open water (Wetzel, 2001), and is likely the cause of the large diurnal variations observed in some beaver pond water levels (Johnston, 2017; Ward and Chaubey, 2000). However, there will be contrasting ET rate responses to a mix of wetland vegetation and open water cover depending on the relative influence of aerodynamic vs radiation drivers. Increased surface roughness will reduce the $E T$ response of open water to wind, but depending on the roughness lengths and vegetation heights, the same wind may increase wetland vegetation transpiration. Wetland vegetation transpiration can diminish as due to stomatal regulation during periods of high vapor pressure deficit (e.g. midday photosynthetic capacity depression), however these conditions should at the same time increase evaporation rates from open water. A particularly interesting case is where beaver dams create ponds and wetlands in drier catchments, since a sustained water presence presents a local anomaly in water availability and may promote vegetation growth, and hence $E T$, to a far greater extent than would otherwise be possible (Fairfax and Small, 2018; Silverman et al., 2019). In semi-arid north-east Nevada, Fairfax and Small (2018) found a large increase in riparian vegetation abundance in beaver dammed river valleys, and estimated riparian $E T$ to be $50-150 \%$ higher than undammed areas. In total, all these dynamics and potential feedbacks highlight that the impact of beaver dam systems on ET in catchment water balances remains a profound knowledge gap.

\subsection{High flow and flood impacts}

At shorter timescales (e.g. event, monthly, seasonal), the hydrological impact of beaver dam systems is expected to be dominated by how $Q_{i n}$ is mediated by the available storage $(d S / d t)$ to generate 
$Q_{\text {out }}$. This is because the creation of additional surface $\left(S_{\text {surf }}\right)$ and subsurface $\left(S_{g w}\right)$ storage can modify the timing and magnitude of flow released downstream $\left(Q_{\text {out }}\right)$ of the beaver dam (or beaver dam cascade) relative to what was received upstream $\left(Q_{i n}\right)$ (Figure 8 ). In principle, any increase in storage capacity can allow greater buffering or hydrologic stability to be imposed on $Q_{\text {out }}$. This modification may apply to all flows, but in terms of hydrological impact is especially important to determine for high flow and baseflow conditions.

The ability of beaver dam systems to attenuate and delay peak flows depends on the available surface storage capacity immediately preceding streamflow rise (i.e. freeboard), relative to the inflowing flood volume. The freeboard available behind beaver dams is in general likely to be small as the water depth behind dams is usually engineered by the beaver to be close to the dam crest height (Figure 7) (Devito and Dillon, 1993). Despite this, noticeable event hydrograph modification has been found in a number of observational studies, e.g.: (Burns and McDonnell, 1998; Nyssen et al., 2011; Puttock et al., 2017). This is somewhat surprising given the low freeboard capacity, but as noted by Westbrook et al. (2006), flood attenuation is likely more reliant primarily on floodplain flow diversion rather than flow retention within the ponds themselves. However, these mechanisms are not yet well documented, especially as the size of events change (e.g. Burns and McDonnell (1998)), and especially as important local site characteristics such as slope and floodplain dimensions differ between studies. Although floodplain flow diversion necessarily begins upstream of the beaver dam, the inundation extent may extend, and be far greater, farther downstream (Westbrook et al., 2006). Nyssen et al. (2011) and Puttock et al. (2017) monitored both $Q_{\text {in }}$ and $Q_{\text {out }}$ in a beaver-impacted system, finding significant attenuation in the flood hydrographs caused by a complex of $5-6$ beaver dams in Belgium in the case of the former (Figure 8), and 4-10 beaver dams in England in the case of the latter. Given the already mentioned wide range in beaver dam densities in cascades, a major limitation to understanding flood attenuation impacts is the cumulative storage and flow diversion processes that can occur both within and between beaver dams. This is likely why modelling studies of beaver flood impacts that do not explicitly include flow diversion find minimal impact on flood water storage, and relatively small effects on hydrograph attenuation (Beedle, 1991). This is not to say that once floodplain diversion is included, all river systems with beaver dams will have significant attenuation. Neumayer et al. (2020) conducted a comprehensive 2D hydrodynamic model experiment by numerically inserting beaver dam cascades into two sites in southern Germany for a wide range of flood event conditions. Interestingly, they found flood volume attenuation and the delay in flood peak timing was only significant for smaller discharge events and were much more pronounced at the site with lower slope and higher floodplain connectivity. However, for flood events matching the 2-year return interval and above, in both sites the impact on attenuation and delay was minimal or absent, even with large increases in floodplain inundation area. These findings highlight the possibility that in many cases, once all factors are considered, beavers may still have minor to negligible impacts on flooding, especially for very large flood events. However, until the full flow diversion and storage changes for river corridors across a wide range of topographic and geomorphic conditions is considered, the extent of beaver impacts on flooding is at risk of continually being misjudged. Some parallels may be made with the work of Dixon et al. (2016) and Lane (2017) who report the effects of multiple instream woody debris dams on flood wave propagation through a river basin network. Importantly, this work shows that the catchment scale effect of debris dams in total is not the same as the sum of the impacts of each debris dam individually, emphasizing the need to look in more detail at precisely how multiple beaver dams impact flood attenuation. In the absence of information on both $Q_{\text {in }}$ and $Q_{\text {out }}$, flood attenuation impacts from 
beaver dams can also be assessed indirectly using the paired catchment approach (e.g. Woo and Waddington (1990)), through discharge time series evaluation at a downstream point that contains both pre-and post-beaver dam periods (Nyssen et al., 2011; Westbrook et al., 2006), or using geochemical tracers (Burns and McDonnell, 1998). Whatever the method, there is a clear need for better and more accurate assessments of the capacity for beaver damming to modify the full range of catchment flood magnitudes. This urgency is enhanced by an increasing desire to re-introduce beavers for the explicit purpose of flood management, despite insufficient science to understand how beaver impacts might actually achieve this (BBC, 2017).

Floods may also cause dam breaches or failure, potentially leading to flood amplification (Butler and Malanson, 2005; Hillman, 1998). However, there is a wide variation and lack of consistency in the discharge thresholds reported to cause dam breach or failure, which suggests structural integrity is also highly variable in both time and space (Andersen and Shafroth, 2010; Demmer and Beschta, 2008; Hillman, 1998; Levine and Meyer, 2014). Recent flume experimental work using simplified beaver dam structures found they could withstand $1.34 \mathrm{~m}^{3} \mathrm{~s}^{-1}$ per $\mathrm{m}$ width for a $1.4 \mathrm{~m}$ height dam (Muller and Watling, 2016). However, the limited range of test conditions makes these results highly preliminary. Interestingly, detailed field surveys from the Canadian Rockies found 31 of 74 dams (41\%) could survive extreme flooding without impact, with failure rates amplified in more restricted river valleys (Westbrook et al., 2020). The large structural variation also highlights that beaver dams can spill (overtop) whilst retaining their integrity across a wide range of flow conditions, in which case they will revert to being important open channel roughness elements when submerged during floods, likely with considerable energy dissipation over the downstream side of the dam. A long-term study of 161 beaver dams by Demmer and Beschta (2008) in central Oregon found 38\% of dams breached due to lateral bank erosion, and $32 \%$ breached in the center (and $9 \%$ filled with sediment), suggesting failure mechanisms vary enormously depending on local bank erodibility, dam cohesion, and force per unit area applied during the high flow event. However, it is worth noting the potential bias in these surveys since the dams included will often by definition be abandoned, and it is unclear what drives the decision for beavers to abandon or actively maintain and repair a dam site following a breach. Further discussion on beaver dam breaches and their impacts is also provided in section 4.2. 


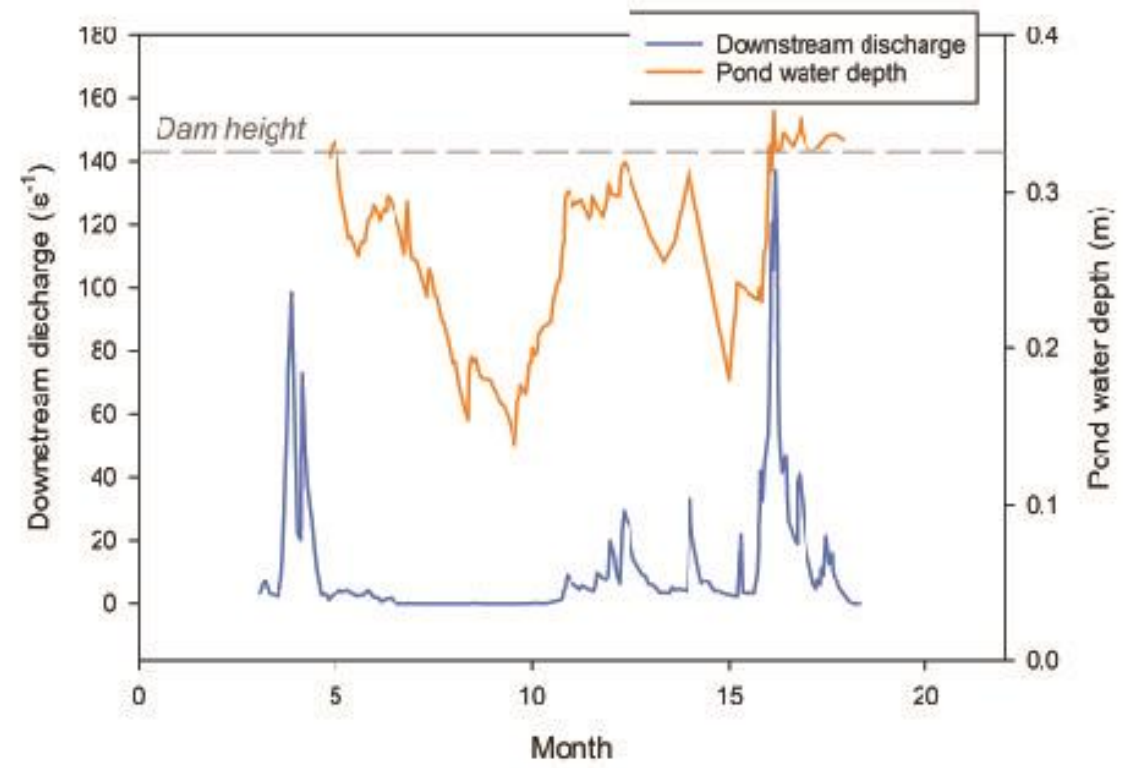

Figure 7 Example of changing freeboard and water storage capacity upstream of a beaver dam (modified from Devito and Dillon, 1993)

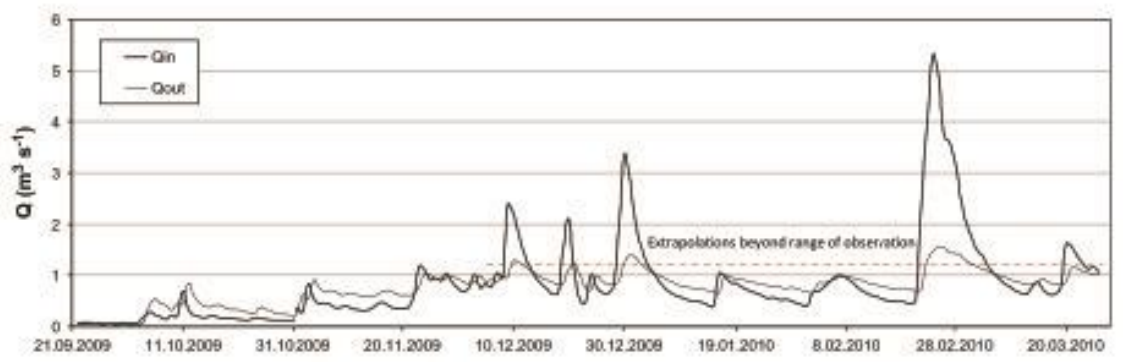

Figure 8_Flood attenuation illustrated through the comparison of inflowing $(Q$ in) and outflowing discharge (Q_out) in a headwater beaver pond cascade system in Belgium (from Nyssen et al., 2011)

\subsection{Low flow impacts}

At low flow, the potential impact of beaver dams is heavily dependent on the mechanisms by which storage is released, which for $d S_{\text {surf }}$ is some combination of $Q_{d a m}$ and $Q_{g w}$, assuming $Q_{f p}$ is very small (Woo and Waddington, 1990). Dams with high throughflow rates will more rapidly deplete surface storage as the level declines (Woo and Waddington, 1990). Furthermore, dams dominated by overflow or gap flow losses may have diminished flow releases downstream $\left(Q_{\text {dam }}\right)$ under baseflow conditions (i.e. as the pond water level drops) if other loss mechanisms (i.e. throughflow and underflow) are small (e.g. Devito and Dillon (1993)). In contrast, dams with higher underflow loss rates may sustain a higher $Q_{\text {dam }}$ contribution to $Q_{\text {out }}$ that is proportional to the rate of decline in pond water level.

If $S_{\text {surf }}$ is the primary storage regulating baseflow in beaver impacted systems, then any increases in evaporative losses, especially in the summer months, will negatively impact baseflow. This appears to be the case in some water balance and spot discharge measurement studies (Correll et al., 2000; Meentemeyer and Butler, 1999; Woo and Waddington, 1990). However, if $S_{g w}$ is sufficiently large then baseflow reductions may be either offset to some degree, or even increase following beaver dam construction. If baseflow does increase, the overall water balance is likely to be maintained through 
high flows that replenish $S_{\text {surf }}$ (and contribute to some increase in ET), but that are also able to recharge to $S_{g w}$. Increased baseflow in beaver impacted systems has been hypothesized or reported by a number of authors (Johnston, 2017; Macfarlane et al.; Puttock et al., 2017; Stabler, 1985, Smith et al., 2020). Majerova et al. (2015) found an increase in downstream mean daily discharges following beaver impact, which could be attributed directly to measured increases in surface and groundwater storage, with the magnitude of this impact increasing with the number of beaver dams in the reach over time. In a comparative before and after beaver impact study, Smith et al. (2020) found a large increase in flow recession duration and reduced diel flow variability, suggesting beaver damming increased flow buffering. Although there was no significant change in mean discharge, an increase in $S_{g w}$ due to beaver damming allowed a significant tempering and delay to low flow releases. Beyond these studies, there is also considerable observational, anecdotal, and in some cases experimental, support for a positive impact of beaver damming on low flows across a range of climatic and landscape settings (Pollock et al., 2003; Rosell et al., 2005; Stabler, 1985). This underscores the strong need for more quantitative studies in this area, as a sustained enhancement of baseflow would have profound ecological implications, especially in otherwise ephemeral river systems and in drier climates (Gibson and Olden, 2014). In addition, under conditions of hydrological and meteorological drought, as streamflow declines or even ceases, beaver ponds and the wetlands they sustain may themselves retain significant amounts of water (Hood and Bayley, 2008a), raising the interesting prospect that they may act as critical ecosystem 'refugia' in the aquatic landscape during drought (Hood and Bayley, 2008a) and even as landscape buffers against fire (Fairfax and Whittle, accepted, Wheaton et al., 2019).

It should also be noted that the very nature of beaver dams also complicates our ability to model how storage changes should impact downstream discharge. This is because the influence of beaver dams on the hydrological processes described above are largely dependent on highly localized factors such as substrate type, construction materials, design integrity (Muller and Watling, 2016), and age (Meentemeyer and Butler, 1999), properties which may not be easy to transfer between different beaver impacted systems, or even between individual dams. Additionally, the large variability in dam locations and densities means their influence on the total storage capacity can be highly dynamic in space and time. This makes it very difficult to undertake meaningful hydrological model calibration without explicit knowledge and tracking of all the changes in the storage and flows occurring in the river corridor.

\subsection{Ground and surface water interactions}

The extent to which increased groundwater storage $\left(S_{g w}\right)$ may supply river baseflow is itself dependent on the hydraulic characteristics of both the river and the aquifer. The total volume of available aquifer storage is driven by the aquifer geometry (bounded by the valley) river channel, and how stratigraphy controls the hydraulic properties. Provided high open water levels in beaver ponds and backwater areas can be maintained, they may serve as an effective recharge pathway, either via the channel boundary or as floodplain infiltration, causing a rise in local groundwater levels (Figure $9 \mathrm{a}, \mathrm{b}$ ) (Karran et al., 2018, Zahner, 1997). The effectiveness of this pathway will be heavily determined by hydraulic conductivity, which may vary by many orders of magnitude in alluvial settings. In the context of beaver impacted systems, the deposition of fine sediment in the ponds and around dam structures, and potentially upon floodplain wetlands, can lower the hydraulic conductivity at these interfaces (Johnston, 2017), similar to what has already been found in other river channels (e.g. Stewardson et 
al. (2016)) and floodplain (e.g. Nowinski et al. (2011)) settings. Nonetheless, even though rates of exchange at a point may be reduced, this impact may also be counteracted to some degree by the expanded area over which ground and surface water interactions will occur. This potential tradeoff between the areal extent vs rates of river aquifer exchange is also an important knowledge gap in beaver impacted systems.

Beaver impacts may therefore introduce an interesting set of changed hydraulic gradient boundary conditions that in an idealized case can be divided into being either upstream or downstream of an individual beaver dam. In this case, we would generally consider beaver impacted systems as generally 'losing' (i.e. net water exchange from the surface to the aquifer) upstream of beaver dams, and 'gaining' (i.e. net water exchange from the aquifer to the surface) downstream, analogous to the dynamics that occur across many man-made instream structures (Hester and Doyle, 2008). If high beaver dam densities exist within a reach, such an idealized case will be too simplistic as many nested flow paths may develop between the dams but may be valid over the whole reach scale. Despite the clear potential for significant changes to the longitudinal hydraulic gradient, the variation in magnitude of upstream losing and downstream gaining conditions within beaver dam impacted systems is not well constrained. This is critical to understand, as it is likely to be a key control on the magnitude of $S_{g w}$, and whether baseflow is likely to increase or decrease as a result of beaver impacts. This sequence of interactions is broadly consistent with the findings of Lowry (1993) in an alluvial river of north-central Oregon (USA), where a groundwater 'wedge' developed upstream and adjacent to a beaver dam (Figure $9 \mathrm{~b}$ ). This increase in groundwater storage (an additional $~ 89 \mathrm{~m}^{3}$ of drainable storage) driven by the losing hydraulic gradients upstream of the dam, in turn sustained groundwater flow back to the river downstream of the dam (i.e.: switch to gaining conditions) (Lowry, 1993). Majerova et al. (2015) also measured a persistent shift to gaining conditions downstream of a beaver dam complex in northern Utah (USA), especially during low flow conditions that were previously losing prior to beaver impacts. Numerous other studies involving floodplain and riparian groundwater monitoring in North America (Hill and Duval, 2009; Marshall et al., 2013; Westbrook et al., 2006) and Europe (Smith et al., 2020; Zahner, 1997) have also found significant changes in upstream and downstream groundwater dynamics in close proximity to beaver ponds. In all cases there was a rise in groundwater levels (as a result of increased $S_{g w}$ ) following dam construction, and in the case of (Zahner, 1997) showed relatively rapid declines in level once the beaver dam was removed (Figure 9 a,b). In addition, depending on local topography and aquifer properties, recharge during flood events may be sufficient to cause local groundwater flooding, and thus contribute to the overall surface inundation (Westbrook et al., 2020). Interestingly, groundwater models have been under-utilized in examining potential impacts from beaver structures. Whilst this would be an imperfect representation of the beaver impacts on groundwater, such an approach has the potential to be a useful tool in evaluating the storage and water balance impacts of beaver dams from the perspective of the aquifer. This in turn will be critical to better understand potential baseflow impacts, especially where $S_{g w}$ is expected to play an important role. Over the longer term, as beaver dams are breached or fill with sediment and beavers abandon or decrease activity, wetland and meadow development may decrease in $S_{\text {surf }}$, however they may still retain significant $S_{g w}$, especially relative to the pre-impact landscape (Grygoruk and Nowak, 2014). If this finding from Grygoruk and Nowak (2014) in Poland is generalizable, it has significant implications for the long-term water storage and flow dynamics of beaver impacted river systems, where unique wetland and meadow successional landscapes with increased water storage may persist even in the absence of actively maintained beaver dams and ponds. 


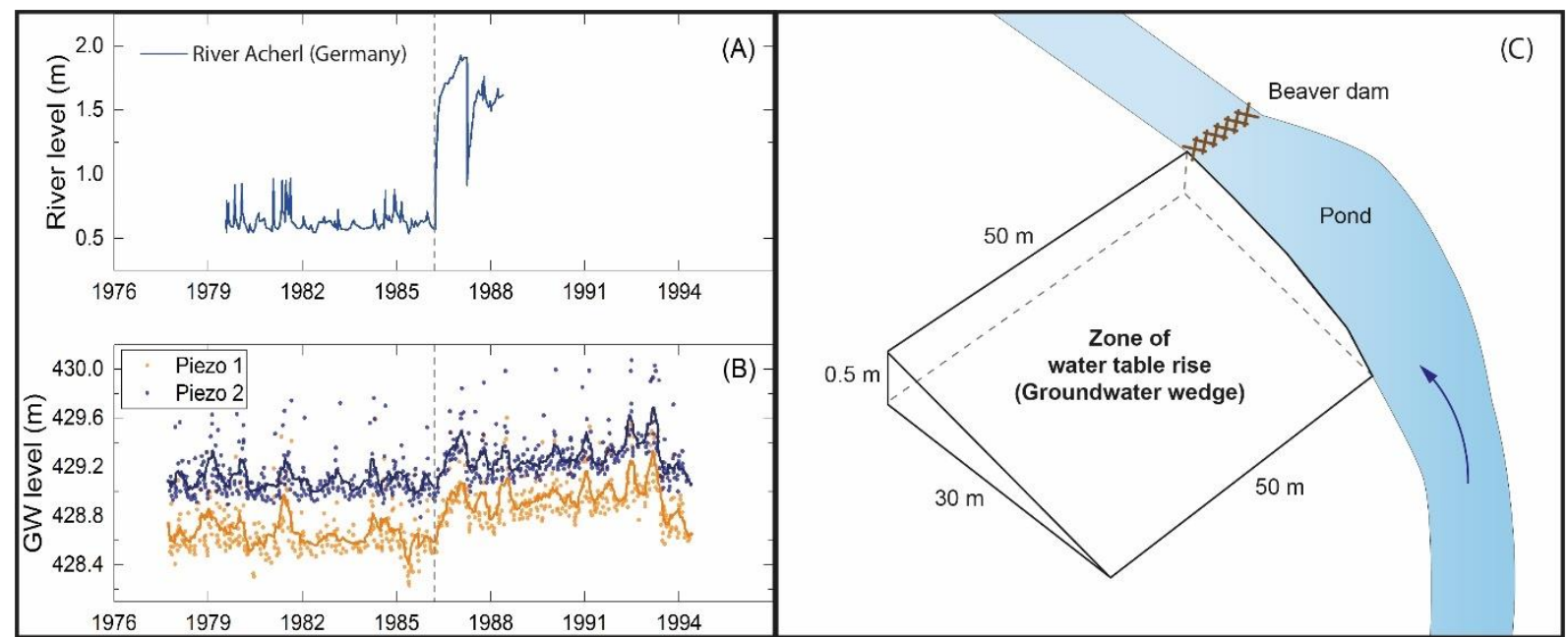

Figure 9Level increase in three low-order rivers in Germany $(A-B)$ and increase in shallow groundwater height (B) in the floodplain of river (A) (modified from Zahner, 1997). (C) Measured geometry of an idealized groundwater 'wedge' developed due to a rise in the groundwater table upstream and adjacent to a beaver dam in the Bridge River, Oregon (USA) (modified from Lowry (1993))

\subsection{Hyporheic exchange}

A related hydrologic process impacted by beaver dams is hyporheic exchange, distinguished from broader ground and surface water interaction as water that enters and returns from the subsurface, with a flow field typically induced by variations in channel topography (e.g. wood, bedforms, weirs, etc) (Figure 4c). Although the total flux of water within this flow path is small relative to that in the channel, it is important to consider given the role of the hyporheic zone in the biogeochemical cycling of river systems. Vaux (1968) developed an analytical description that is useful to illustrate the potential effects of beaver dams on the vertical component of hyporheic exchange at the interface between the streambed and surface water $\left(v_{z}\right)$

$$
v_{z} \cong \frac{P g}{\mu} \frac{h}{d x}\left(k b \frac{d z}{d x}\right)
$$

where $P$ is the streambed interface pressure $\left(\mathrm{FL}^{-2}\right), \mu$ is viscosity, $h$ is water depth (L), $x$ is the stream length (L), $k$ is mean permeability $\left(\mathrm{L}^{2}\right), b$ is the depth of the streambed containing the hyporheic flow field, and $d z / d x$ is the downstream variation in the streambed surface elevation. Positive values of $v_{z}$ at a point indicate vertical hyporheic flow from the streambed to the river (i.e. upwelling) and negative values indicate flow from the river into the streambed (i.e. downwelling). A key dynamic is introduced by $d z / d x$, i.e. whether travelling in the downstream direction the streambed is broadly concave and promoting upwelling, or convex and promoting downwelling. For the case of a single beaver dam, the change in $d z / d x$ is not gradual, but abrupt. Nonetheless, the shape can be approximated as a strongly concave element and therefore conducive to upwelling. The effect of an abrupt change rather than a gradual concave profile is to 'tighten' the flow net (or velocity flow field) beneath the dam, and thus increase the magnitude of $v_{z}$ upwelling downstream (Figure 4c). In very flat terrain or a channel without pronounced bedforms, beaver dams may provide the only significant hyporheic exchange element in the system, and therefore introduce a large local change in subsurface flow dynamics. In steeper environments, or where channels have considerable variation in the channel bed elevation (e.g. large pool and riffle sequences), beaver dams will represent one component of the overall 
hyporheic exchange (though still likely distinct given the abruptness of changes in $d z / d x$ across a beaver dam). In addition to the influence of $d z / d x, P$ and $h$ will likely decrease downstream of beaver dams due to the abrupt decrease in water level, which also serve to increase $v_{z}$ downstream. The data collected by Hartmann and Törnlöv (2006) nicely demonstrates that the capacity for beaver dams to generate increased vertical hydraulic gradients is much greater where the downstream water depth is lower (Figure 10), imposing an additional constraint on beaver dam influences on hyporheic processes.

Despite the clear potential for beaver dams to impact hyporheic flow, relatively few studies have explicitly examined them. White (1990), Lautz et al. (2006) and Wang et al. (2018) all found enhanced hyporheic exchange induced by beaver dam structures. In the case of White (1990) this was measured directly as higher $v_{z}$ downstream of a beaver dam, in Lautz et al. (2006) as an overall increase in subsurface residence times through the enhancement of short hyporheic flow paths beneath the dam, and Wang et al. (2018) estimated this from high spatial resolution measurements of hydraulic gradients and chloride concentrations. Briggs et al. (2013) also found consistent downwelling flux conditions upstream of beaver dams, albeit with considerable variability tied to the river morphology and streamflow conditions. These results are also consistent with the hyporheic response expected across man-made channel structures (Hester and Doyle, 2008), especially ones that span the full channel width (as is typical for beaver dams).

There are some important caveats that will moderate the potential influence of beaver dams on hyporheic exchange. As in any river system, the degree of exchange will also depend on the overall regional ground and surface water gradients, which are not explicitly included in Equation (4). Thus, strongly losing or strongly gaining conditions will also influence the relative impact of beaver dams on $v_{z}$. In an extremes case, an isolated beaver dam within strongly losing or strongly gaining systems would be unlikely to have a significant impact on hyporheic exchange at the reach scale. The considerable heterogeneity in riverbed $k$ will also exert a strong influence on $v_{z}$. As already discussed, there is a higher likelihood of encountering lower permeability flow paths upstream of beaver dams due to deposition of finer sediments which will reduce local downwelling rates, and thus also reduce any downstream upwelling, even if $k$ again increases downstream. It is also important to emphasize that any impacts of beaver dam induced hyporheic exchange will be highly localized, and that the impact will therefore be enhanced when many dams are present within a reach, but less impactful when a reach has fewer dams. Nonetheless, equation 4 illustrates the potential for considerable enhancement of hyporheic exchange driven by beaver dams, especially compared to most other channel roughness features typically encountered in river corridors. This influence on hyporheic flow has important implications for overall water residence times (section 3.7), and influence the extent to which biogeochemical reactions can occur there (see section 5). 
603

604

605

606

607

608

609

610

611

612

613

614

615

616

617

618

619

620

621

622

623

624

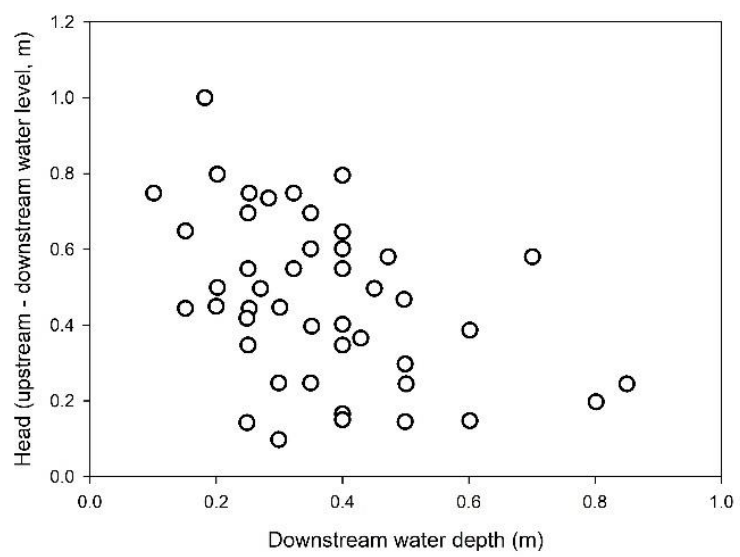

Figure 10: Vertical hydraulic gradients (upstream - downstream) across beaver dams (modified from Hartmann and Törnlöv (2006))

\subsection{Water residence times}

Any enhanced hyporheic flow as described above will be but one mechanism by which water residence times are increased in beaver impacted river reaches. Overall, any system in which the storage capacity increases to capture a greater proportion of inflowing water necessitates that the residence time of the water leaving the system also increases. In the case of beaver impacts, even though the increase in hyporheic and subsurface flow and storage will be large, it is the nature of the surface water storage changes to which residence times will be most sensitive, since this is the storage with which the vast majority of the flow will be interacting. The simplest characterization of the water residence time $(\tau)$ for a beaver impacted system is the nominal residence time $\left(\tau_{n}\right)$

$$
\tau_{n}=\frac{V_{n}}{Q}
$$

Where $V_{n}$ is the total (nominal) volume of surface water storage $\left(\mathrm{L}^{3}\right)$ in the beaver system, and $Q$ is the volumetric flow rate $\left(\mathrm{L}^{3} \mathrm{~T}^{-1}\right)$. There is a longstanding ambiguity as to which flow rate should be used, $Q_{\text {in }}, Q_{\text {out }}$, or an average of the two. Ideally, it would be preferable to use the latter if sufficient monitoring information is available, and in this case $Q$ is often referred to as the through-flow rate. However, as in all natural systems, flow mixing leads to zones of faster and slower flowing water in the ponds and wetlands. This means that over seasonal or annual timescales not all the water will participate in active flow through the system and that $\tau_{n}$ is almost always an overestimate of actual residence times. Therefore, it is important to understand the volume of storage engaged in active flow $\left(V_{\text {active }}\right)$

$$
V_{\text {active }}=V_{n} e_{V}
$$

Where $e_{V}$ represents the volumetric efficiency of the beaver impacted system, which lumps together several factors that may generate stagnant pockets of water (such as vegetation, large woody debris, and irregular hypsometry) as well as any uncertainties in the $V_{n}$ estimates. Thus, a better representation of $\tau$ in beaver impacted systems is

$$
\tau=\tau_{n} e_{V}
$$


Unfortunately, there is no a priori theory to predict $V_{\text {active }}$ and thus $e_{V}$ from information on $Q$ and $V$ alone. Therefore, snapshot measurements of tracers that 'track' the flow of water are essential since this will capture the full mixing process of the system and allow the key moments of the residence time distribution (e.g. mean and variance) to be extracted. Majerova et al. (2015) conducted tracer experiments over a relatively short $(\sim 750 \mathrm{~m})$ river reach before and after the construction of $\sim 10$ beaver dams in a first order perennial mountain stream in Utah, and found residence times had increased from 27 to 89 minutes (a 230\% increase). Devito and Dillon (1993) also reported residence time estimates, however the exact method was not specified, but they are likely to be $\tau_{n}$ based estimates and thus overestimate actual $\tau$ to some extent. Nonetheless, assuming the pre-beaver residence time over the reach would have had the same structure as the outflow, they report average annual residence times have increased from 6 hours to 47 days. However, it is also worth noting this is an average of two distinct flow regimes operating in this system, namely high snowmelt dominated water fluxes in spring with very short residence times, and of very low water fluxes over the summer and autumn periods with very long residence times. Given the paucity of results on the impact of beaver damming on water residence times, it is useful to also note some similarities with debris dams, which although are far more porous structures, have nonetheless consistently been found to also increase reach scale water residence times across a variety of flow conditions (e.g. Ehrman and Lamberti (1992))

For future research it is important to note that $\tau$ will also be dynamic over time in two important ways in beaver impacted systems: 1 ) through the impact of changing $Q_{\text {in }}$ on $V_{\text {active }}$ depending on the pond hypsometry of the system, and 2) through the seasonal growth and decay of vegetation and its impact on $e_{V}$. Therefore, we should expect large variation in $\tau$ as both flow and vegetation vary seasonally in beaver impacted systems. For larger values of $\tau$, there is also an increasing likelihood that $Q_{i n}$ does not remain constant for the duration of the tracer measurement, and that $E T$ and infiltration can also impact $V_{\text {active, }}$ all of which can confound the interpretation of tracer based $\tau$ estimates. A thought experiment comparing residence times between water and sediment as the number of beaver dams in a system increases is provided in the geomorphology section (section 4).

\subsection{Water temperature}

The changes in hydrology due to beaver impacts described above also have potential implications for water temperatures within a beaver impacted reach, as well as downstream of beaver dams. Any regulation of $Q$ will have some impact on the advective component of the river reach energy budget, but it may not necessarily be a large impact. An increase in surface water storage area can increase the influence of the radiative component of the river energy budget, especially if this is accompanied by a decline in riparian vegetation cover. This means the ponds behind beaver dams are likely to be the main water body influencing any changes to the temperature regime downstream. This is supported by Harthun (1998) and Harthun (2000) who found beaver ponds were on average $2.3^{\circ} \mathrm{C}$ warmer than adjacent stream sections in central Germany. It is also likely that beaver ponds are usually too shallow to develop significant temperature stratification (Naiman and Melillo, 1984), except in ponds that experience lengthy ice formation (Devito and Dillon, 1993), or in littoral zones with abundant macrophytes (Majerova et al., 2020). An increase in groundwater storage can increase the supply of water at the local groundwater average temperature, provided this is also contributing to downstream $Q$. Groundwater temperatures are typically slightly above the local mean annual air temperature (Benz et al., 2017), and considerably less variable in time than surface water temperatures. However, if the groundwater recharge rate has increased as a result of beaver ponding, 
the temperature of recharging stream water can also have a substantial legacy effect on the shallow groundwater temperatures (Lowry, 1993). The combined effects of these changing energy balance dynamics are difficult to untangle mechanistically for beaver systems, nonetheless a large metaanalysis found water temperatures on average increased downstream of beaver dams (Ecke et al., 2017). This warming can be extremely heterogeneous and site specific, for example McRae and Edwards (1994) found no relationship between the size or number of beaver ponds and the extent of warming, however Majerova et al. (2015) did find that temperature increased cumulatively with the number of dams. Moreover, within a single beaver pond and wetland system, there is considerable spatial heterogeneity in the thermal regimes that itself mirrors the increased habitat variability, with the more marginal and shallower wetland and pond regions exhibiting the most warming and variation (Majerova et al., 2020). The increased surface water storage following beaver damming has also been found to act as a buffer of summertime low flow temperatures, increasing minimum and decreasing maximum diel ranges without a change in the mean temperature (Weber et al., 2017). This study also found an increase in localized groundwater upwelling which provided isolated zones of colder water refugia (Weber et al., 2017). In terms of overall downstream impact, Margolis et al. (2001) found water temperatures were higher downstream of a beaver dam complex in spring, summer, and autumn, and potentially colder during winter. Interestingly, Avery (2002) found that beaver dam removal in some Wisconsin (USA) streams led to an overall decrease in average stream temperatures, and in the western Great Lakes region (USA) there are numerous catchment studies where beaver dams have been found to elevate stream temperatures, except in streams with higher groundwater inputs (Johnson-Bice et al., 2018). There is therefore sufficient evidence to suggest beaver dam building and pond creation has the potential to increase the average downstream water temperature, however this is by no means universal and the overall energy budget dynamics that determines the magnitude of this increase remains poorly understood. This is especially the case at shorter time scales where the relative importance of site specific conditions on water temperature increases. The magnitude of these potential water temperature changes is particularly important to understand given their local influence on aquatic ecosystems, and fish in particular (section 6.3), through both metabolic and dissolved oxygen controls.

\section{The influence of beavers on river-floodplain Geomorphology}

Dam construction, channel and burrow digging, changing vegetation and introduction of wood into streams by beavers can cause changes in sediment flux, river morphology and channel planform. The magnitude of the associated impacts is dependent on the overall hydro-geomorphic setting in which the beaver streams are located. However, the range of geomorphic conditions under which dam construction can initiate remains uncertain. It is clear however, that prevailing channel geometry, valley and floodplain dimensions (Pollock et al., 2003), as well as human activity and wood availability all play some role (Polvi and Wohl, 2013; Westbrook et al., 2013). Hartmann and Törnlöv (2006) and Zahner et al. (2018) found a 4m channel width threshold, above which burrows in banks were more likely to be constructed than dams. It is important to note dams are also constructed at larger channel widths, just with far lower frequency. Beaver dams also rarely appear in very steep headwater streams, indicating that stream power might be a factor controlling dam constructing activity. Taken at face value, these results suggest the scale of hydro-geomorphic impacts from beavers is likely to decrease with river size, and therefore with increasing stream order, meaning only minor construction activity 
should be expected in larger river systems (Levine and Meyer, 2014; Naiman et al., 1988). However, many larger river systems also have increasing levels of anthropogenic modifications to floodplain and channel environments and flow regulation, meaning the reduction in dam construction frequency on larger river systems may be difficult to disentangle from the increase in human influence. This section explores the geomorphic impact of beavers on 1) sediment transport and deposition, 2) erosion (including beaver dam breaches) and channel stability, and 3) long-term river valley formation.

\subsection{Sediment transport and deposition in beaver systems}

An important geomorphic impact of beaver dams is to reduce the longitudinal (downstream) hydrological and sediment transport connectivity in rivers (Figure 4). The reduced velocity upstream of dams (backwater effect) causes a decline in sediment transport capacity, with bedload initially deposited as sediment wedges against the dams (Figures 11, 12 a), and over time some suspended load will settle out as the still- water area of the beaver ponds expand to cover the bedload deposits. These dam-wedge and pond deposits are also rich in particulate organic carbon (POC), which is partly produced by the decomposition of in-situ aquatic vegetation, but also transported from upstream. Additionally, beavers add organic matter to the stream by felling trees, encouraging habitat for macrophyte and biofilm growth, and intentionally submerging vegetation for winter food storage (see sections $5,6.2,6.5)$. Sediment wedges have their highest thickness at the dam and decrease in thickness with distance from the dam in the upstream direction (Figures 11, 12a) and are also influenced by active construction and modification by beavers themselves. However, dam-wedge sedimentation dynamics and geometry can be difficult to quantify and is therefore rarely taken into account in assessments of overall beaver pond sediment deposition and storage.

Whilst the sediment wedge against the dam is often the thickest area of deposition within a beaver pond, the progressive development of backwater environments can also result in the upstream deposition of bedload as delta-like deposits (Harthun, 1998) (Figure $12 \mathrm{~b}$ ), although this has not been reported in all studies (de Visscher et al., 2014). Delta-like deposition can often be generated due to the supply of a sediment pulse from the breach of an upstream beaver dam (see below), and might therefore be more common in systems that have had the opportunity to develop multiple dams. These sedimentation patterns may also reflect the influence of distinct flow stages, e.g. wedge deposition during high flows, and delta-like deposition during low and medium flows. However, further research is needed to better understand depositional patterns in beaver impacted reaches.

Across these range of sedimentation mechanisms, it is clear that beaver dams and ponds trap sediments to a much greater extent than would otherwise occur in their absence (Table 2). However, these sedimentation rates also vary widely, with estimates ranging between 0.2 up to $45 \mathrm{~cm} \mathrm{yr}^{-1}$ (Table 2). These comparatively large rates demonstrate that sediment trapping efficiency of beaver ponds can be very high (Giriat et al., 2016). However, the large variability also attests to the importance of local conditions in controlling the overall trapping efficiency and sediment supply, which can also be seen in the comparatively high sedimentation rates in beaver systems from more mountainous regions, and generally reduced sedimentation rates in lowland regions (Table 2). It is important to note however, that this is a 'between catchment' spatial trend and does not track downstream changes in sedimentation rates in a single system, or at a single site over time. Most research has focused on 'snapshots' of sedimentation within beaver pond cascades, but this storage capacity is also transient 
over longer timescales because beaver dams either eventually breach or the associated ponds fill with sediment, and hence the capacity of dams to store additional sediment will diminish to become negligible over time (Demmer and Beschta, 2008; Levine and Meyer, 2014; Persico and Meyer, 2009). This is also supported by the observation that deposition rates in ponds can be very high just after dam construction, but reduce with age (Meentemeyer and Butler, 1999). Even if the variation in sediment rates over time is not well known, there is in principle an upper limit to the sediment storage capacity of beaver dams. The simplest expression of this maximum sediment storage $\left(V_{m}\right)$ for a single beaver dam, represented as a triangular prism, can be formulated following Pollock et al. (2003) as:

$$
V_{m}=\frac{H^{2} W}{2 S}
$$

where $H$ is the beaver dam height, $W$ is the pond or valley, and $S$ is the valley or river slope. This is a highly idealized estimator, and therefore may not be applicable over shorter term timescales (e.g. < $10^{1}-10^{2}$ years) where irregular storage geometries across multiple beaver dams will be highly influential. This also makes Equation (8) difficult to test (Wohl and Scott, 2016). However, $V_{m}$ may be conceptually more informative over longer-term (e.g. millennial) timescales where some of these variations may be averaged out. Since it is a squared term, Equation (8) is also highly sensitive to the estimation of beaver dam height $(H)$, which may not always be known accurately if there is significant variation in dam heights change over time. Thus, it is recommended that Equation (8) only be used conceptually, and not as a definitive estimate of the upper limits to beaver dam sediment storage capacity.

Within beaver dam cascades (Figure 2a, 12d) the relationship between age and deposition rate breaks down when sediment released by dam breaching is simply re-captured by other beaver ponds downstream (Figure 12d), a process which significantly delays the overall timescales of sediment transport downstream. It also implies that sediment storage in space and time within beaver ponds is not a linear function that can be extrapolated from shorter-term deposition rate estimates. In addition, the resuspension and downstream transport of pond sediments is possible without dam breaching (e.g. de Visscher et al. (2014)) (Figure 12c), which may also account for some of the variability in sedimentation rates that can found within a cascade of beaver dams. In systems with valley bottom spanning beaver ponds and beaver meadows, the longer-term mid-late Holocene sediment deposition rates on the floodplain have been found to be much lower $\left(0.05 \mathrm{~cm} \mathrm{yr}^{-1}\right)$ than shorter-term pond deposition rates (Polvi and Wohl, 2012). These floodplain sediments are however usually distributed over a much larger area, and given they are much less influenced by shorter-term dam breaches, the volume of sediment stored on floodplains due to beaver activity is likely to be far more significant over the longer term (Figure 12c). This is supported by the finding that steeper headwater catchments seem to not preserve longer-term records of beaver pond deposits despite their higher aggradation rates, compared to lower gradient streams which can preserve a wealth of alluvial activity (Persico and Meyer, 2009).

It is therefore clear that some sediment will be trapped and sequestered over longer timescales, and some fraction of sediment will continue to be transported through a beaver dam cascade system albeit with some delay. Although we are not aware of previous attempts to do so, it is possible, in principle, to combine these elements into a complete sediment mass balance of this system, from the perspective of beaver dam $n$ 


$$
\underbrace{V_{n} \frac{d C_{\text {sed }}}{d t}}_{\begin{array}{c}
\text { Change in sediment } \\
\text { mass behind dam }
\end{array}}=\underbrace{Q C_{\text {sed }}}_{\begin{array}{c}
\text { Sediment mass } \\
\text { inflow }
\end{array}}-\underbrace{Q C_{\text {sed }}}_{\begin{array}{c}
\text { Sediment mass } \\
\text { outflow }
\end{array}}-\underbrace{V_{n} \alpha C_{\text {sed }}}_{\begin{array}{c}
\text { Sediment mass } \\
\text { sequestered }
\end{array}}
$$

Where $V_{n}$ is the storage volume available behind beaver dam $n, C_{s e d_{n}}$ is the concentration of sediment in suspension or available to be transported on the bed behind dam $n, Q$ is the volumetric water flux (inflow or outflow), $C_{\text {sed }}$ is the concentration of sediment flowing into dam $n$ (potentially from the dam immediately upstream), and $\alpha$ is the long-term sediment deposition rate that sequesters sediment away from the active transport pathways. Where many beaver dams occur in a cascade, Equation (9) would be integrated across all dams in the system. We propose Equation (9) because it is conceptually useful, although we also note there are considerable limitations to its use in practice given the paucity of reliable data. However, it is also interesting to use Equation (9) to ask to what extent a system of beaver dams may delay the downstream transport of sediment that is not being sequestered over the longer-term. Analogous to water residence times (section 3.7), we can define $\tau_{\text {sed }}=V_{n} / Q$ as the residence time (or transport delay) of sediment from a single beaver dam. If we then assume all $n$ beaver dams have equally sized storages and equal values for $\tau_{\text {sed }}$ (i.e. the delay in sediment transfer is the same between all dams), it is possible to consider how a pulse of sediment (or water) acting as a tracer would pass through this system. Although it is beyond the scope of this paper to provide the full working, substituting $\tau_{\text {sed }}$ into Equation (9) and then performing a Laplace transform, it is possible to evaluate the sediment tracer outflow from the $n^{\text {th }}$ downstream beaver dam as

$$
C_{\text {sed }}(t)=\frac{t^{n-1}}{(n-1) ! \tau_{\text {sed }} n} e^{-\left(\frac{t}{\tau_{\text {sed }}}+\alpha t\right)}
$$

814

815

816

817

818

819

820

821

822

823

824

825

826

827

828

829

Equation (10) is a result well known across different fields by different names, for example as the tanks in series residence time distribution used in chemical engineering (Fogler, 2006), and also as the very popular Nash storage cascade rainfall-runoff model in hydrology (Nash, 1957), though $\alpha$ takes on a differnt meaning in these separate applications (and is implicitly 0 for the Nash cascade in hydrology).

This approach can also be used for tracers of water, however there is often a very large difference between values for $\tau$ (water), which may be on the order of $0.2-2$ days and $\tau_{\text {sed }}$, which may be closer to the order of $100-1000$ days. Given this important difference, we can apply Equation (10) in a useful thought experiment to consider the implications for tracer outflow as the number of dams increases. If we consider a system where the number of beaver dams $(n)$ is increasing from 2 to 5 , and then to 10 beaver dams, $\alpha=0$ and the time taken for $50 \%$ of the water or sediment tracer outflow to be released from the system $\left(t_{50}\right)$, then $t_{50}$ for water will increase from 2.2 days ( 2 dams) to 9.2 days (10 dams), while $t_{50}$ for sediment outflow increases from 0.46 years ( 2 dams) to 2.6 years ( 10 dams) (Table 3 ). The assumption of $\tau$ and $\tau_{\text {sed }}$ being equal between all dam structures in a cascade is of course unrealistic. Nonetheless, the thought experiment does show the potential for creating very long delays in sediment transport through beaver dam systems compared to water, especially as the number of dams $(n)$ becomes large. 


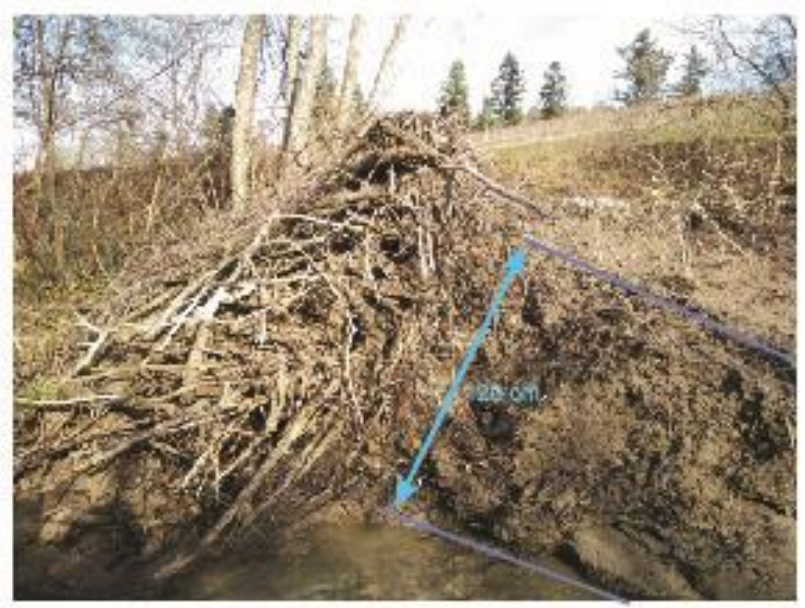

Figure 11_Example of a sediment wedge deposited against a beaver dam (Langwisenbach, Switzerland)
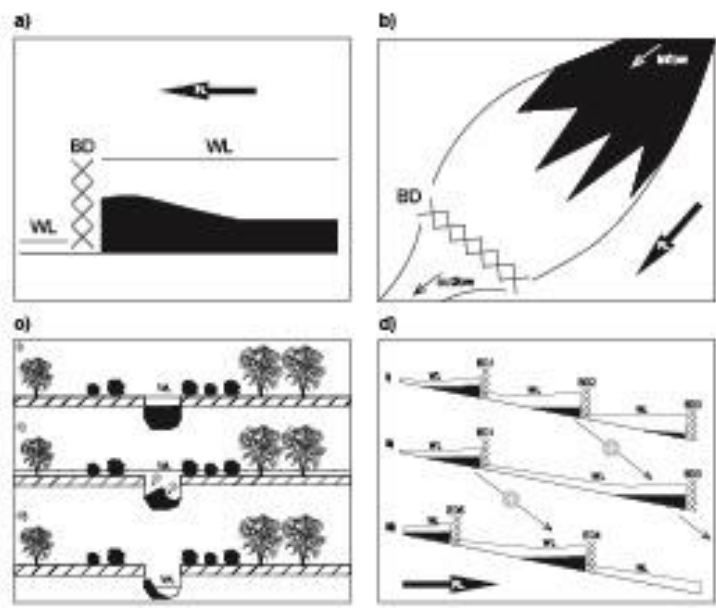

Figure 12_Conceptual model of beaver dam influenced sedimentation patterns

\subsection{Erosion in beaver systems}

Established beaver dam cascades reduces the potential for streams to incise, mimicking to some extent artificial grade control structures. However, if and when beaver dams breach, outburst flows can be large and have been reported as damaging roads, rail tracks and pipelines, and also causing mortalities (Butler and Malanson, 2005). The stability of beaver dams depends on many factors, which are largely unexplored, and have been discussed in more detail in the hydrology section. Beaver dams mostly breach during high discharge events when sediment transport capacities and load are at their peak. A breach not only releases water that was previously retained in the beaver pond, but also sediment eroded from the bed directly upstream of the dam. Beaver dams can breach centrally or laterally, and if the latter can also trigger further bank and floodplain erosion as well as channel widening (Demmer and Beschta, 2008). The water and sediment released during dam breaching adds to the already high event discharge and sediment load, however the overall contribution to the event may be small. However, little is known about the longer-term fate of sediments released from breached beaver dams, due to the difficulty of monitoring rare flood events (Jakob et al., 2016). In North America, dam breaches have been documented to easily erode previously deposited pond sediments, re-incising the streams to their previous base level but with minimal lateral bank erosion (Butler and Malanson, 2005). In central Europe, local fisherman observed no noticeable change in channel shape or sediment transport after a managed breach of a beaver dam, until a larger natural flood event initiated a sandy sediment slug which then moved progressively through the downstream river reaches (personal communication, local fishery department Karlstadt, Germany). Hillman (1998) also reports channel incision occurring upstream of a beaver dam breach in the beaver pond deposits, with some evidence for boulder transport, testifying to high sediment transport capacities over short distances following a breach (Butler and Malanson, 2005). One explanation for high transport capacities over short distances might be the local initiation and rapid migration of an alluvial knickpoint at the step in the long-profile created by the sediment wedge on the lee side of beaver dams (Figure 11, 12 a) (Burchsted et al., 2010; Burchsted and Daniels, 2014). The height of the knickpoint depends on the depth of the sediment wedge deposited against the dam, which is commonly reported to be between $1-2 \mathrm{~m}$ in thickness (example in Figure 11, section 4.1). Once initiated, the knickpoint then migrates upstream until the 
slope equilibrates with the upstream and downstream reaches. Knickpoint migration would explain the high but localized increase in sediment transport, and the creation of downstream sediment slugs. Knickpoints can also develop where water has been diverted on the floodplain because of beaver activity and re-enters the channel as return flow via a channel bank (John and Klein, 2004). In this case, knickpoint migration beginning where the return flow breaches the channel bank can also initiate floodplain channel erosion. As already described above, sediment eroded during and following beaver dam breaches may largely be trapped by subsequent beaver dams if a cascade system exists (Burchsted et al., 2010) (Figure $12 \mathrm{c}$ ). Although not yet investigated, it is interesting to speculate that the sedimentladen flows generated by beaver dam breaches may also counteract any bed incision that would otherwise occur directly downstream of the breach (Butler and Malanson, 2005; Meentemeyer and Butler, 1999).

\subsection{The role of beaver channels, burrows and dams in the hydro-geomorphology of rivers and floodplains}

Beavers dig small channels within floodplains to extend their habitat mobility (Harthun, 1998; Hinze, 1950; Hood and Larson, 2015). Beavers also dig channels on the pond floor, which may create sufficient water depths such that the ponds do not completely freeze during winter (Hood and Larson, 2015). These channels have average widths of $60-90 \mathrm{~cm}$, a depth of $35-70 \mathrm{~cm}$, relatively steep slopes and can extend more than $100 \mathrm{~m}$ in length (Gurnell, 1998; Hinze, 1950), in some instances even up to 300 $\mathrm{m}$ (Hood and Larson, 2015). They are often interspersed by deeper sections, which are probably used as a refuge. Sediment removed during the digging process is not typically observed adjacent to be the beaver channels on floodplains, so it is likely pushed into the main river channel where it is available for transport further downstream. One study has estimated the magnitude of sediment removed from these smaller channels to be $22,300 \mathrm{~m}^{3}$ over a $13 \mathrm{~km}^{2}$ area populated by beavers in Alberta, Canada (Hood and Larson, 2015), thus dpending on the size and transport capacity of the main channels, this may be a significant source of sediment. The development of beaver floodplain channels are also likely to play an important role in increasing the hydrological and ecological connectivity between rivers and floodplains (Hood and Larson, 2015), and in the transport and retention of surface water on floodplains (Westbrook et al., 2013) (Figure 6, section 3.1). Importantly, these channels greatly improve the areal extent of floodplain wetland development. In Alberta (Canada), the construction of floodplain channels by beavers lead to a $575 \%$ increase in wetland area in one study (Hood and Larson, 2015). If reasonable hydraulic conductivity values can be maintained, they may also facilitate the rise in shallow ground water levels typically found adjacent to beaver dams (section 3.5). However, the creation of channels may already depend on relatively high floodplain ground water levels in the first place, as beavers may preferentially construct channels when the height difference between in-channel water level and floodplain is relatively small (Stocker, 1985). This may be because in more incised river systems beaver channels could be very effective in draining the floodplain surface, and thus be counterproductive in terms of wetland habitat creation.

In addition to building dams, beavers also burrow into channel banks and floodplains, and can steepen river banks and lead to destabilization and collapse (Figure $13 \mathrm{c}$, d). The length of these burrows is usually less than $10 \mathrm{~m}$, but they may extend up to several $100 \mathrm{~m}$, and are around $15-30 \mathrm{~cm}$ in diameter with occasional widened sequences (Djoshkin and Safanow, 1972). Studies have found a complicated network of burrows in the subsurface of older beaver colonies (Djoshkin and Safanow, 1972), meaning 
903

904

905

906

907

908

909

910

911

912

913

914

915

916

917

918

919

920

921

922

923

924

925

926

927

928

that their influence on bank stability can potentially be significant. When beaver burrows collapse, they can create preferential flow paths for infiltration, which can further enhance bank erosion, and finally promote channel widening. This mechanism has been suggested to enhance lateral migration of streams (Giriat et al., 2016), but quantitative studies examining the extent to which this may occur are still needed. Collapsed beaver burrows have also been observed to create spillways and the diversion of stream water around the main dam, which over time are likely to incise and create side channels (Giriat et al., 2016). Within beaver ponds, underwater digging activities by beavers (e.g. removal of sediments from the base of banks after failure) in combination with sediment instability due to pore water pressure changes and fluvial erosion and deposition processes lead to a general widening of the beaver pond, which then contributes to a widening of river sections in the case of dam breaching (Figure 13 b,e) (Giriat et al., 2016). In contrast, Polvi and Wohl (2013) argued that beavers increase bank stability because they promote the deposition of finer sediment on floodplains, which provides more cohesive and higher river banks. Abandoned dams incorporated into the stream banks may also reinforce bank stability, thus helping to limit channel migration and promote a combination of bed incision and high-angle channel bends (Figure 14). Also important for bank stability is the possible rise in shallow groundwater levels near beaver dams (see section 3), and any change in riparian vegetation root mass, which can shift if there is dieback of existing tree species and a promotion of pioneer species vegetation assemblages (see section 6.5). There is also the importance of changes in pore pressure as surface water recedes following dam breaching and pond drainage in promoting bank instability. In summary, whether or not beaver activity enhances or reduces bank stability will depend on the extent of burrowing activity, the frequency of dam disruption and pond drainage, fine sediment deposition, and groundwater-vegetation feedbacks over the longer term. Further long-term research is clearly needed to better understand the relative importance of these different drivers. 

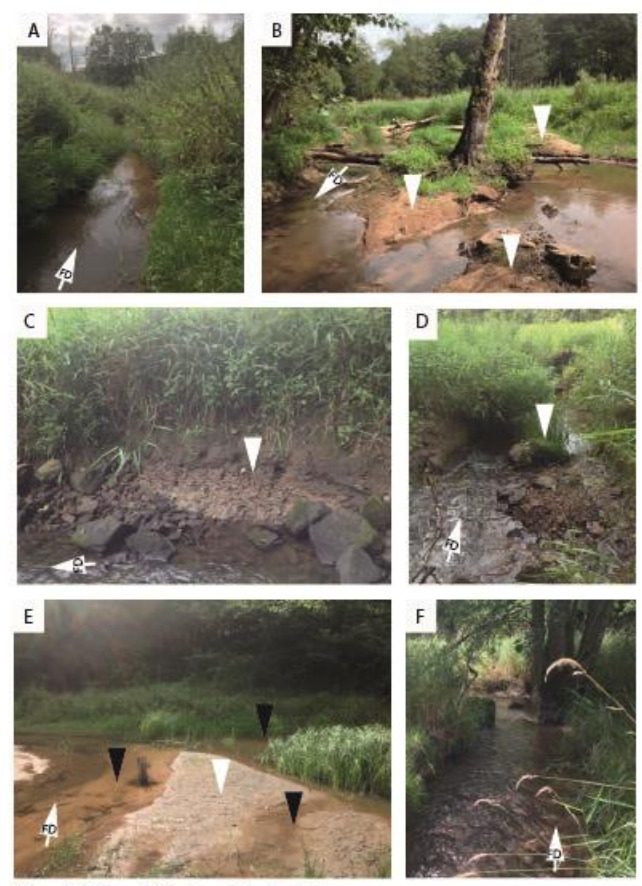

$$
\text { Figure 13_Channel widening and bank stability }
$$

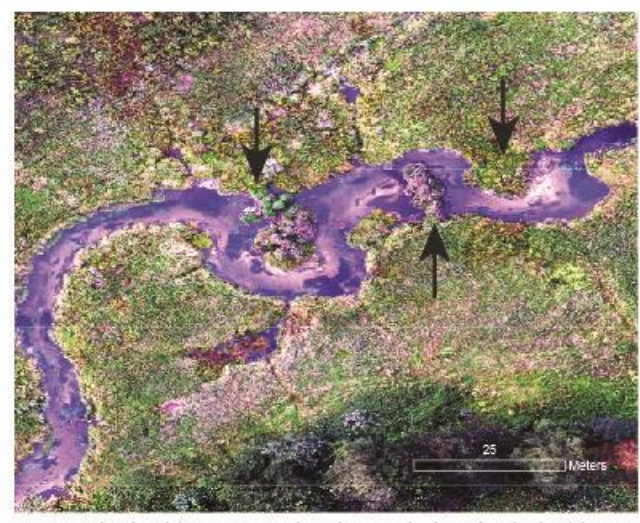

\subsection{Decadal to millennial valley formation mediated by beavers}

932 It has been long suggested that beavers have had an important influence on long-term valley formation. Beaver damming activity was descried by Rudemann and Schoonmaker (1938) as generating "gently graded, even valley plain, horizontal from bank to bank" river corridors, as the agent of valley floor aggradation that is enhanced over time by their valley-wide beaver dam construction (Ives, 1942). Their medieval eradication in western Europe has also been put foreward as one explanation for the expansion of braided river planforms, at the expense of more channelised patterns with wetlands, across post-glacial river valleys draining from the European Alps (Rutten, 1967). These earlier studies argued that although beaver dams disappear over time, their accumulated floodplain and meadow deposits remain, forming fertile river valleys. Buried beaver dams found in the Colorado headwaters also lend some weight to this hypothesis (Ives, 1942; Kramer et al., 2012), though it is unclear how widespread such features are in floodplain architecture. Kramer et al. (2012) calculated beaver influenced sediment deposition to be roughly $1.3 \mathrm{~m}$ thick, and to constitute between $32-53$ $\%$ of post glacial alluvial sedimentation. Nonetheless, the objective differentiation between beaver- 
related sedimentation and otherwise natural aggradation remains difficult (Levine and Meyer, 2014), especially since periods with active beaver related aggradation might also alternate with periods of a) no aggradation, b) aggradation unrelated to beavers or c) incision related to changes in climate or beaver site abandonment (see section 8) (Persico and Meyer, 2009). Beaver assisted valley sedimentation may also lead to changes in the soil carbon and nutrient status which in turn influences vegetation succession and long-term meadow vegetation composition (see section 7.2) (Johnston and Naiman, 1990b, Johnston, 2017; Polvi and Wohl, 2012; Westbrook et al., 2011; Westbrook et al., 2013). In any case, the long-term aggradation rates on floodplains and meadows influenced by beaver damming is low compared to ponds (table 2), and also heterogeneous in time and space due to the highly variable beaver occupation and landscape constraints (Persico and Meyer, 2009; Polvi and Wohl, 2012). Most beaver-induced changes to long-term valley floor evolution are attributed to the creation of wet beaver meadow complexes (Ives, 1942; Polvi and Wohl, 2012), which are considered to develop due to a combination of: (1) damming and flow diversion onto floodplains, facilitating sedimentation, (2) the silting-up of shallow ponds on floodplains, (3) the introduction of wood into channels, further facilitating flow diversion and a decrease in stream power, (4) beaver floodplain digging activity channelizing flow diversion, and (5) rising shallow ground water levels and associated vegetation feedbacks, promoting grasses and sedges which can also effectively trap sediments, and the reduction of tree species (see section 6.5, Figure 13). Following the introduction of beaver dams, some of the largest terrestrial ecosystem impacts are within beaver meadows and wetlands (see section 6).The persistence of beaver meadows and implications for vegetation, nutrient cycling, and carbon storage is covered in section 7.2 .

One of the most profound long-term geomorphic influences of beavers is their suspected capacity to change postglacial fluvial channel patterns, with implications for the aquatic and terrestrial ecosystems within these river corridors (Polvi and Wohl, 2013, Rutten, 1967). Examining gravel-bed river corridors with a snow-melt hydrological regime and set in semi-confined mountain valleys partially dammed by glacial moraines, Polvi and Wohl (2013) hypothesize that beavers came to occupy postglacial environments after they had transitioned from braided to single thread, meandering channel planforms, since this would have provided the riparian vegetation necessary for beaver populations to thrive. This may not be an exclusive transition, and changes to anabranching systems with vegetated islands may have also be sufficient. Beavers may also promote anabranching channel planforms due to (1) the water diversion processes as a result of damming, (2) fine sediment accumulation on valley floors, and (3) increased wood in streams, forming, for example, log jams and promoting partial flow diversion (Polvi and Wohl, 2013). More specifically, Polvi and Wohl (2013) hypothesize that beaver occupation and meadow development follows a long-term sequence from the post-glacial recovery of vegetation leading to the creation of log-jams within early post-glacial braided rivers, which in turn promotes fine sediments deposition, and the initial creation of floodplains. Beaver meadow vegetation is well adapted to inundation, which then sufficiently stabilizes banks, islands and floodplain patches to create avulsion and promote stable anabranching channel patterns. In contrast, the removal of beaver dams and log-jams would promote incision and contraction to a single, mostly meandering channel system. It has also been suggested that the widespread and rapid removal of beavers from dryland, discontinuous streams in the US ('arroyos') is one reason for post-European settlement channel incision response, and to the evolution of the modern continuous stream networks (Cooke and Reeves, 1976, Fouty, 2018). A key feature of discontinuous streams is a relatively stable aggregational surface within a section of the channel and floodplain, a feature that is often associated 
with local wetlands. The historical accounts of these wetlands in US drylands have all the characteristics of beaver meadows and their wetland complexes, though this is not definitive evidence of causation since beaver wetlands can appear very similar to non-beaver wetlands (Fouty, 2018). It has therefore been suggested that once beavers were removed from these streams, the wetlands dried up, the vegetation cover disappeared, and the channels incised and became continuous (Cooke and Reeves, 1976; Fouty, 2018). In the gravel-bed rivers of non-glaciated regions in the north-east USA, the pre-European Holocene deposits dominated by fine-grained organic-rich sediments have been interpreted as the product of small anabranching channels within extensive vegetated wetlands (Walter and Merritts, 2008), an interpretation that is also consistent with beaver meadow characteristics. In Europe, the long-term influence of beavers on river valleys are difficult to determine, because of the widespread eradication of beavers between $\sim 1000-150$ years ago (Zahner et al., 2005). However, John and Klein (2004) have also observed an anabranching planform emerge in southern Germany a decade after beaver re-introduction. Nonetheless, the suggested geomorphic feedbacks between beaver engineering and long-term river corridor vegetation dynamics may re-inform traditional models of biogeomorphic succession (e.g. Corenblit et al., 2007) which have not yet considered beaver influences (see sections 6.5, 7.2). More evidence from sediment archives and longterm monitoring studies of bio-geomorphic changes to river corridors following beaver introduction is clearly required to better understand the role of beaver engineering in long-term river valley formation.

\section{Changes in biogeochemistry, carbon and nutrient cycling, and water} quality

Changes to the biogeochemical functioning of beaver impacted systems, and therefore their potential impact on riverine water quality and ecosystem processes, can be divided into their influence on (i) pathways, i.e. modification of existing pathways or introduction of pathways not previously present, (ii) the spatial extent of these pathways and their rates, and (iii) the degree to which water flowing through the system can interact with these pathways (i.e. residence time and hydraulic efficiency). Impacts on these processes have important consequences for aquatic and terrestrial ecosystem processes and productivity, which in turn will also produce positive or negative feedbacks on the biogeochemical cycling. Thus, from a mass balance perspective the development of beaver ponds, wetlands and meadows may create both sources and sinks of e.g. carbon, nitrogen, and phosphorus in the riverine nutrient cycles (Figure 15). However, it remains unclear when and how these process modifications should interact over different spatial (e.g. one vs many beaver dams) and temporal (e.g. event, seasonal, annual) scales.

\subsection{Changes to biogeochemical pathways}

In terms of potential changes to biogeochemical pathways, the combination of increased surface water inundation extent, turbulence reduction, higher temperatures, and higher floodplain water tables can combine to diminish dissolved oxygen concentrations and enhance the extent of anaerobic conditions present in beaver impacted systems (Dahm et al., 1987; Naiman et al., 1994). This spatial enhancement of anaerobic conditions is typically focused along saturated boundaries with limited turbulent exchange, for example within benthic ponds and wetland areas where biofilm communities are abundant, which typically contain a variety of aerobic and anaerobic metabolic pathway communities 
(Battin et al., 2016) or within permanently or seasonally saturated floodplain or meadow soils. The enhancement of anaerobic conditions is important since a shift from aerobic to anaerobic metabolism will tend to slow the overall rate of organic matter cycling, and utilize electron acceptors beyond dissolved oxygen, such as nitrate $\left(\mathrm{NO}_{3}{ }^{-}\right)$, iron $(\mathrm{Fe})$ and manganese $(\mathrm{Mn})$ oxides, sulfate $\left(\mathrm{SO}_{4}{ }^{2-}\right)$, and eventually $\mathrm{CO}_{2}$. This in turn creates new loss pathways for the nitrogen, carbon and sulfur cycles via reduction to atmospheric nitrogen $\left(\mathrm{N}_{2}\right)$ (or nitrous oxide $-\mathrm{N}_{2} \mathrm{O}$ ), methane $\left(\mathrm{CH}_{4}\right)$, and hydrogen sulfide $\left(\mathrm{H}_{2} \mathrm{~S}\right)$ respectively, as well as concentration enrichment pathways for $\mathrm{Fe}, \mathrm{Mn}$, and aluminum (AI) via the dissolution of their respective oxides. The breakdown of organic matter containing appreciable nitrogen under anaerobic conditions will also yield ammonium $\left(\mathrm{NH}_{4}{ }^{+}\right)$, which can be subsequently oxidized to $\mathrm{NO}_{3}^{-}$(via nitrite $-\mathrm{NO}_{2}{ }^{2-}$, i.e. nitrification) if transported back into aerobic conditions or internally cycled within biofilm communities. This potential re-oxidation pathway has the capacity to counteract or diminish any reduction in $\mathrm{NO}_{3}{ }^{-}$(due to denitrification) downstream of beaver dam complexes, depending on the rates and extent of mineralization ( $\mathrm{NH}_{4}{ }^{+}$production) and subsequent nitrification (to $\mathrm{NO}_{3}{ }^{-}$). $\mathrm{NH}_{4}^{+}$can also be taken up directly by many plant communities, which may be an important pathway in beaver meadow or wetland development (Naiman et al., 1994). Enhanced anaerobic conditions also have implications for the phosphorus cycle, as organic matter breakdown may release orthophosphate, in addition to the phosphorus absorbed onto mineral surfaces (e.g. Fe oxides) that is released as these minerals dissolve following the transition from oxic to anoxic conditions. With the enhancement of anaerobic conditions and associated biogeochemical pathways in beaver impacted systems, a key question is therefore how these biogeochemical pathways and rates will act in combination with changes to the overall storage of nutrients to influence any net changes in water quality and ecosystem dynamics. These feedbacks, over a range of timescales, are critical to understand since they will determine the implications of beaver modification for the riverine carbon, nitrogen, and phosphorus cycles and the ecosystems which depend on them (Figure 15).

\subsection{Beaver impacts on the carbon cycle}

In terms of the carbon cycle, a key consideration in determining the relative impact of beavers is the carbon storage existing within the landscape prior to beaver modification. If floodplain forests are present, then the standing carbon stored in woody biomass will be greatly reduced as a result of floodplain inundation and rising water tables (Naiman et al., 1994), in addition to species specific tree felling and consumption by the beaver populations (see section 6.5) (Martell et al., 2006; Mitchell and Niering, 1993). The death and felling of these forests following inundation may in some cases create substantial storages of submerged woody biomass; (Johnston, 2017; Thompson et al., 2016). If widespread floodplain forest is not initially present, at the very least, reductions in riparian zone woody biomass is likely (Martell et al., 2006; Stabler, 1985). Thus, as beaver modifications promote the expansion of lentic open water area and anaerobic conditions, there is the potential for significant net transfers of carbon stored as woody biomass carbon to herbaceous and grass biomass, as well as increased sediment carbon storage (Johnston, 2014; Naiman and Melillo, 1984; (Wohl, 2013). Furthermore, much of the woody biomass that enters the beaver system, either from landscape conversion, or via the fluvial network, may not be very labile relative to other carbon inputs (Hodkinson, 1975). In general, woody biomass can provide some soluble sugars and cellulose during the initial stages of decomposition, however the large fraction of remaining lignin in woody biomass is notoriously slow to decompose (Reddy and DeLaune, 2008). Adding to this context, a very important experimental finding from Naiman et al. (1986) was that the expansion of anerobic conditions due to beaver daming considerably reduced the decomposition rates (by $81 \%$ and $61 \%$ ) of both labile and 
non-labile woody biomass inputs respectively, compared to downstream aerobic riffle environments. This promotion of anerobic environments, slower decomposition rates, and abundance of refractory woody carbon is therefore condusive toincreased long-term carbon storage. Beavers can themselves also directly import large masses of plant detritus and woody material into the river corridor that contributes to carbon storage. The amount of woody biomass harvested by beavers remains highly uncertain, Francis et al. (1985) report $\sim 1 \mathrm{t}$ per year per adult of woody biomass harvested, and Nummi et al. (2018) report on average $~ 8.8 \mathrm{t}$ per year is harvested in the browsing zone surrounding ponds per colony. However, the vast majority of this wood is used for dam construction (Nummi et al., 2018), which (Johnston and Naiman, 1990b) found on average contained $\sim 7.7 \mathrm{t}$ of wood per dam. In any case, it would be difficult to justify extrapolating these estimates beyond their local settings without further knowledge on how dependent such woody biomass harvesting may be on wood availability, type, food availability, and landscape controls on the damming activity.

Additional mechanisms by which beavers can increase carbon storage in river corridors include 1) trapping of allochthonous particulate organic carbon (POC) inputs, and 2) through greater autochthonous inputs derived by increasing net aquatic ecosystem productivity (NEPaq, or gross primary production minus respiration). In terms of 1 ), POC inputs can include: leaf litter and small twigs and branches (macro-organics), as well as coarse and fine POC fractions which come in various stages of decomposition and from a variety of sources. These sources of POC may have some overlap with 2), increased NEP ${ }_{a q}$, especially for the fine POC fractions. These overlaps arise depending on the scope of NEP aq feedbacks considered within beaver systems. If NEP aq from only the lentic (pond) zone is considered, benthic biomass increases but is generally a small percentage (e.g.: $4-12 \%$ ) of the carbon budget for beaver impacted systems (Hodkinson, 1975; Stanley et al., 2003). In contrast, if the promotion of new littoral zone and wetland habitat vegetation is also considered, the increase in NEPaq, and therefore autochthonous inputs to $C$ storage, may be far more substantial (Hodkinson, 1975; Stanley et al., 2003). This increase in NEP aq is also discussed in section 6.1, suffice to say it is critical to recognize as it builds a foundation for changes to carbon cycling and storage in river corridors impacted by beavers (Mann and Wetzel, 1995).

Thus, increasing autochthonous carbon contributions from higher productivity lentic, littoral and wetland ecosystems, in combination with the enhanced capacity to trap allochthonous POC and woody debris inputs, and slower breakdown rates of both labile and refractory woody biomass (Naiman et al., 1986), likely explain the widely observed increases in carbon storage within river corridors impacted by beavers (McDowell and Naiman, 1986, Wohl et al. 2012; (Hodkinson, 1975; Mann and Wetzel, 2000; Wohl, 2013). However, it is also important to note that beaver landscape modifications may not always imply large changes in carbon storage. In Minnesota, $70 \%$ of sites occupied by beavers were found to have already been peatlands or wetlands prior to flooding (Naiman et al., 1994), and similarly in Patagonia a large fraction of impoundments from invasive beaver populations are within pre-existing peatlands and wetlands (Anderson et al., 2006a; Skewes et al., 2006b), which are already comparatively high in carbon storage. Nonetheless, it is interesting to note that Ulloa (2012) did find a large increase in both the carbon storage and decomposition rates in beaver impacted rivers in Patagonia.

The general finding of increased to carbon storage, combined with the expansion of anaerobic conditions, have important implications for how carbon is exported from beaver impacted systems. In terms of fluxes to the atmosphere, the additional mass of organic matter available for aerobic and 
anaerobic microbial metabolic pathways can increase overall $\mathrm{CO}_{2}$ fluxes relative to those prior to beaver impact. Although before and after studies have yet to be undertaken, beaver ponds have been found to be very large net sources of $\mathrm{CO}_{2}$ relative to surrounding river networks (Roulet et al., 1997; Yavitt and Fahey, 1994). $\mathrm{CH}_{4}$ fluxes from beaver ponds are also elevated (Ford and Naiman, 1988; Lazar et al., 2015; Roulet et al., 1997; Yavitt et al., 1990), especially relative to the fluxes that would likely occur from the river system in their absence (Ford and Naiman, 1988), or even relative to other regional wetlands, particuarly in boreal regions (Bubier et al., 1993; Roulet et al., 1997). However, measured $\mathrm{CH}_{4}$ fluxes from beaver systems to date are almost exclusively from the higher latitude regions of North America (Nummi et al., 2018), and are highly variable regionally (Nummi et al., 2018; Whitfield et al., 2015), locally (Bubier et al., 1993; Lazar et al., 2015), and even within a single pond (Weyhenmeyer, 1999; Yavitt et al., 1992). These increased $\mathrm{CH}_{4}$ fluxes, and to some extent $\mathrm{CO}_{2}$ fluxes, along with their high spatial and temporal variability, are a result of the expanded benthic anaerobic conditions following beaver impacts promoting metabolic pathways that include methanogenesis. However, $\mathrm{CH}_{4}$ fluxes are also higher in beaver ponds per unit area compared to similar water bodies, which as Weyhenmeyer (1999) notes, raises the question as to whether this is due to higher methane production rates, differences in methane oxidation rates in the sediments and water column, or some combination of both. In terms of $\mathrm{CH}_{4}$ production rates, this could be due to higher organic carbon quality (Weyhenmeyer, 1999), perhaps as a result of inputs from the the relatively high ecosystem productivity noted earlier, though this remains speculative and needs further research. In terms of differences in oxidation rates, this question may come down to the relative importance of ebullition, which Weyhenmeyer (1999) found to dominate (65\%) over diffusive fluxes in a beaver pond in Ontario, Canada. Though only a single study, this is important as it would shift the dominant controls on $\mathrm{CH}_{4}$ flux sensitivity being mainly due to water depth in the case of diffusive fluxes, which have been shown to be susceptible to significant oxidization in the water column, even in relatively shallow beaver ponds (Yavitt and Fahey, 1994; Yavitt et al., 1990), and more towards atmospheric pressure and sediment temperatures (Weyhenmeyer, 1999). Nonetheless, even if the diffusive fluxes are a smaller component, they are still likely to be significant enough to permit water depth, and thus also beaver pond hydrology and wetland hypsometry, to play an important role. Indeed, Yavitt and Fahey (1994) found the $\mathrm{CH}_{4}$ tended to be higher, though not always, in beaver ponds with shallower water depths. An interesting result was also found by Yavitt et al. (1990) where the flowing water river sections between beaver dams tended to have higher $\mathrm{CH}_{4}$ fluxes than the ponds themselves. This makes sense from the perspective of the streams having higher turbulent fluxes, but only if a high $\mathrm{CH}_{4}$ supply can be maintained, suggesting hyporheic and groundwater flow from the upstream ponds and wetlands are in this case able to subsidize the downstream $\mathrm{CH}_{4}$ fluxes from the stream. In terms of $\mathrm{CO}_{2}$, it is important to note that some anaerobic pathways produce, and others consume, $\mathrm{CO}_{2}$. Thus, it is difficult to make general speculations on the extent to which $\mathrm{CO}_{2}$ fluxes should increase. Nonetheless, small water bodies are known to disproportionately contribute to natural $\mathrm{CO}_{2}$ and especially $\mathrm{CH}_{4}$ evasion (Holgerson and Raymond, 2016), and the areal extent of small water bodies generated by beavers is increasing (Hood and Bayley, 2008; Nisbet, 1989; Whitfield et al., 2015), especially in boreal zones (Nisbet, 1989). For this reason, it is important to consider the role of beavers on regional and global $\mathrm{CH}_{4}$ emissions, and Whitfield et al. (2015) have estimated a $\sim 20 \mathrm{x}$ increases in $\mathrm{CH}_{4}$ emissions from expanding beaver ponds and wetlands over the last century across Europe and North America. This outsized influence on $\mathrm{CH}_{4}$ emissions per unit water area led Moore (1988) to wonder "whether the beaver is aware the greenhouse effect will reduce the demand for fur coats". Nonetheless, it is critical to emphasize that speculation regarding beaver impacts on $\mathrm{CO}_{2}$ and $\mathrm{CH}_{4}$ emissions should be placed in 
the context of both the total greenhouse gas emission flux ( $\sim 0.001 \%$ of total $\mathrm{CH}_{4}$ emissions) as well as the full carbon mass balance of the aquatic system being studied, especially the increase in carbon storage, which is discussed in greater detail later in this section.

An additional mechanism of carbon export from beaver systems is downstream fluvial transport, which comprises three main components: dissolved inorganic (DIC), dissolved organic (DOC), and particulate organic (POC) carbon. Within fluvial systems, DOC is typically the dominant export mechanism interacting with the organic carbon storages (Regnier et al., 2013). However, with the expansion of anaerobic conditions following beaver modifications, $\mathrm{HCO}_{3}{ }^{-}$is also produced via multiple pathways (e.g. $\mathrm{NH}_{4}{ }^{+}$production, $\mathrm{Mn}^{2+}, \mathrm{Fe}^{3+}$, and $\mathrm{SO}_{4}{ }^{2-}$ reduction) which typically dominates total DIC under the $\mathrm{pH}$ range of natural surface waters (Reddy and DeLaune, 2008). Given sufficient concentrations, $\mathrm{HCO}_{3}{ }^{-}$ will also contribute to additional $\mathrm{CO}_{2}$ outgassing and even to stream biofilm precipitates. Cirmo and Driscoll (1993), Smith et al. (2020), and Margolis et al. (2001) all found increases in alkalinity immediately downstream of beaver dams, which then tended to decrease with distance downstream. This suggests the production of higher concentrations of $\mathrm{HCO}_{3}{ }^{-}$in beaver systems were being subsequently diminished by conversion in the carbonate system to $\mathrm{CO}_{2}$ (Cirmo and Driscoll, 1993; Margolis et al., 2001), which is another potentially important source of $\mathrm{CO}_{2}$ evasion related to beaver impacts, but one that is not captured by the focus on pond water quality measurements behind the dams.

In terms of DOC export fluxes, a largely consistent finding is an overall increase in DOC concentrations downstream of beaver systems (Figure 16). Although this result only considers the direction of change in DOC and not the magnitude, it nonetheless suggests sufficient reactive transport interaction between the increased organic carbon production, storage and residence times of flowing water within beaver systems to drive net increases in DOC concentrations. This represents a profound change in riverine DOC behavior relative to what would occur in these same river reaches in the absence of beaver impacts, with important implications for carbon export dynamics and ecosystem processes. It is also largely consistent with the impact of similar within stream network lakes and wetlands that buffer river flow and enhance DOC concentrations (e.g. Kalinin et al. (2016); Kling et al. (2000). This is because a comparatively low NEP aq environment (e.g. the forested stream) flows into a higher NEPaq lentic environment (e.g.: lake, wetland, beaver pond) which as a result has to establish enhanced carbon storage and cycling feedbacks (Kalinin et al., 2016; Kling et al., 2000; Wetzel, 2001). This is also supported by the few studies that have examined sub-annual dynamics (e.g. seasonal, monthly, event) in beaver impacted systems, where the majority have found outgoing DOC fluxes, and to some extent DIC fluxes, to be strongly seasonal, likely reflecting the importance of wetland vegetation and algal biomass production and breakdown as well as hydrological feedbacks (Mann and Wetzel, 1995). The hydrological feedbacks include enhanced riparian soil carbon interaction as beaver dams cause water levels to rise (on average, as well as seasonally), which has been found to increase pond DOC concentrations (Hill and Duval, 2009; Wang et al., 2018). This is also a potential mechanism that can explain the increase in DOC concentrations following beaver related water level increases in Finnish lakes (Vehkaoja et al., 2015). However, Nummi et al. (2018) suggest the initial DOC sources following damming are from the decay of existing organic matter stocks rather than new interactions with riparian and littoral zone organic matter. This mechanism is in contrast to most other studies examining DOC source and export dynamics that emphasize the importance of hydrological feedbacks with the riparian zone, however it does highlight the need to better understand the unique DOC source-sink dynamics that may occur in beaver systems. 
Changes in the quality of DOC could also provide insights into the availability of these different carbon sources as well as the implications for downstream ecosystem carbon cycling. However, there is relatively little information available on DOC quality from beaver impacted systems. Two studies that have examined DOC quality changes, found either no change in total DOC (Koschorreck et al., 2016) or a decrease (Kothawala et al., 2006) in total DOC due to beaver impact, results which are unusual compared to the majority of findings (Figure 16). The decrease in DOC found by Kothawala et al. (2006) was accompanied by a corresponding decline in the molecular weight of DOC, with both these factors potentially dependent on the unusually high DOC inputs from the headwater swamp upstream. Koschorreck et al. (2016) found no significant difference in either DOC or quality (as measured by UV indices) from sites draining beaver dams, though by study design (paired catchment, rather than upstream - downstream comparison) these results are somewhat inconclusive. The quality of DOC and its concentration within beaver ponds is also likely to be dependent on the age of the system given the observed evolution in biogeochemical cycling from initial damming to pond systems that have been functioning for $>10$ years (Catalán et al., 2016). In this case, there is a hypothesized increase in labile carbon during the early stages of beaver impact which then diminishes with age (Ecke et al., 2017). However, the extent and timescales over which this should occur remain speculative. In an already well-established beaver dam system, Mann and Wetzel (1995) found the increase in DOC due to beaver impacts is not necessarily accompanied by a change in bioavailability, however the limited sample comparisons emphasize the clear need for further work in this area.

To our knowledge, only Naiman et al. (1986) has measured temporal beaver impacts on DOC and POC simultaneously, yet they found no significant change in either over a 2-year monitoring period. Again, these results are somewhat unusual given that the clear majority of studies find a downstream increase in DOC, and that the limited number of studies $(n=8)$ examining changes in suspended sediment concentrations, which can be indicative of POC behavior, find a decrease in concentrations downstream of beaver dams (Figure 16). However, Naiman et al. (1986) did find very large concentrations of coarse and fine POC in snapshot sampling across beaver impacted river systems in Quebec, Canada. In addition, Naiman et al. (1986) attribute the findings of no difference in the temporal DOC analysis to a) the monitoring of a mature beaver dam system, and b) monitoring of a single dam that was already downstream of 10 other beaver dams, making it more difficult to capture any remaining carbon cycling dynamics on a single downstream dam. Kroes and Bason (2015) investigated changes in both suspended sediment and POC concentrations in beaver impacted systems on the piedmont region of Virginia and the coastal plains of North Carolina (USA). Interestingly, this study found both suspended sediment and POC decreased (increased) downstream of the beaver systems depending on whether there were more (less) and older (younger) dams present. Although it is clear from spatial snapshots beaver systems can act as significant sinks for coarse and fine POC, further research is clearly needed to examine the significance of $\mathrm{POC}$ within the overall carbon budget, especially given the near ubiquitous increase in woody debris introduced by beavers to river corridors (Anderson et al., 2014; Thompson et al., 2016). This is also important because the POC filtering vs production effectiveness of beaver systems will regulate the downstream delivery of this important component of the aquatic carbon cycle.

The full mass balance of changes to the storage and fluxes of carbon that can occur as result of beaver modifications, especially across the spectrum of terrestrial and aquatic carbon sources and sinks, remains poorly understood (Nummi et al., 2018; Wohl, 2013). This is partly because the mass balance strongly depends on the spatial and temporal frames of reference considered, and the availability of 
suitable controls for context. For example, some studies consider the change in storage and fluxes with respect to the beaver pond (Naiman et al., 1986), and others the change in carbon storage within the beaver modified wetlands and floodplains (Wohl, 2013). Such frameworks are potentially confusing, since beaver modifications can both create conditions for enhanced storage as well as aquatic and terrestrial primary production (e.g. wetland vegetation and biofilms). Thus, the increase in exported fluxes ( $\mathrm{POC}, \mathrm{DOC}, \mathrm{CO}_{2}, \mathrm{CH}_{4}$ ) is likely to be due to some combination of increased allochthonous carbon storage, as well as enhanced in situ carbon production (NEPaq) and decay, both of which can be highly interactive with water flow paths through the system. As already mentioned, the large expansion of anaerobic conditions is likely to be a key driver of these increases in both aquatic (Cirmo and Driscoll, 1993; Naiman et al., 1986) and terrestrial (Johnston, 2014; Wohl, 2013) carbon storages in beaver modified systems. These changes to carbon storage and fluxes also have implications for the residence time of carbon in river channel and floodplain systems, which will increase as storage increases in order to maintain continuity in the carbon mass balance, although this is unlikely to ever reach steady state given the large variation in timescales over which the different storages and fluxes operate (see also section 7.2).

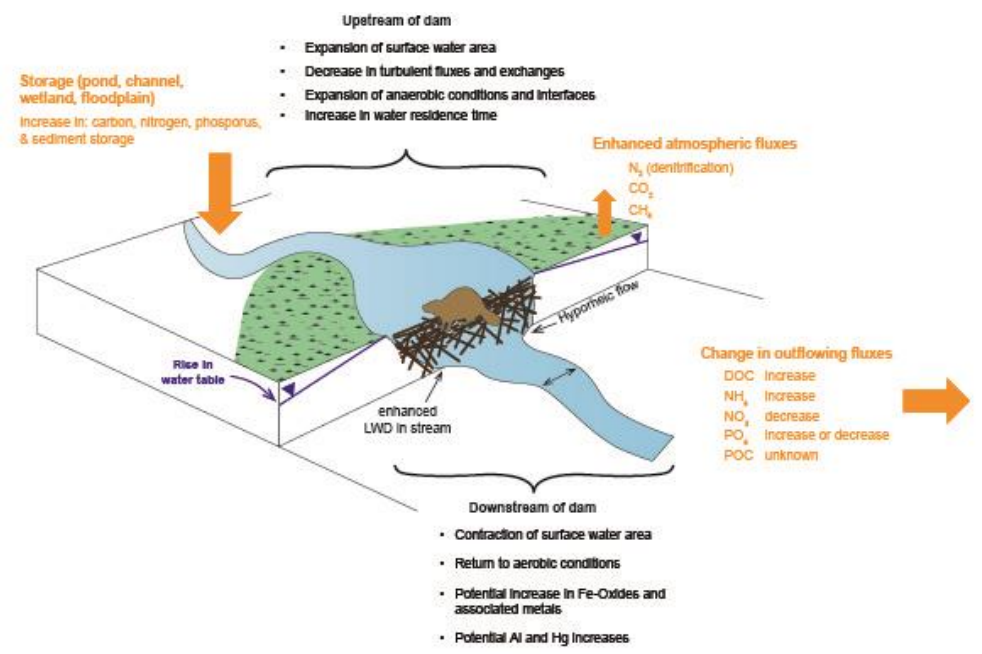

Figure 15: Conceptual model of beaver related biogeochemical changes

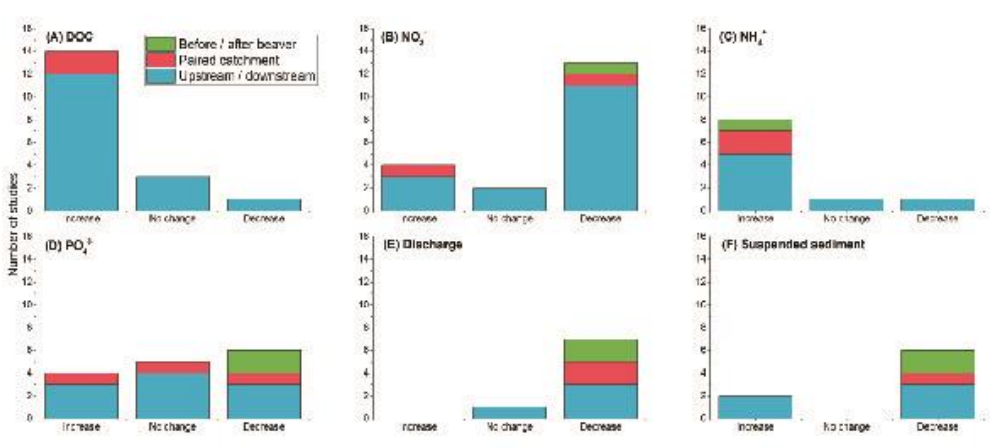

\subsection{Beaver impacts on the Nitrogen cycle}

1269 In terms of changes to the nitrogen cycle, the documented increase in organic carbon storage within beaver impacted systems is likely to also be accompanied by some increase in total organic nitrogen storage (Naiman and Melillo, 1984). Francis et al. (1985) estimate large increases in organic nitrogen 
accumulation once beaver ponds are established, relative to what would accumulate in their absence (e.g. within riffle sequences). This is not necessarily because nitrogen uptake rates are enhanced, but rather due to the large spatial increase in biofilm extent across beaver pond sediments (Francis et al., 1985), as well as the expanded sequestration of initial and new organic matter inputs (Devito and Dillon, 1993). Naiman and Melillo (1984) also found beaver impacted systems greatly enhanced nitrogen storage (per unit length or area) within beaver pond sediments, and similarly found this was likely to be due to the increased biofilm uptake of nitrogen. However, it remains unclear as to whether such large increases in nitrogen storage are restricted to more nitrogen-limited systems (Naiman and Melillo, 1984), and whether this should change as nitrogen availability also changes. Beaver vegetation consumption and waste can itself also be a considerable input of nitrogen and phosphorus to the system (Naiman and Melillo, 1984). Uptake of inflowing nitrogen (primarily $\mathrm{NO}_{3}{ }^{-}$and $\mathrm{NH}_{4}{ }^{+}$) by wetland vegetation has been found to be a key seasonal storage component (Devito and Dillon, 1993; Naiman and Melillo, 1984). However, the degree of long-term sequestration is unclear since this biomass also undergoes seasonal decay. Within sediment and soil pore waters, $\mathrm{NH}_{4}{ }^{+}$diffusively released during the biomass decay process (mineralization) will also increase the total nitrogen storage provided anaerobic conditions are maintained and the advective transport is slow. This is supported by evidence from Dahm et al. (1987) Naiman et al. (1994); Triska et al. (2000), and Stanley and Ward (1997) all of whom reported an order of magnitude increase in $\mathrm{NH}_{4}{ }^{+}$concentrations (as well as very low $\mathrm{NO}_{3}{ }^{-}$ concentrations) due to organic matter breakdown within beaver impacted sediment pore waters relative to sites without beaver impacts. In colder climates, the capacity for beaver ponds to develop ice cover also been found to promote both increased anaerobic conditions and $\mathrm{NH}_{4}{ }^{+}$production (Devito and Dillon, 1993). In terms of export, downstream increases in $\mathrm{NH}_{4}{ }^{+}$due to beaver damming have been found within the majority of studies in which $\mathrm{NH}_{4}{ }^{+}$concentrations have been reported (Figure $16 \mathrm{c}$ ). However, $\mathrm{NH}_{4}{ }^{+}$export or retention may have a large seasonal bias (Devito and Dillon, 1993; McHale et al., 2004), and the production of higher $\mathrm{NH}_{4}{ }^{+}$concentrations will not necessarily be sustained for significant distances downstream given the likelihood of nitrification to $\mathrm{NO}_{3}$.

In addition to these potential storage changes for nitrogen, the increase in anaerobic conditions provides an important avenue for denitrification, primarily within benthic biofilms and subsurface microbial communities (Lazar et al., 2015). This increase in denitrification capacity, in some combination with biomass uptake, likely explains the general decrease in $\mathrm{NO}_{3}{ }^{-}$concentrations downstream of beaver impacted systems identified in the majority of published studies (Figure 12b). However, it should be noted that the magnitude of this reduction varies markedly between studies. As already noted $\mathrm{NH}_{4}{ }^{+}$can also be converted to $\mathrm{NO}_{3}{ }^{-}$, meaning the overall impact of beaver modifications on downstream nitrogen fluxes is not clear. Studies that have tracked both $\mathrm{NH}_{4}{ }^{+}$and $\mathrm{NO}_{3}{ }^{-}$with increasing distance downstream of beaver systems have found the initial increases in $\mathrm{NH}_{4}{ }^{+}$are subsequently diminished while $\mathrm{NO}_{3}{ }^{-}$increases (Błędzki et al., 2011, Harthun, 2000), strongly suggesting nitrification may be an important pathway to consider downstream of beaver systems where aerobic conditions again dominate. All these uncertainties in combination highlight the need for a more comprehensive mass balances of nitrogen dynamics within beaver impacted systems.

Despite these knowledge gaps, the literature seems clear on the increased likelihood of net retention of $\mathrm{NO}_{3}^{-}$(Figure 12b) and net export of $\mathrm{NH}_{4}^{+}$(Figure 12c), within the caveats already mentioned above, and a less clear likelihood of increased organic nitrogen retention (Devito and Dillon, 1993; McHale et al., 2004) within beaver impacted systems (also see section 5.6 for further discussion on source vs sink behaviour). Increasing atmospheric fluxes as from beaver ponds as $\mathrm{N}_{2}$ have also been found (Lazar et 
al., 2015). Interestingly, this study also found that pond conditions were sufficiently anaerobic to allow complete denitrification, thus limiting the fluxes of $\mathrm{N}_{2} \mathrm{O}$ and allowing most atmospheric losses to occur as $N_{2}$ (Lazar et al., 2015). Taken together, these findings are largely consistent with syntheses of nitrogen dynamics in river systems interacting with wetlands and lakes without beaver impacts, whereby the mechanisms of nitrogen retention in order of decreasing importance have been found to follow: denitrification > sedimentation > biomass uptake (Saunders and Kalff, 2001). If this sequence also holds in beaver impacted systems, this suggests the reduction in downstream $\mathrm{NO}_{3}{ }^{-}$is being driven primarily through an increase in the atmospheric losses, and secondarily as increasing within-system storage, however the limited evidence thus far on full nitrogen cycling in beaver systems highlights much more work remains to be done in this area.

\subsection{Beaver impacts on the Phosphorus cycle}

The development of beaver ponds and wetlands is likely to lead to a large increase in the storage of total sorbed and particulate phosphorus (Devito and Dillon, 1993; Maret et al., 1987), given it also creates a large storage capacity for suspended sediment and organic matter, to which a large fraction of available phosphorus is sorbed (e.g.: Fe oxides) or complexed within. Although the total storage of phosphorus may increase, so too will the likelihood of sediment exposure to anaerobic conditions in beaver modified systems. Thus, phosphorus sorbed to redox-sensitive mineral phases such as Fe or $\mathrm{Mn}$ oxides may be readily released as dissolved orthophosphate $\left(\mathrm{PO}_{4}{ }^{3-}\right)$ as these phases dissolve under anoxic conditions (Klotz, 1998). Separately, $\mathrm{PO}_{4}{ }^{3-}$ concentrations may also increase under anaerobic conditions due to the mineralization of organic phosphate (Roden and Edmonds, 1997). However, the extent to which these mechanisms separately contribute to phosphorus dynamics in beaver impacted systems is not understood. This contrast between increased storage potential and the ability to release phosphorus under anaerobic conditions may explain the lack of consistency in the downstream behavior of $\mathrm{PO}_{4}{ }^{3-}$ concentrations in beaver impacted systems across all published studies (Figure 16d). Seasonal biomass uptake of phosphorus and release during decay may also contribute to this lack of trend, although this effect is likely to be smaller in magnitude than the influence of storage changes and the availability of anaerobic flow paths (Reddy and DeLaune, 2008). Fuller and Peckarsky (2011) found beaver systems were more likely to retain or release phosphorous depending on whether the vertical hydraulic gradient over the dam(s) was low or high respectively. This interesting result doesn't reveal a clear mechanistic explanation but highlights the need to better understand how the extent of anaerobic conditions, transport and residence times, and increases in phosphorous storage conspire to determine the magnitude of phosphorous retention or export downstream of beaver systems. Moreover, the export or retention of phosphorous may depend on the form measured, Devito and Dillon (1993) monitored the outflow of a beaver pond in Canada and found that $\mathrm{PO}_{4}{ }^{3-}$ was more likely to be retained, and organic phosphorous was more likely to be released. This may also explain the results found by Smith et al. (2020), in which $\mathrm{PO}_{4}{ }^{3-}$ concentrations diminished downstream of a beaver pond in Germany, but total phosphorous concentrations remained the same. The variability in $\mathrm{PO}_{4}{ }^{3-}$ responses downstream of beaver systems (Figure 16d) therefore presents some difficulty in terms of broader mechanistic interpretations, however some constraints are possible to outline. If $\mathrm{PO}_{4}{ }^{3-}$ decreases downstream, then it is likely that any increase in phosphorus storage occurred without sufficient exposure to anaerobic flow paths. Conversely, if $\mathrm{PO}_{4}{ }^{3-}$ increases downstream, then it is likely that increases in phosphorus storage were exposed to sufficient anaerobic flow paths, and that the conditions at the point of sampling did not yet diminish these increased concentrations via re-sorption or biomass uptake as aerobic conditions returned. There may also be a beaver dam age effect; in large 
review, Ecke et al. (2017) found on average beaver dams released phosphorus (albeit with considerable variation), but that this was mostly in younger beaver dams, with older dams more likely to retain phosphorus. In any case, the clear lack of dominance in either response, as well as the large frequency of 'no change' in downstream $\mathrm{PO}_{4}{ }^{3-}$ concentrations (Figure 16d) also suggests these competing mechanisms are likely to be of similar magnitudes in beaver impacted systems.

These mechanisms are important to consider because phosphorus is often considered to be the key limiting nutrient for primary production in freshwater ecosystems. However, under natural conditions (i.e. limited human impact), and depending on the stoichiometry of primary producers, nitrogen can sometimes be equally limiting. Thus, the degree of phosphorus or nitrogen limitation within beaver impacted systems, and therefore the overall impact on downstream water quality, will depend to some extent on the supply from upstream land use, as well as atmospheric deposition in the case of nitrogen. Given the high seasonal loadings of nitrogen in many areas of Europe and North America, it is reasonable to expect phosphorous also to be the limiting nutrient and thus its downstream availability may be determined to a large extent by beaver dam construction and whether these new conditions promote phosphorus retention or release.

\subsection{Impacts on iron cycling, mercury, and additional contaminants}

Aside from the cycling of the major nutrients, beaver impacts also have potential implications for other nutrients and contaminants, especially those that are redox sensitive given the expansion of anaerobic conditions that can occur. As already mentioned in the phosphorus cycle (section 5.4), Fe-oxides are particularly sensitive to changing redox conditions, and high concentrations of $\mathrm{Fe}^{3+}$, due to the reduction of $\mathrm{Fe}^{2+}$, have been found in the pore water of beaver impacted systems (Donahue and Liu 1997). This is a pathway for the liberation of sorbed phosphorus, and also for some metal contaminants such as arsenic. The cumulative effects of these expanded pathways are not well known in beaver systems, but it is nonetheless a mechanism to increase the concentration of $\mathrm{Fe}^{3+}$ and associated metals and nutrients in solution, which may then in turn be re-oxidised by a variety of abiotic and biological mechanisms if these pathways re-enter downstream anaerobic surface waters (Figure 15). Indeed, Briggs et al. (2019) found that beaver dam induced diversion of water across a floodplain resulted in subsequent return flow to the main channel that was variable in redox status and substantially enriched in iron, manganese, aluminium, and arsenic concentrations. Some combination of expanded anaerobic conditions and flow mixing may thus lead to the enhancement of $\mathrm{Fe}^{2+}$ concentrations downstream of beaver systems, which Cirmo and Driscoll (1993) found could be up to four times higher than inflowing concentrations. This suggests the ability of beaver systems to enhance downstream supply of iron and thus also any associated sorbed nutrients and contaminants warrants further research attention.

The enhancement of anaerobic conditions following beaver impacts also increases the opportunity for the methylation of mercury (MeHg), which is considerably more toxic than the natural or anthropogenically enhanced supply of $\mathrm{Hg}$ (in other inorganic or organic forms). The potential for beaver damming to facilitate increased MeHg concentrations and uptake in food webs has received some attention (e.g. Painter et al. 2015; Roy et al. 2009a; Roy et al. 2009b; Levanoni et al. 2015). In general, it appears MeHg concentrations increase downstream of beaver dams (Ecke et al. 2017), but this may decrease in magnitude with increasing dam age and colonization history (Roy et al. 2009a; Roy et al 2009b; Levanoni et al. 2015). The increase in MeHg concentrations is also expected to increase 
Hg availability and uptake in downstream ecosystems (Painter et al. 2015; Bergman and Bump 2014), although it is important to emphasize the data on this potential impact remains quite limited.

Given the array of hydrological and biogeochemical changes that beaver impacts may introduce to river systems, it is likely they will have a role to play in the cycling of additionally important and emerging contaminants, such as pesticides, pharmaceuticals, and microplastics, all of which remain to be examined. This is especially the case in river systems under the burden of industrial or urban pollution, and that also may have re-emergent beaver activity. The demonstrated capacity of beaver impacts to increase water, sediment, and nutrient storage within expanded anaerobic conditions is likely to influence the storage, residence time, and cycling of pesticides and pharmaceuticals with a wide variety of breakdown pathways (e.g. redox or photo oxidation sensitivity). Microplastics and other particulate urban or industrial pollution may also find a high storage and retention capacity within beaver dam complexes, and one that has the potential to be far more efficient than river reaches without beaver impacts.

\subsection{Impacts on source vs sink behavior, and the evolution of overall water quality and} its variability

Understanding the diversity of water quality impacts from beaver modifications requires some insights from the coupling between water transport and biogeochemical reactions, and how these are likely to change. However, a formal quantitative analysis is difficult given the need to derive full mass balances of both nutrients and water within beaver modified systems, which are unlikely to be in steady state at sub-annual scales (e.g.: water) or even at annual (e.g.: nitrogen) or decadal (e.g.: carbon and phosphorus) time scales. Nonetheless, it is an important issue to address since it can help explain the extent to which a river corridor will act as a source or sink, which can be far more dynamic following beaver impacts (Wegener et al. 2017), as well as how efficiently each source or sink may be operating. An insightful analysis in this regard was provided by Stanley and Ward (1997), who compared the net retention of different nitrogen components (total nitrogen, $\mathrm{NO}_{3}{ }^{-}, \mathrm{NH}_{4}{ }^{+}$) and water (discharge), as: $\left(\right.$ Flux $_{\text {in }}-$ Flux $\left._{\text {out }}\right) /$ Fluxin, where the nitrogen fluxes have the units $\mathrm{MT}^{-1}$ and water $\mathrm{L}^{3} \mathrm{~T}^{-1}$ (Figure 17). Consistent with the discussion in the preceding hydrology (section 3) and biogeochemistry (section 5) sections, there was net retention of water, $\mathrm{NO}_{3}{ }^{-}$and $\mathrm{NH}_{4}{ }^{+}$(i.e.: Fluxin $>$Flux out) for the majority of monthly sampling intervals, with only 2 winter months displaying net release (i.e.: Flux $_{\text {out }}>$ Flux $_{\text {in }}$ ). However, it is important to note that the correlation between net water and nutrient fluxes is partly spurious, since the same discharge values contribute to both axes, and is a common issue in water quality analysis. Nonetheless, variation about the 1:1 balance can be informative, since Flux in - Flux $_{\text {out }}$ is representative of the total change in storage of water or nutrients (named here $\Delta S_{Q}$ or $\Delta S_{N}$ respectively) at the time of sampling. Within this beaver modified system on the coastal plain of Alabama (USA), $\mathrm{NO}_{3}{ }^{-}$fluxes were almost always retained to a greater extent than water, while water fluxes were generally retained to a greater extent than $\mathrm{NH}_{4}{ }^{+}$fluxes, which had a much higher frequency of net release (Figure 17). This result is important because it emphasizes the first order control of water storage changes on the downstream water quality dynamics, which are likely critical to many other beaver impacted systems. In addition, it also demonstrates important second order effects, such as the far more efficient retention of $\mathrm{NO}_{3}{ }^{-}$fluxes compared to $\mathrm{NH}_{4}{ }^{+}$, even when both are operating overall as net sinks, due to their different reaction and production mechanisms (discussed in the nitrogen impacts section 5.3). These results are also similar to DeVito and Dillon (1993), who demonstrated the capacity of a beaver dam to retain nitrogen and phosphorus was controlled to the first order by the 
extent of water retention and runoff, with the added complexity of seasonal ice cover enhancing reducing conditions and therefore also the seasonal release of some fraction of $\mathrm{NH}_{4}{ }^{+}$and $\mathrm{PO}_{4}{ }^{3-}$. Higher frequency monitoring of discharge, carbon and nutrient fluxes is also important, and a recent study by Wegener et al. (2017) found net release of all these fluxes during high flows, and net retention during low flows in a beaver impacted river reach. In combination, these studies highlight the need for more studies accounting for the full mass balance of both water and nutrients, which involves higher frequency monitoring of changes in water and nutrients over a fixed reach or volume, and over identified flow paths, which can reveal far greater insights into the overall water quality dynamics beyond only characterizing system behavior as being either a net source or sink.

In terms of the temporal variability in biogeochemical dynamics, only c. $40 \%$ of studies examined in Figure 16 reported 'sub annual' dynamics (e.g. variation at seasonal, monthly, or event timescales). From these studies that do examine sub-annual dynamics, it is clear that many of the export fluxes display considerable seasonal variation (Cirmo and Driscoll 1993; Devito and Dillon; Smith et al., 2020; Stanley and Ward, 1997). However, it is unclear to what extent beaver systems themselves might influence these processes, since some seasonal and event trends in many water quality parameters would occur even without beaver impacts. For example, the degree to which variations in hydrology and carbon supply influence the expansion and contraction of anaerobic zones (Cirmo and Driscoll, 1993), as well as the sensitivity of nutrient storage and export regulation to seasonal temperature and biomass changes are particularly unclear. In addition, very few studies have examined the influence of event scale dynamics (Wegener et al. 2017 is an exception), but it is also likely that many of these export fluxes display considerable variation over individual hydrographs, just as they do in river systems without beavers. Again, this is an important knowledge gap in our understanding of reactive transport dynamics within beaver systems. It is important to note that biogeochemical functioning of beaver systems may also evolve with age of that system (Catalán et al., 2016; Naiman et al., 1986; Roy et al., 2009), particularly as the carbon, nitrogen and phosphorus storages mature, potentially diminishing their influence on outgoing fluxes over time.

Over the longer term (i.e.: > $1 \mathrm{yr}$ ), it is clear that increased storage of water and nutrients (per unit length) should also increase their residence times. However, this increase in residence time must be mediated to some extent by the observed increases in outflowing fluxes such as $\mathrm{DOC}, \mathrm{N}_{2}, \mathrm{CO}_{2}, \mathrm{CH}_{4}$, $\mathrm{NH}_{4}$, and in some cases $\mathrm{PO}_{4}{ }^{3-}$ (Figure 15 ). There is also likely to be large variability in the relative magnitude of residence times between these components, e.g.: carbon > phosphorus $>$ nitrogen $>$ water. Indeed, Naiman et al. (1988) estimated an order of magnitude increase in pond sediment carbon residence times as the storage increased. This may be especially important when considering the long-term resilience of beaver modified systems to climate and anthropogenic change, as well as how beavers can be used in river management, since water and nitrogen fluxes will likely be more sensitive to short term fluctuations than phosphorus and carbon, however these suggestions remain purely speculative. The long-term carbon feedbacks are discussed further in section 7.2. In natural wetland and lake systems, residence times, and therefore biogeochemical functioning, is linked to the degree of hydraulic connectivity between inflowing and outflowing water fluxes (Cohen et al., 2016). Although longitudinal (downstream) hydrological and biogeochemical connectivity is reduced in the short term by beaver dams (and thus increasing residence times), over seasonal and annual time scales the vast majority of water flow must still pass through and interact with the beaver impacted river reach. In contrast, many other wetland and lake systems in river networks usually interact with a much smaller fraction of total flows (Cohen et al., 2016). This is important when considering the potential 
for wetland, lake, or beaver modified systems to influence the evolution of downstream water quality and attenuate water quality problems such as high nitrate concentrations, since the overall effectiveness may be higher within beaver modified systems as they can provide increased water residence times whilst still interacting with the majority of water flow in the system.
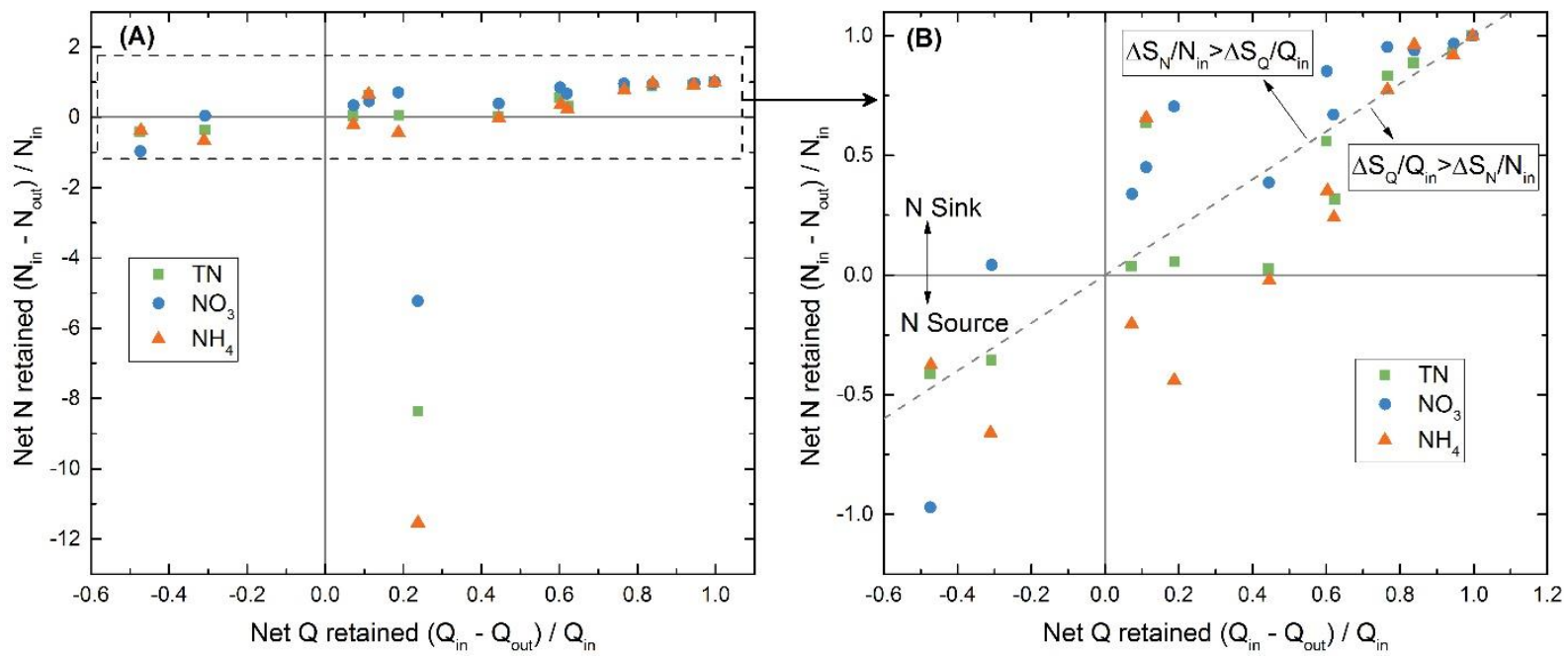

Figure 17: Net retained (flux in - flux out/ flux in) $N[M / T]$ and $Q[L / T]$ for a beaver pond and wetland in southern Alabama (Talladega wetland)

\section{Beaver impacts on aquatic and riparian ecosystems}

The clear capacity for beaver modifications to impact reach scale hydrology, geomorphology, and the biogeochemistry of nutrient cycling in combination have important feedbacks with, and consequences for, aquatic and riparian ecosystems. These can result in landscape scale changes to both aquatic and terrestrial ecosystem dynamics, function, and assemblage diversity.

\subsection{Creating a mix of lotic and lentic environments, disruptions to the river continuum,} and changes to aquatic ecosystem productivity

A general framework for the functioning and downstream evolution of aquatic and riparian ecosystems as they adapt to changing hydrologic and geomorphic conditions is provided by the river continuum concept (RCC) and its various derivatives (Junk et al., 1989; Thorp and Delong, 1994; Vannote et al., 1980; Ward and Stanford, 1995). Broadly, the RCC states that lower order streams are dominantly heterotrophic, receive most of their organic matter as inputs from the terrestrial ecosystem, and have macroinvertebrate community compositions adapted to break down and filter these inputs. As stream order and size increases downstream, light availability increases which means more organic matter can be provided through aquatic primary production, and macroinvertebrate communities diversify to filter material from both benthic and water column environments. The RCC also places an emphasis on nutrient cycling and ecosystem stability, with the extent of biological activity and disturbance in low order streams having an influence on the net retention or export of nutrients to downstream and higher stream order ecosystems.

Reach-scale beaver modifications to the physical process templates upon which ecosystems adapt and function therefore disrupt this traditional RCC framework, especially in low order stream habitats, with important consequences for our conceptualization of river ecosystem processes. The primary reason 
beaver modifications pose such a disruption to the RCC is because of the increasing extent of ponded surface water behind individual dams, and collectively within beaver dam complexes, which constitute an abrupt reach-scale shift from almost exclusively lotic (flowing water) to a complex mix of lentic (still water) and lotic conditions and transitions between them (Naiman et al. 1998). This variation between lotic and lentic ecosystems has been covered in conceptual models that include anthropogenic dams in regulated river systems (e.g.: the serial discontinuity concept of Ward and Stanford (1995)), however the scale and number of lentic-lotic transitions are likely very different between beaver ponds and human engineered reservoirs. Thus, building on these concepts, as well as the patch dynamic concept in fluvial ecology (Poole 2002), Burchstead et al. (2010) presented an elegant ecological framework that acknowledges beavers as the consummate disrupter of fluvial continuums. This discontinuous river ecosystem paradigm acknowledges the patchiness of lotic-lentic transitions provided by beaver damming over reach scales, and the temporal evolution of such a system towards more open river corridors comprised of wetland and meadow habitat rather than tall riparian forest (Burchstead et al. 2010). Within a single low stream order river reach, these discontinuous lentic-lotic transitions can create considerable diversity in hydro-geomorphic conditions serving as ecosystem habitat that would not be present without beaver impacts (Gibson and Olden, 2014; Hossack et al., 2015; Johnston and Naiman, 1990; Law et al., 2016; Margolis et al., 2001; Naiman et al., 1988; Snodgrass, 1997). Specifically, beavers facilitate a mix of finer sediment and particulate organic matter benthic habitat in deeper water lentic environments (e.g. beaver pond and backwater channels), a replacement of lotic 'riparian' zones with lentic 'littoral' zones, which are shallow water vegetated environments (e.g. beaver meadow and wetlands), and coarser sediment and particulate in shallow water lotic environments (e.g. immediately downstream of beaver dams) (Figure 13). In addition, a rather unique feature of beaver impacts is the very large increase in large woody debris within aquatic habitats, especially within dams themselves but also elsewhere in the channel and floodplain system, all submerged to varying degrees under flow variations (Benke and Wallace, 2003; Levine and Meyer, 2019; Kreutzweiser et al., 2005; Naiman et al., 1986; Thompson et al., 2016).

The creation of new lentic environments due to beaver damming is also a function of decreased longitudinal and increased lateral hydrologic connectivity (Burchsted et al., 2010; Polvi and Wohl, 2012; Wohl and Beckman, 2014), including a rise in the shallow groundwater table. This expands benthic habitat in ponds and backwater channels, and littoral habitat in riparian areas and floodplain wetlands (Polvi and Wohl, 2012; Stocker, 1985; Westbrook et al., 2006) due to the promotion of emergent macrophyte communities and grasslands at the expense, to varying extents, of riparian woody vegetation and its canopy shading. This increase in slower flowing lentic and littoral habitats with higher light availability should, in general, promote higher ecosystem productivity. From the perspective of beaver ponds, benthic and planktonic biomass (Coleman and Dahm, 1990; SongsterAlpin and Klotz, 1995; Mann and Wetzel, 2000) and primary production has been found to increase, with the latter measured either as increased chlorophyll-a concentrations (Ecke et al. 2017), or as a component of a full NEP aq budget (Hodkinson, 1975; Naiman et al., 1986; Stanley et al., 2003), albeit with strong seasonal variations (Wegener et al., 2017). However, this pond productivity increase is relatively small (e.g.: $4-12 \%$ of $\mathrm{NEP}_{\mathrm{aq}}$ ) compared to the increase in other organic matter inputs they receive, meaning the ponds are largely heterotrophic (Hodkinson, 1975; Naiman et al., 1986; Stanley et al., 2003). Nonetheless, if we consider a more integrated view of beaver influenced ecosystem productivity including the beaver pond, littoral zone and wetland habitats, then there is likely to be a mix of autotrophic and heterotrophic ecosystem components, with increased productivity from beaver 
created wetlands and littoral zones contributing substantial new biomass, and through its breakdown an increased supply of coarse and fine particulate organic matter to the heterotrophic ponds and ecosystems downstream (Hodkinson, 1975; Naiman et al., 1986). It is this integrated mix of heterotrophic and autotrophic components in addition to the lentic and lotic transitions that makes beaver influenced ecosystems such a departure from the traditional RCC concept. This highlights the profound role of wetland vegetation and the littoral zone biomass production can have on NEP aq once lentic conditions are introduced, and by extension probably helps explain the widespread increase in net DOC export from beaver impacted systems (Figures 15, 16). This is also consistent with findings from other wetland and small lake ecosystems where productive littoral zones can be maintained (Wetzel 2001).

\subsection{Beaver impacts on ecosystem biodiversity and functioning: Macro-Invertebrates}

Macro-Invertebrates serve as a key component in aquatic food webs. They are an important food source for fauna higher in the trophic chain and are themselves consumers of organic detritus and biomass in river systems. Their number and diversity in streams are often taken as a signal for the quality of the aquatic ecosystem, because macro-invertebrates are sensitive to changes in sediment, organic matter accumulation and water velocity, all of which are influenced by beaver damming (Law et al., 2016). The new habitat created by beavers allows greater habitat diversity and availability, which has been shown to increase overall reach-scale diversity of macro-invertebrate communities increases (Law et al., 2016; Margolis et al., 2001) (Figure 18). However, in a large meta -analysis, Ecke et al. (2017) found overall net decreases occurred in diversity and / or abundance of macroinvertebrates from upstream to downstream of beaver dams. There may be a difference in the way biodiversity differences are estimated in this case, e.g. upstream vs downstream or at the overall reach scale, nonetheless the emerging downstream changes across all studies warrants further process investigation.

The creation of lentic habitats can generate a larger abundance of particulate organic matter, plant tissue and nutrients within the ponded section, which increases the numbers of shredders and gatherer/collectors, which can otherwise usually only be found in low percentages within lotic reaches (Law et al., 2016). Although the new lentic habitats created by beavers may have more restricted assemblages compared to the lotic habitats, it is the capacity of beavers to facilitate and maintain a mosaic of both habitats and the transitions between them that allows reach scale assemblage diversity to increase (Robinson et al., 2020). However, the influence of beaver ponds on benthic macroinvertebrates can be highly seasonal, which needs to be considered in studies targeting these differences (Margolis et al., 2001). The larger diversity found in beaver influenced reaches may also be influenced by the increase in woody debris, with submerged wood adding considerable habitat diversity for macro-invertebrates in streams, which is known to increase macroinvertebrate numbers and species diversity (Benke and Wallace, 2003). Submerged large woody debris also creates pools on the channel bed, providing additional habitat for many invertebrate species (Benke and Wallace, 2003) as well as the wood dam structures themselves becoming a potential hotspot for macroinvertebtrate habitat (Rolauffs et al., 2001). Hence, it is likely that beavers can increase not only the diversity of invertebrate species in the habituated stream section, but also potentially throughout entire stream reaches through the pervasive increase in large woody debris increasing the abundance of macroinvertebrate taxa specialised in wood herbivory. However, these larger spatial scale effects of 
increased large woody debris on macro-invertebrate assemblages depend strongly on the local hydrogeomorphologic conditions and requires further study in order better understand the influence of beaver impacts on macro-invertebrates in the aquatic food chain across a gradient of stream order sizes. Drift dispersal is also a critical component of many macro-invertebrate life cycles, and it can be expected that beaver dam construction might delay or filter this dispersal to some extent. However, in a comparative study Redin and Sjöberg (2013) surprisingly found no impact on drift density downstream of beaver dams. This may suggest beaver dam filtering of drift dispersal is not likely to be significant, although lags may still exist. Given this is a single study, further work is clearly also needed to understand drift dispersal responses across beaver impacted reaches in a wider variety of landscape contexts.

\subsection{Beaver impacts on ecosystem biodiversity and functioning: Fish}

The potential impacts (positive or negative) of beaver dams on fish populations can be separated into migration, habitat, growth, population dynamics and diversity, and thermal regulation. It should not be controversial to state the following based on the process feedbacks already discussed in this review: 1) constructing a beaver dam will restrict (but not necessarily stop) fish mobility, just as it does the transport of water and sediment, relative to the same river with no dam, 2) habitat diversity will increase, especially lentic habitat but also potentially in lotic zones through the general increase in large woody debris availability, and 3) river shading has the potential to decrease, and therefore locally increase water temperatures (see section 3.8), with flow regulation from dams potentially also stabilizing downstream temperatures. If these statements are largely without controversy, the fishy question therefore becomes, are these changes likely to have noticeable positive or negative impacts on fish populations?

In terms of mobility impacts, there is an important dependence on the migratory needs of the species being considered, and thus whether the species is potamodromous (i.e. freshwater only), e.g. pike, or diadromous (i.e. migrating between salt and freshwater), e.g. salmonids. In addition, the timing and developmental stage during migration is critical, and especially whether higher mobility periods tend to occur during high or low flow regimes and whether they embark as juveniles or adults. As a result of these caveats, there is enormous variance in the research findings concerning fish mobility impacts. The cases with the largest negative impact on mobility have been found for juveniles migrating downstream (Mitchell and Cunjak, 2007; Schlosser, 1995; Virbickas et al., 2015), or on adult mobility during low flow periods (Bylak et al., 2014; Collen and Gibson, 2000; Cunjak and Therrien, 1998; Mitchell and Cunjak, 2007; Schlosser, 1995; Taylor et al., 2010). In one study over 4 summers, large fractions of total upstream and downstream fish movement over dams occurred over only a 1-2 day period that had slightly elevated streamflow, though not all days with elevated streamflow had increased mobility (Schlosser, 1995). In some cases, the restricted mobility may even be seen as an ecological benefit, for example (Mitchell and Cunjak, 2007) found that beaver dams on coastal rivers prevented upstream migration of salmon, which through competitive exclusion increased fish species diversity upstream. These are however, far from ubiquitous results for all fish, with considerable variation between taxa (Schlosser, 1995), and many studies finding limited or negligible mobility impacts of beaver dams, across a range of flow conditions (Bouwes et al., 2016; Ecke et al., 2017; Lokteff et al., 2013; Malison and Halley, 2020), with the caveat that the presence of lateral flow pathways around dam structures may be important in mitigating dam impacts in some of these cases (Cutting et al., 2018). However, it is important to note that relatively few beaver impact studies have 
used fish tracking or tagging, and many instead rely on downstream vs upstream, or beaver site vs control site abundance, which is a far less reliable measure of actual mobility, and may in fact overestimate the mobility impacts of dams (Johnson-Bice et al., 2018). Thus, given this wide range of uncertainty, it is probably most apt to consider beaver dams as 'semi-permeable' barriers to fish movement (Schlosser, 1995).

In terms of habitat and fish assemblage diversity, most studies agree that as beavers promote greater habitat complexity, fish assemblage diversity also increases (Bouwes et al., 2016; Collen and Gibson, 2000; Hägglund and Sjöberg, 1999; Kemp et al., 2012; Mitchell and Cunjak, 2007; Pollock et al., 2003; Smith and Mather, 2013). This makes sense when the whole river reach is considered, and over a sufficiently long-time scale such that a generational succession of beaver dams exists in varying states of maintenance and intactness, creating a rich variety in lentic and lotic habitat transitions. In this context, Schlosser and Kallemeyn (2000) found relatively 'closed' beaver dam pond habitats had the largest number of fish but lowest diversity, while stream reaches with relatively 'open' collapsed and breached dam structures had the greatest fish species diversity. This led Schlosser and Kallemeyn (2000) to suggest the relatively closed lentic habitat acted as 'sources' for fish populations, and the relatively open lotic habitats as 'sinks'. In an interesting study from Oregon, a single beaver pond accounted for only $\sim 2.5 \%$ of the river area but produced $\sim 50 \%$ of the juvenile salmon in the river (Müller-Schwarze, 2011). The importance of succession in beaver dam habitat was also emphasized by Snodgrass and Meffe (1998), who also found species richness was highest in 'middle age' (9-17 yrs) abandoned dams and ponds, with species richness lower in both younger active dams, and older (>17 yrs old) abandoned dams. Moreover, this result was only for headwater streams, with lowland sites exhibiting little difference in species richness with pond age. At more local scales, there is some concern that the coarse bed sediment habitat required for salmonids may be reduced by finer sediment deposition induced by beaver damming (see section 4), since if this is too extensive, it can result in some salmonid species being outcompeted by others (Müller-Schwarze, 2011). However, the finer sediment ponds may be advantageous for other fish species, for example in Sweden these finer beaver pond sediments have been found to be preferred habitat for minnow spawning (Hägglund and Sjöberg, 1999). Over time, beaver ponds may also select for species more tolerant of oxygen stress (Schlosser and Kallemeyn, 2000) given the tendency of ponds to have diminished dissolved oxygen, especially at depth (see section 5). Finally, beaver dam impacted rivers can also provide critical habitat refugia for fish during drought and summer low flow periods (Hägglund and Sjöberg, 1999; Hanson and Campbell, 1963; Leidholt-Bruner et al., 1992), and in regions with seasonal ice cover (Brown et al., 2011; Nickelson et al., 1992).

When fish size and beaver impacts are examined, a fairly ubiquitous result emerges that the largest fish tend to be found in beaver ponds (Bylak et al., 2014; Hägglund and Sjöberg, 1999; Kukuła and Bylak, 2010). Beaver ponds also seem to be a net positive in terms of growth rates, particularly for salmonid juveniles (Sigourney et al., 2006). These increased sizes and growth rates are likely possible through a combination of reduced energy expenditure by the fish and greater food availability (e.g. macroinvertebrates) due to the higher overall ecosystem productivity (Pollock et al., 2003), and also perhaps due to the reduced mobility imposed by dams. However, some surveys also report no impact on growth rates (Malison and Halley, 2020).

It is evident that water temperatures can rise both in beaver ponds and downstream, but this is far from ubiquitous and contains many nuanced dynamics (see section 3.8). The questions regarding 
water temperature and fish impacts are therefore 1) whether any temperature increase reaches the thermal tolerance thresholds for the species of interest, and 2) whether sufficient thermal refugia exist or are created through habitat modification that can mitigate against any stream sections that may now reach these thermal thresholds. Of particular concern here are cold water fish species, especially salmonids, which is particularly sensitive given their economic importance in many regions to fisheries and recreation. It is also likely that many cold-water species may already have a spatial range reflective of their thermal stress limits, and thus any temperature increase due to beaver impacts may at the very least lead to a constriction in the spatial distribution of these species. It is therefore not surprising that many studies do find a negative link between beaver impacts on increased water temperatures, and cold-water fish abundance (Johnson-Bice et al., 2018; Kemp et al., 2012). There is also an important spatial dimension, with the steeper gradient streams tending to be colder and having less thermal impact from damming, while lower gradient streams that are already warmer having the most impact (Johnson-Bice et al., 2018).

It is important to note that beavers and fish were presumably able to co-exist across a wide range of conditions prior to the large-scale declines in beaver populations across Europe and North America. However, modern river corridors cannot easily return to these conditions, with considerable human regulation of the landscape, and population dynamics of both beavers and fish that may be interacting outside their previous ranges, together means that the past may not be a terribly good guide to evaluating current impacts and potential management strategies. Modern stream habitats and their management ideals are also in many cases likely quite different from those during the beaver - fish co-existence of the distant past, meaning their re-unification may not easily revert to the desired harmonious balance of old. Many fish species of concern may also not be native, further complicating this dynamic. On the other hand, it may be the case that many of the documented impacts (positive or negative) on fish are too short term in focus. Provided sufficient time and space is available, as a river corridor begins to experience beaver dam and habitat succession, intact individual dams may collapse or promote channel avulsion, and the relatively closed habitat of intact single dams can become a mosaic of lentic and lotic habitats with sufficient migratory passages and thermal refugia. However, in many current river corridors, the luxury of the necessary time and space to achieve this successional mosaic may not be available.

In practice, effective management of beaver impacts for the potential benefits for fish such as increased growth rates, and assemblage and habitat diversity, against the potential negatives such as temperature and mobility, may be difficult, especially as the balance between overall net positive or negative can shift over time (Johnson-Bice et al., 2018). Moreover, given the wide range in published outcomes, we cannot reasonably expect any one study on fish impacts to be definitive, thus we should similarly not rely on results from single studies to guide management policy. Effective management of beaver impacts on fish may simply come down to careful consideration of individual dam and site characteristics such as dam geometry, flow pathways and plunge pool depth on the one hand, and the characteristics of the fish species being considered on the other, such as migration timing, preferred habitat, behavior, and energetics and metabolism. Since it is impossible to know the individual dam characteristics until after they have been constructed, it is important to emphasise the benefits of flexibility in these fish management practices, including beaver dam removal and relocation options. 


\subsection{Beaver impacts on ecosystem biodiversity and functioning: Other fauna}

Although a comprehensive examination is beyond the scope of this review, it is worth noting that dam construction by beavers can have a range of impacts across many other fauna (Rosell et al., 2005). These are too numerous to list here, however some notable examples include the benefits to waterbirds, reptiles, amphibians and dragonflies benefit in terms of both abundance and diversity from the creation of new beaver pond and beaver meadow habitats (Dalbeck et al., 2014; Dalbeck et al., 2007; Hossack et al., 2015; Nummi, 1989; Nummi and Holopainen, 2014) (Figure 18). Dragonfly species have been shown to be $89 \%$ higher when compared to reaches not dammed by beavers (Schloemer, 2014). In central Europe, amphibian species were observed to increase by 85 to $100 \%$ in beaver ponds compared to lotic reaches (Dalbeck et al., 2014; Dalbeck et al., 2007). In North America, beaver pond construction attracted much higher colonization rates of some, but not all, endangered amphibians (Hossack et al., 2015). The common frog (Rana temporaria) is known to benefit from the development of shallow beaver ponds, which creates large breeding areas (shallow ponds) during times of reproduction (Dalbeck et al., 2014). Waterbird diversity and density is also much higher in beaver created wetlands (Grover and Baldassarre, 1995). These results indicate a close association between beaver impacts and many wetland-dependent species and hence their potential to facilitate the recovery of many of these fauna and flora, of which many of these species are critically endangered (Hossack et al., 2015), and are further threatened by land use changes and climate change (McMenamin et al., 2008).

\subsection{Beaver impacts on ecosystem biodiversity and functioning: Vegetation}

In the terrestrial realm of river corridors, beavers impact vegetation in two main ways: 1 ) through the increase in water inundation and rise in groundwater levels as a result of dam building, and 2) through consumption as a generalist herbivore, browsing and felling trees, herbaceous forbs, grasses, sedges, and aquatic plants (submerged and emergent). However, it is unclear if beavers with multiple habitate selection options prefer already forested sites. In a study across 51 dam locations in southeastern Germany, $60 \%$ were constructed in areas of uniform riparian forest and only $2 \%$ in areas with no riparian forest (Neumayer et al., 2020), in Lithuania they preferred forested drainage canals (Ulevičius et al., 2011), however deciduous tree abundance was only of marginal importance in site selection in Sweden (Hartman, 1996). In terms of initial impacts, when permanently inundated, most deciduous canopy trees will die within a year, and smaller sub-canopy species even earlier (Härkönen, 1999; Müller-Schwarze, 2011), but given more variable surface inundation or a slowly rising groundwater table from below, trees at the margins or at slightly higher elevations may die a slower death or even survive, albeit potentially under sub-optimal growing conditions and thus with stunted growth (Härkönen, 1999; Reddoch and Reddoch, 2005). Using tree ring analysis, Bocking et al. (2017) found that evergreen spruce trees below a critical inundation elevation all died in the same year as the beaver dam construction, but trees $2-30 \mathrm{~cm}$ above this elevation resisted death for another $5-16$ years. Thus, depending on variations in local topographic conditions of the river corridor and the extent of dam building activity, forest dieback can be extensive (Bhat et al., 1993; Burchsted et al., 2010; Johnston and Naiman, 1990a; Martell et al., 2006; Nummi and Kuuluvainen, 2013) (Figure 19), but with some capacity for both deciduous and evergreen tree survival at the margins.

Trees within river corridors that survive or surround inundated areas are not breathing a sigh of relief, as they are also subject to browsing, girdling and felling by beavers. There are a large number of studies documenting tree preference on the basis of species, size, and foraging distance (Haarberg and Rosell, 
2006; Jenkins, 1980; Martell et al., 2006). However, there is no clear definitive list of these preferences, given that studies vary considerably in species and size availability, as well as in the timescale of beaver impact on the riparian vegetation being studied. It is generally accepted however, that all these preferences are constrained by 1) optimal foraging theory, in which the beaver seeks to maximize net energy intake during foraging from a central location per unit time (Belovsky, 1984; Fryxell and Doucet, 1993; Jenkins, 1980; McGinley and Whitham, 1985), and 2) by the need to overcome plant chemical defenses (secondary metabolites) through generalist herbivore foraging strategies (Basey et al., 1988; Basey et al., 1990). The impact of these constraints can be seen across many studies that find e.g. browsing intensity (Haarberg and Rosell, 2006; Jenkins, 1980; Martell et al., 2006; McGinley and Whitham, 1985), as well as tree size and species preferences (Basey and Jenkins, 1995; Fryxell and Doucet, 1993; Haarberg and Rosell, 2006; Jenkins, 1980; Raffel et al., 2009) of beavers clearly shifting with increasing distance from water. Consistent with optimal foraging theory, this is likely because the foraging time costs increase with distance from a central water location compared to the energy gained (Belovsky, 1984), and also because tree species and their size vary considerably in terms of energy availability and secondary metabolites (Basey et al., 1988). However, the choices available to beavers are not everywhere the same, thus beavers cannot always be religious in tree selection and local species availability will be a strong constraint on preference. Nonetheless, it is possible to infer the broad upper and lower bounds of woody species preferences, with willow (genus Salix), aspen (or poplar, or cottonwood - genus Populus) and birch (genus Betula) species clearly preferred when available, mixed results for alder (genus Alnus), oak (genus Quercus) is less preferred, and there is a clear avoidance of conifer species, though even these will be consumed under duress (Dvořák, 2013; Janiszewski et al., 2017; Jenkins, 1975; Müller-Schwarze, 2011). Many other tree species are browsed to varying extents within these preference ranges as part of the generalist herbivore strategy, subject to the caveats already mentioned above. There is also a considerable seasonal cycle to woody vegetation consumption, which dominates beaver diets over winter (Svendsen, 1980) and especially in ice covered regions within submerged food cache's that are progressively compiled underwater in ponds for overwintering (Hartman and Axelsson, 2004). Apart from dietary intake, it has been noted that less palatable species will often be felled for use in dam construction (Pinkowski, 1983). However, this is not likely to be a consistent result, since beavers are only targeting the inner bark, leaves, and twigs of woody plants for consumption, thus depending on the tree sizes available there can be a considerable volume of wood left over from many species across the palatability spectrum for use in dam construction.

The combined impact on riparian trees is therefore likely a local decrease in diversity (Nolet et al., 1994), that may also come to be dominated by quickly regenerating tree species able to grow as shrubs, as well as those that are less palatable to beavers (Barnes and Mallik, 2001; Naiman et al., 1988; Pastor et al., 1988). Importantly, this also results in a distinct shift in both the age and size demographics of the riparian forest towards younger and smaller trees, albeit with a strong dependence on distance from water. This substantial impact on riparian forest cover is in flagrant disregard of many current forestry and conservation management practices (Martell et al., 2006), though it is unclear whether any fines or other penalties have been issued. Thus, if retaining forested riparian areas in combination with beaver occupation is a desired management outcome, as it may be in many areas of the world, managers would be wise to consider a composition dominated by species less palatable to the beaver, or even potentially using the leaves of less palatable species as protection (Basey, 1999). 
Although tree species diversity may decrease locally, this is usually not the case at the landscape scale if forested areas away from the riparian and inundation zones remain. Indeed, beaver impacts are generally considered to increase overall vegetation species richness at the landscape scale by creating a new mosaic of terrestrial and aquatic vegetation habitats (Wright et al. 2002; Bartel et al. 2010; Naiman et al. 1988; Johnstone and Naiman 1990). This is achieved through a combination of: 1) increased light availability through canopy reduction (Barnes and Dibble, 1988)), 2) increase soil moisture and nutrient status (Naiman et al., 1994), and 3) a large increase in open water area (see section 3). The net effect of 1 ) and 2) is to favour early successional shrub species such as willows, herbaceous forbs, sedges and grasses, all generally with faster regrowth and lower shade tolerance (Pastor and Naiman, 1992; Rosell et al. 2005). In terms of 3), this creates a large increase in lotic, littoral, and wetland habitat for a rich variety of aquatic vegetation and macrophytes (Law et al., 2016; Pollock et al., 1995; Ray et al., 2001), which along with grasses and forbs, can dominate the summer season diet of beavers as NEPaq reaches its peak (Bergman and Bump, 2015; Parker et al., 2007; Severud, 2013; Svendsen, 1980). Importantly, much of this new vegetation assemblage would not have been present in the river corridor prior to beaver impact, and if already present in the understory, certainly not at the new levels of abundance following the opening up of the riparian forest canopy (Wright et al., 2002). This transformation in aquatic and terrestrial vegetation assemblages is sometimes regarded as 'reverse' succession, since as an agent of active disturbance, beavers can facilitate a return to early successional species dominance across these new habitat mosaics (Barnes and Dibble 2011; Rosell et al. 2005; Kivinen et al., 2020; Nummi and Kuuluvainen 2013; Remillard et al., 1987). This is also a shift towards wetter riparian habitats which may provide important benefits such as buffering against climatic variation in drier climates or landscapes with rapidly draining soils (Silverston et al. 2018; Gibson and Olden 2014). On the negative side, as a disturbance agent beavers may also facilitate invasive riparian vegetation expansion (Lesica and Miles, 2004; Mortenson et al., 2008), but conversely may heavily consume and thus help reduce invasive aquatic plant abundance (Parker et al. 2007).

In any case, the longer-term impact and stability of these successional changes in river corridors fundamentally depend on the frequency and length of disturbance that beavers can impose. Beavers may occupy sites with one or multiple ponds along a river reach over multiple generations for $\sim 1-20$ years (Johnson and Naiman 1990; Logofet et al. 2016; Nummi and Kuuluvainen 2013), although longer occupancy has been recorded (Butler and Malanson 2005). As the occupancy time period increases, individual dams and ponds undergo succession to grow the extent of old and new ponds, wetlands, and meadow sites dominated by herbaceous and shrub vegetation, each with its own stages of succession (Hay, 2010; Kivinen et al., 2020; Martell et al., 2006; McMaster and McMaster, 2001). Sites can become abandoned as herbivory becomes restricted (Baker et al. 2005; Rosell et al. 2005) which generally occurs through 1 ) the increasing coverage of less palatable species, and 2) the overexploitation of remaining food resources. Higher concentrations of secondary metabolites are generally found in longer lived and slower growing vegetation (Basey et al., 1990), thus quick growing pioneer species in beaver meadows tend to invest more in biomass production than chemical defenses during regrowth (Veraart et al., 2006), but they may also be flexible in their chemical defense investments in juvenile sprouts in response to beaver cutting (Basey et al. 1990). This likely create a complicated mix of poorly understood negative and positive feedbacks that may allow some vegetation species to maintain a dynamic equilibrium with beavers (Pollock et al. 1995), and others to decline, all of which remains poorly understood. However, it is important to note there is a strong bias 
towards higher latitudes in terms of our understanding of herbivory restriction and resource depletion, and many more studies from lower latitudes as beaver ranges expand are needed.

The net result of reduced herbivory is to force beaver migration or population decline, which in principle allows later successional species to return to the meadow, with the nature of this succession depending primarily on the ongoing flooding frequency and water retention capacity of the site (McMaster and McMaster 2001; Kivinen et al., 2020; Nummi and Kuuluvainen 2013; Johnstone and Naiman 1990), and whether or not beavers come back to re-occupy the site at some stage during meadow succession (Logofet et al., 2016). In sites with very limited (e.g. $1-3$ yrs) occupancy, forest succession may begin in only $2-3$ years following abandonment (Hyvönen and Nummi, 2008). On the other hand, longer-term occupancy (e.g. 10-20 years) generally translates to prolonged herbaceous and shrub dominated meadow persistence that can be much longer than the original beaver occupancy, e.g. in the order of $10-60$ yrs (Johnson and Naiman 1990; Logofet et al. 2016; Rudemann and Schoonmaker, 1938; Terwilliger and Pastor, 1999; Pastor et al. 1991). The long persistence of meadows and delay in forest succession following beaver abandonment has been partly attributed to the 1) occasional short bursts of beaver re-occupancy and disturbance (Hay, 2010; McMaster and McMaster, 2001), 2) flood frequency impacts on seed germination (Sturtevant, 1998), 3) reduction in easily decomposable litter due to browsing, especially in boreal forests (Pastor and Naimann 1992) and 4 ) in terms of conifer succession, potentially by a the lack of ectomycorrhizal fungi in beaver meadow soils (Terwilliger and Pastor, 1999). The eventual forest succession that does occur may not necessarily resemble the riparian forest prior to beaver occupation, as higher moisture retention in meadows may result in 'wet' or 'moist' forest types (Logofet et al. 2016) or alternatively in the development of fen and peatlands (Johnstone and Naiman 1990; Nummi and Kuuluvainen 2013). Yet another alternative is determined through competition with other herbivores, particularly elk and other undulates that may come to graze on meadows naturally or through human land use. In this case, willows as a critical food resource are more rapidly overgrazed by the undulates which browse fresh regrowth shoots (Baker et al. 2005), as opposed to beavers which generally allow longer stem growth and germination of willows prior to cutting (Baker et al. 2005; Jones et al., 2009), and in this case meadows may progress instead to drier elk grasslands (Baker et al. 2012). Many of these scenarios for beaver driven succession of river corridors have come to be referred to as 'alternate stable states' and are considered in more detail in section 8. It is clear however, that the profound vegetation transitions induced by beaver impacts in river corridors, especially the initial reverse and then delayed forward succession of meadows, are yet to be incorporated in traditional models of riparian succession and are increasingly important to consider in light of continued expansion of beaver populations. 


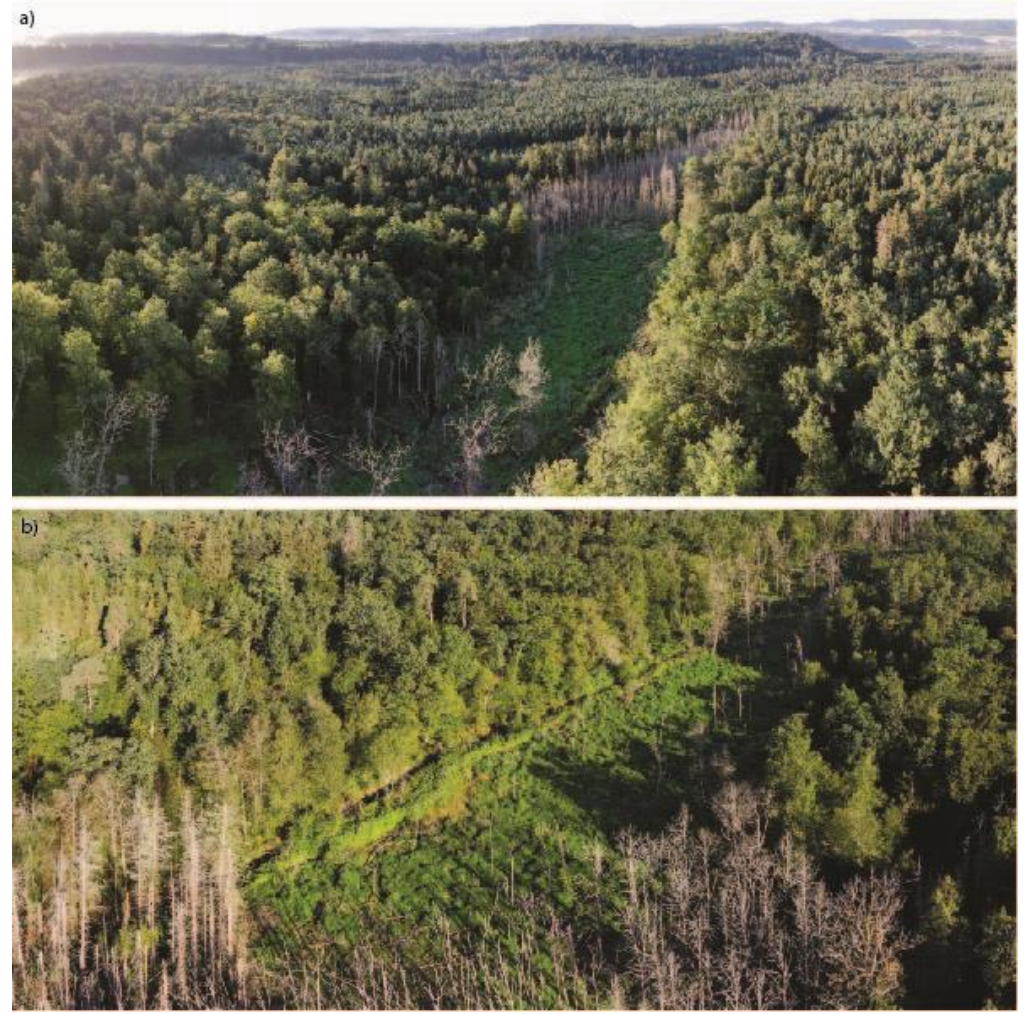

Figure 19_River corridor tree mortality due to beaver induced flooding (Marthalen, Switzerland)

\section{Interconnections} geomorphology

\section{biogeochemistry} and impacted streams

This is the first of three sections that discuss the emergent issues synthesized from the findings of this review. Thus far, this review has summarized the key changes and processes dynamics stemming from the impact of beaver damming of river corridors on hydrology, geomorphology, biogeochemistry, and ecosystems (table 1). Whilst many important connections between these fields have already been described, it is useful to examine how all these impacts are connected in a more comprehensive way.

\subsection{Initial and shorter-term impacts: the importance of floodplain inundation and} disturbance

Disturbance by beaver activity has a cascading series of consequences for river corridors that begins with their primary impacts, namely the damming of river channels, digging riverbank and floodplain burrows and channels, and actively gnawing woody vegetation on riparian and floodplain areas (yellow circles Figure 20). Tree felling provides material for dam construction, and dam construction can result in profound increases to water storage and hydrology (blue circles), sediment storage and river corridor geomorphology (brown circles), nutrient cycling and storage (red circles), and terrestrial (light green circles) and aquatic ecosystems (aqua circles). Our perceptual model of the links between all these feedbacks is not intended to be definitive, but it does highlight that floodplain inundation emerges as a central initial driver of many subsequent feedback connections (Figure 20). 
Floodplain inundation is a hydrological feedback caused by backwater ponding behind dams that reaches above the level of the adjacent floodplain, which can also extend downstream of the dam as shallow overland flow or as new wetlands. Thus, in terms of hydrology, beaver damming decreases longitudinal hydrological connectivity, but can increase lateral and vertical (e.g. hyporheic) connectivity. The scale of these feedbacks depends on the capacity of river systems to convert the rise in surface water behind dams to an increase in the areal extent of water. This geomorphic context dependency is discussed in greater detail in sections 4 and 10. The extent of floodplain inundation is important because it can: (1) increase aquatic habitat area and diversity, which in turn expands the interface between terrestrial and aquatic trophic chains and increases net aquatic ecosystem productivity (section 6, Figure 18), (2) increase surface and groundwater water storages, and may in some cases be linked to increased flood retention capacity and to locally enhanced baseflow (see section 3, Figures 4, 6, 8). In terms of biogeochemical processes, floodplain inundation allows (3) an expansion of anaerobic conditions, via diminished oxygen transport and increased organic matter storage and production. This allows a larger diversity of biogeochemical pathways and fluxes to emerge, which in combination with enhanced vertical (hyporheic) exchange can diminish $\mathrm{NO}_{3}{ }^{-}$export (via increased denitrification and biomass uptake) and enhance DOC export (see section 5, Figure 15, 16 17). Floodplain inundation also increases the lateral connectivity between aquatic and terrestrial food webs (McCaffery and Eby, 2016), with new lentic and littoral habitat transitions enhancing the aquatic ecosystem productivity and organic matter cycling (Anderson et al., 2009; Naiman, 1982). In terms of geomorphology, floodplain inundation can (4) increase sediment deposition and storage (section 4, Figure 12,13). This change in depositional environment, in combination with tree loss and vegetation shifts due to (5) higher soil water content, increased flood disturbance, and herbivory (Figure 19), as well as beavers digging new floodplain channels, and the substantial increase in large woody debris within the river, may in turn encourage (6) river corridor planform shifts to anabranching, multi-thread flow patterns, and an increase in floodplain carbon storage (Sutfin et al., 2016; Wohl, 2013). In summary, the cascading impacts stemming from beaver damming, in which hydrological feedbacks through the extent of floodplain inundation can be a key moderating factor, has the potential to create a distinct environmental functioning of the entire river corridor in which the hydrology, geomorphology, biogeochemistry, terrestrial and aquatic ecosystems, and the multiple feedbacks between them have to adjust to new steady-state conditions (Figure 21).

\subsection{Longer-term impacts: Perpetual succession of landscapes and ecosystems, and} feedbacks driving carbon sequestration potential

As beaver occupation of a river corridor extends in timescale, especially $>10^{1}$ years, the initial landscape impacts that follow on from the hydrological changes described above will remain important, but will also be modified as the river corridor adjusts towards a state of 'perpetual succession'. In this context, 'succession' is meant in a holistic sense and refers to landscape and ecosystem processes changes that take longer timescales to manifest (Figure 21). Thus, we suggest the critical impact of beavers on river landscapes is to amplify the natural mechanisms of adjustment that operate over these longer timescales, which they do by (1) creating a succession of dams with a mix in ages and integrities, as older ones fill with sediment or are breached, and new ones are constructed (section 4.2, 6.3), (2) shifts in aquatic ecosystem assemblages to reflect the new mosaic of lentic-lotic transitions, increased habitat complexity, increased net ecosystem productivity, and trophic level changes (section 6.1), (3) succession in geomorphic channel adjustments distinct from the initial impacts mentioned above, e.g. due to meander development around old and new dams, evolving bank 
stability through succession in the riparian zone, as well as floodplain and valley meadow development through sediment and carbon sequestration (Rudemann and Schoonmaker, 1938; Westbrook et al., 2011; Wohl, 2013), 4) evolution in soil nutrient status through vegetation and water content changes (Naiman et al., 1994; Westbrook et al., 2011), and (5) (reverse) succession in terrestrial vegetation assemblages driven by water availability and herbivory (section 6.5). These impacts are 'perpetual' only so long as the disturbance from beaver activity can be maintained, which may include cycles of abandonment and re-occupation. Therefore, following abandonment the state of perpetual succession may be largely reversible (Naiman et al. 1988), or they may trend towards alternate states, discussed in detail in section 8 . The net effect of perpetual succession through beaver impacts is to create, as described by Naiman et al. (1988), a 'spatial and temporal mosaic' of environmental conditions and habitat complexity along the river corridor, that cannot develop without prolonged beaver activity.

The fate of the increased carbon storage facilitated by beaver impacted river corridors (see section 5), and alluded to in point (4) above, is the subject of considerable interest and speculation. In particular, the question is how much, carbon will remain in storage over longer timescales (e.g. $>10^{2}-10^{3} \mathrm{yrs}$ ), and how much of the shorter-term carbon storage is likely to be exported downstream. In terms of the aquatic component of this system, Naiman et al. (1988) reported order of magnitude increases in organic matter residence (or turnover) times in beaver ponds up to 161 years. Such a large increase in residence times are to be expected in beaver ponds where the relative increase in carbon storage is very large, however it is of course unlikely that individual beaver ponds and the carbon stored within them will remain intact for this length of time, given many dams can be abandoned or breached over the $1-10^{1} \mathrm{yr}$ timescale. Thus, the actual long-term fate of the aquatic carbon storage in beaver systems is likely to be set by the frequency of dam disruption on the one hand, and the geomorphic capacity of the river system to sequester any remaining pond deposits within a water saturated alluvial stratigraphy on the other (e.g. via overbank deposition whilst keeping water tables relatively high). As a result of these constraints, it is likely that only a small fraction of the available aquatic carbon storage will be sequestered over the long-term. In terms of riparian zone soil carbon, the 'reverse succession' process promoting pioneer vegetation on beaver meadows enables higher biomass input rates to the soil (Rosell et al., 2005), resulting in higher soil carbon accumulation in beaver meadows (Westbrook et al., 2011; Wohl, 2013). However, similar to the challenges in preserving aquatic carbon over the long-term, this increase in soil carbon may difficult to retain unless the high biomass inputs from the meadow and higher water tables can be also maintained by continuous beaver occupation, or alternatively sequestered within water saturated alluvial deposits. Given beavers do not occupy sites indefinitely, beaver meadow soil carbon stocks can diminish over time once abandoned (DeAnna and Wohl, 2019), likely though a combination of reduced biomass inputs and declining water tables. The overall long-term carbon storage potential in beaver impacted river corridors therefore seems to be most sensitive to 1) whether or not continuous beaver activity (or at least cycles of re-occupation) can be maintained, and 2) the geomorphic and hydrologic capacity of the corridor to stratigraphically sequester the carbon deposits. These constraints offer some explanation as to why the long-term storage rates of carbon in beaver systems are far lower that the shorter-term rates (Wohl et al., 2012). It is also clear that in the case of site abandonment, the pathways of subsequent landscape and ecosystem transitions will determine the fate of the beaver assisted carbon storage. These potential pathways are covered in the following section (section 8). 


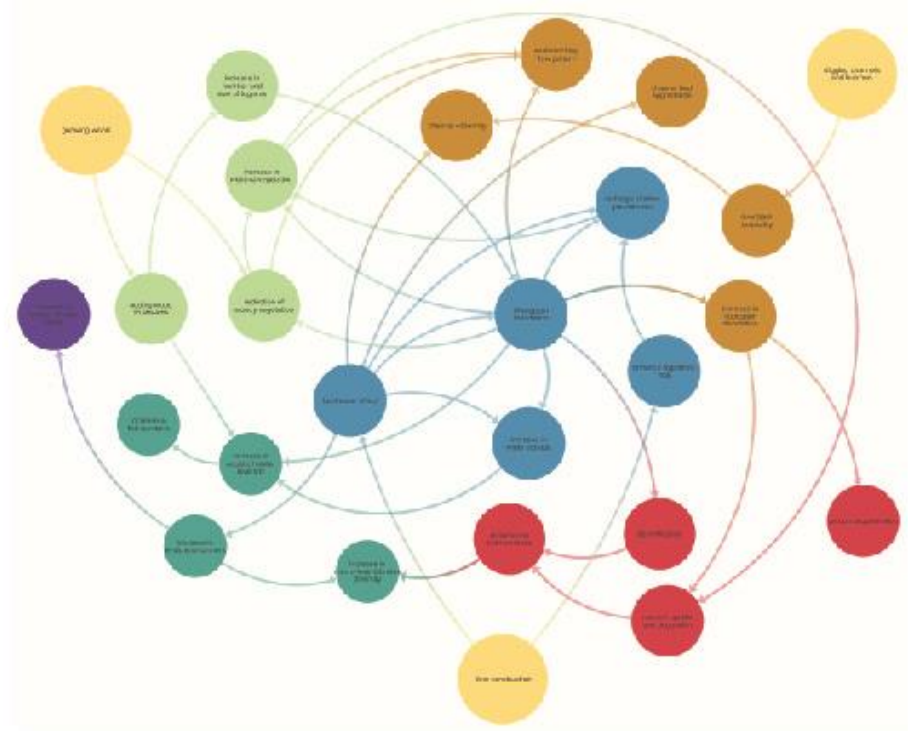

Figure 20_Main described cause-effects and short-term feedbacks caused by beaver dam construction, digging, and gnawing in a river-floodplain system (including hydrology, geomorphology, ecology, water quality, biogeochemistry).

\begin{tabular}{|c|c|c|}
\hline Timescale & $\begin{array}{c}\text { Shorter-term }(<3-10 \mathrm{yrs} \text { ) and initial } \\
\text { (year 1) feedbacks }\end{array}$ & Longer-term (e.g. > 3 - 10 yrs) feedbacks \\
\hline \multicolumn{3}{|l|}{ Example } \\
\hline $\begin{array}{l}\text { Process } \\
\text { feedbacks }\end{array}$ & $\begin{array}{l}\text { Dominated by hydrological changes, } \\
\text { overbank flooding, increased lateral and } \\
\text { vertical connectivity, expanded interfaces, } \\
\text { increased carbon storage }\end{array}$ & $\begin{array}{l}\text { Dominated by 'perpetual succession' in dams, } \\
\text { geomorphology, soils and vegetation. Habitat } \\
\text { mosaic in both aquatic (lentic - lotic) and } \\
\text { terrestrial (meadow development) systems, } \\
\text { uncertain carbon sequestration }\end{array}$ \\
\hline
\end{tabular}
corridor landscapes and ecosystems?

An interesting question is whether beaver impacts promote successional ecosystem states that are 'stable' and distinct from what would have occurred in their absence. More specifically, this question of alternate stable states usually refers to whether beaver meadows will revert to some previous condition, follow a new trajectory of succession, or perhaps something in between. However, in all cases the concept of 'stable' is not necessarily clearly defined. There are several alternate ecosystem and landscape states that have been proposed involving beavers, yet it is unclear how all these pathways fit together in a coherent framework. Based on the synthesis of feedbacks provided by this review (section 7), we propose an overarching framework to capture all these potential pathways as mediated by landscape constraints and the mechanism of beaver abandonment (Figure 22). This extends the previous frameworks proposed by Wolf et al. (2007), Baker et al. (2012), and Johnston and Naiman (1990a), to more explicitly account for the broad range of potential hydrological and 
cycle of abandonment and re-occupation, which can maintain beaver meadow landscapes and ecosystems for prolonged periods (section 6.5), or whether 2 ) beavers abandon the site without reoccupation. In the case of abandonment, the subsequent trajectories can lead to either 2a) successional increases in tree species abundance whilst maintaining some degree of 'wetness' (section 6.5 ), or $2 \mathrm{~b}$ ) geomorphic responses such as channel incision that promote 'drier' meadows. Trajectory 1) requires the development of cyclic food resource development and over-exploitation, however long-term data on these interactions are generally lacking (section 9.1). Abandonment without reoccupation (trajectory 2) may occur because the beaver colony has independently depleted food resources and decides not to return, or because of interactions with undulate herbivores such as elk (Cervus elephantus) and moose (Alces americanus). This latter feedback emerges because moose and elk are more active browsers of juvenile vegetation shoots, substantially reducing the overall regeneration of willow and aspen (Bergman and Bump 2015; Baker et al. 2005). In contrast, beavers generally 'coppice' willow vegetation, allowing full stem regrowth prior to cutting (Wohl, 2019). Baker et al. (2012) found that elk herds browse willows to far shorter heights, which is then largely unsuitable for consumption and dam construction by beavers, resulting in their competitive exclusion from meadows. However, if the competitive interactions can be reduced, e.g. via predator re-introduction (Beschta and Ripple, 2019; Gable et al., 2018) (see also section 9.1), or because the meadow already supports a more diverse and productive browsing assemblage, browsing pressure from elk may instead lead to competitive exploitation, in which beavers are able to adapt their foraging behavior without abandoning the site (Hood and Bayley, 2008b). A notable example of this latter feedback is the recovery of beaver meadows in Yellowstone National park (USA), were predator reintroduction is hypothesized to have reduced elk browsing pressure, allowing willow recovery and beaver recolonization (Wolf et al. 2007). However, the causal steps in the feedback chain of this case study may require some degree of moderation and reflection. For example, variation in willow and aspen growth dynamics are not always well explained by elk browsing pressure (Kauffman et al. 2010; Marshall et al., 2013) and pre-existing site differences may also be important (Tercek et al. 2010). Nor is there a consistent impact of wolf presence on elk browsing (Middleton et al. 2013), thus, more work on the detailed causal feedbacks at this site is clearly required.

Whatever the mechanism causing beaver abandonment, in our framework (Figure 22) trajectory 2a) develops when the abandoned meadow is still able to maintain a relatively elevated water storage capacity, facilitating alternate stable state fens or peatlands (Johnston and Naiman, 1990a), or perhaps relatively wet riparian forests (Logofet et al., 2016). In the case of trajectory 2b) meadow abandonment leads to geomorphic adjustments such as channel incision, which can sometimes be initiated following beaver site abandonment, and in turn lowers the water table and results in drier soil conditions. The likelihood of incision following abandonment is difficult to constrain, and depends on a number of geomorphic feedbacks, e.g. stream water level drop following dam loss, bank stability, whether the system is single channel or multi-thread, and channel slope, all of which can combine in different ways to increase stream power and drive incision (see section 4). In any case, this framework can encapsulate the majority alternate pathways that beavers can promote in river corridor landscape and ecosystems, based on the explicit geomorphic, hydrologic, and vegetation feedbacks explored within this review.

It is also worth considering whether the alternate stable state framework (e.g.: Byers et al., 2006; Suding et al., 2004) is conceptually complete in the case of river corridors influenced by beavers. This is primarily because the 'stable' component of this framework is subject to considerable variation and 
interpretation. For example, as an agent of disturbance, beavers must maintain this disturbance in order for beaver meadows to develop and remain. Does the meadow therefore constitute a stable state? As documented in Figure 22, and in the vegetation section (section 6.5), even following beaver abandonment, meadows may persist for considerable periods of time, but this depends on a range of initial conditions and it is clear they will inevitably undergo some landscape and ecosystem transitions. Therefore, without continued beaver activity, meadows are clearly not themselves stable systems if sufficiently long time periods are considered. However, the alternate stable state framework is very useful in highlighting the necessary role of beavers as an ecosystem engineer in enabling these landscape and ecosystem transitions that would likely not occur in their absence. For example, the trajectory of channel incision and floodplain drying following beaver abandonment in Figure 22 would be difficult to reverse without beaver re-introduction facilitating the recovery of incised channels, as was the case at Yellowstone once elk browsing pressures were reduced (Wolf et al., 2007). However, we note that the attribution of river incision solely to beaver abandonment at this site is problematic, and that a more complex interplay with climatic (Persico and Meyer, 2013) and fire (Meyer et al., 1992) is likely involved and is also important context to consider for all beaver assisted river recovery efforts.

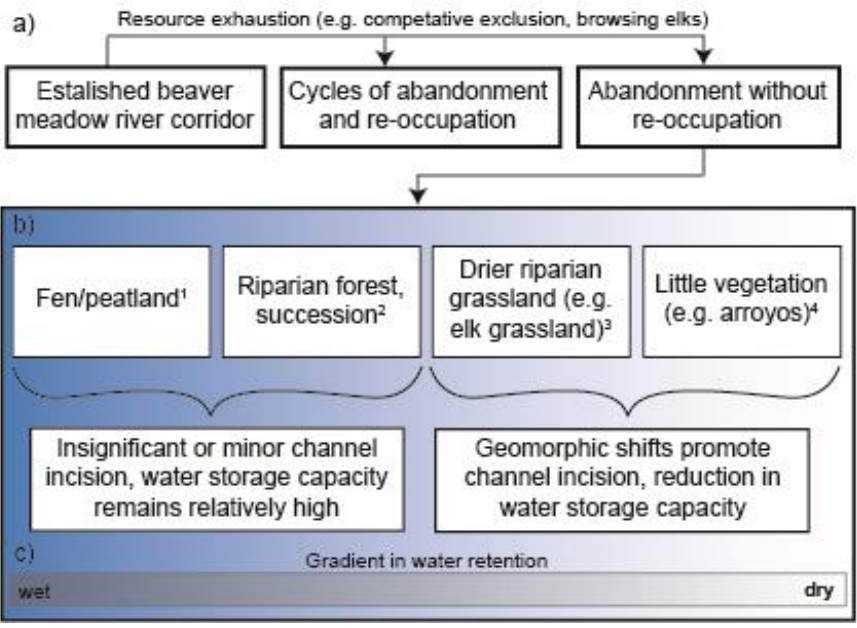

Figure 22_Potential alternate riparian trajectories of river corridors depending on weather beaver occupation can be sustained. If the site is abandoned, the trajectory depends on the valley hydro-geomorphic context.

\section{Natural landscapes, perception, and the role of beavers in stream management and rehabilitation}

\subsection{What is natural, and what might the future hold?}

This review has synthesized the profound impacts that beavers can have on river corridor hydrology, geomorphology, biogeochemistry and ecosystems, and the myriad of feedbacks between them. Yet, the interpretation of these impacts in terms of what is 'natural', in terms of the future role of beavers in river management and rehabilitation, and in terms of public perception and government policy are fraught with uncertainty and a large potential for misunderstanding. Are beavers an invasive pest to be removed, a natural part of landscape functioning whose impacts should be embraced, or somewhere in between as an ecosystem engineer that itself requires some level of management? Here, we briefly review the challenge of defining 'natural' landscapes, and spectrum of positions and contexts in which beaver impacts and their implications have been considered. 
There is comprehensive evidence for the widespread historic reduction in both the geographic range and population densities of both North American and European beavers, although the timing of this impact is much earlier in Europe than in North America (Morgan, 1868; Müller-Schwarze, 2011; Zahner et al., 2005). However, estimates of these historic population densities and ranges throughout the river networks of both continents prior to human impact remains uncertain, with relatively unbounded speculations in North America ranging from $60-400$ million (Naiman et al., 1988). This limits the context in which the current recovery in beaver populations in both North America and Europe can be placed, and will always render interpretations of 'natural' population densities and ranges, or the carrying capacity of the landscape, with some level of uncertainty. Hence, the full range of habitats that beavers can occupy remains unclear, particularly in marginal environments such as ephemeral streams with little riparian vegetation, low order streams at increasing elevation, Eurasian steppe landscapes, and streams heavily modified by humans (Bailey et al., 2019). This knowledge gap has led in some cases to the re-introduction of beavers into unsuitable habitats, and therefore delays in reintroduction success (Stocker, 1985). Despite these overall limitations, it is useful to try and constrain the potential range of beaver habitat at more regional and local scales. Recent work on streams of the south-west USA used information on the permanence of water sources, available riparian vegetation, channel width, magnitude and frequency of typical floods, and channel gradient and mean discharge as predictors for the potential beaver habitat within these hydrological sensitive river networks (Macfarlane et al., 2017). More research is clearly needed to constrain potential and preferred beaver habitat ranges.

However, the overall landscape carrying capacity of beavers is more complex than potential habitat, and considered from a population point of view, there are two broad constraints on beaver populations: 1) predators (e.g. wolves, where present) as a top down control (Gable et al., 2018), and 2) food supply as a bottom up control, which includes interaction with other herbivores (see section 8). However, it is not intuitive how these constraints should operate in the very common case of beaver populations that are either re-introduced or recovering. Interesting data in this case comes from beaver populations re-introduced to Sweden between 1922 and 1939, which long term monitoring reveals has followed the Riney-Caughley 'irruptive' population model for introduced ungulates, whereby they experienced a growth phase for $24-35$ years, followed by a steady population decline to a more stable (though still dynamic) level (Hartman, 1994; Hartman and Axelsson, 2004). Such a population dynamic suggests 1 ) that there is a general lack of top down predator control, and 2) that beavers as an expanding population may exploit food supply beyond the landscape carrying capacity and therefore decline in numbers. However, it is also important to note that this population trend is from the boreal zone and may not be as predictive of expected population expansions throughout more temperate regions. In addition, except for some regions of the USA, Canada, Poland, Latvia and Russia, beavers across many regions of the Northern Hemisphere are not expected to encounter significant top-down predation pressures (e.g. from Wolves) in the regions in which they are recovering or being reintroduced (Gable et al., 2018). In a separate line of evidence, river geomorphic conditions have been found to be more influential than forest type in habitat selection as beavers colonize new areas (Hartman 1996), and a general finding across Europe has emerged in which beavers first increase in habitat range before increasing in population (Halley and Rosell, 2002). This suggests the growth phase is a case of being spoilt for choice (not that vegetation availability is unimportant), with habitat selection becoming more marginal as the landscape approaches carrying capacity (Pinto et al. 2009), suggesting the eventual population decline may be due to a delayed feedback regarding food supply 
and the ecosystem engineering impacts of beavers discussed in detail in this review, as well as the need to eventually move into increasingly marginal habitats. Where competition with other herbivores such as elk are present, the population outcome may be much more dynamic and beaver populations may instead suffer heavy declines as the food resources are even more quickly depleted, and with fewer chances for recovery (Wohl, 2019, also see sections 6.5, 8). This longer-term relation between ecosystem engineering, food stocks, and landscape carrying capacity remains very poorly understood, and urgently needs further research. However, it is important to note than an irruptive population dynamic may not always occur, outside countries with large forested areas such as Sweden, beaver population expansion may have far greater habitat competition and conflict with human land use (Halley and Rosell, 2002). Nonetheless, as warned by Hartman (1994), it would be prudent for managers and policy makers to be cognisant of the potential beaver population consequences of having no natural predators or habitat competition given the risk of over-exploitation of food resources during population recovery and reintroduction efforts. Regardless of the uncertainty surrounding the 'natural' landscape beaver carrying capacity and projected population dynamics across European and North American landscapes, any future capacity is still likely to be higher than the present population numbers in many regions. If we consider the trajectory from current population numbers to the theoretical landscape carrying capacity as a legitimate future scenario, then, as documented throughout this review, this will set in motion a large suite of landscape and ecosystem feedbacks and changes to the river corridor that will require thoughtful and potentially vexing management and policy decisions into the foreseeable future. In some cases, an expansion of beaver populations to the landscape carrying capacity may be welcome, and beavers could potentially re-establish river conditions to those present prior to European impact (Polvi and Wohl, 2013). However, in many regions it is unlikely that beaver populations reaching the theoretical landscape carrying capacity is a desired outcome as envisaged under a majority of river and landscape management scenarios, which by design must balance the needs of multiple stakeholders. Thus, the active human management of beaver population numbers and their impacts is all but certain to increase into the future as their populations expand, and this management is already well underway in some regions (BAFU, 2016; Halley and Rosell, 2002; Wróbel and Krysztofiak-Kaniewska, 2020).

\subsection{Insufficient context can skew the interpretation of beaver impacts}

As this review has attempted to reveal, beaver modifications to river corridors set in motion a wide range of feedbacks between hydrology, geomorphology, biogeochemistry, and ecosystems. In addition, as beaver populations expand, the extent to which their impacts are considered positive or negative by various stakeholders also depends on management priorities, which themselves will be heavily dependent on the magnitude of change that beavers are expected to deliver within human modified or natural landscapes. In terms of placing the magnitude of beaver impacts in an experimental context (e.g. before-after-control-impact, $\mathrm{BACl}$ ), the practice is relatively rare, but more beaver impact studies are embracing this kind of approach (Bouwes et al., 2016; Conner et al., 2016; Weber et al., 2017), which will be increasingly important for engaging with stakeholders on outcomes. In any case, given the wide range of feedbacks that can occur, it can be difficult to interpret these impacts if insufficient information or understanding of the underlying feedbacks are available. Therefore, a narrow process understanding of these impacts risks interpretations that can be skewed as either net positive or negative from a management or policy point of view. This means care is needed when isolating individual impacts, lest they be used to strengthen the perception of beaver 
impacts being either net positive or negative for the landscape in question. This lack of context is further amplified by the relative paucity of process studies that provide actual data on these feedbacks. Based on our review of the underlying processes (hydrology, geomorphology, biogeochemistry, and ecosystems) (Table 1), a set of illustrative, but not exhaustive, examples in which impacts considered in isolation could be construed net positive or net negative is provided in Table 4. Whist it is certainly interesting from a management or policy perspective to highlight positive impacts, which are often considered 'ecosystem services', it would be remiss to exclude the potential negative impacts linked to the same process or feedback. Likewise, only pointing to net negative impacts can ignore the many potential benefits that beaver impacts may provide. This highlights the subjective nature of interpretations based on insufficient process context, and the clear need to interpret all the feedbacks associated with beaver modifications in a holistic way (see sections 7,10 ). Nevertheless, there are clear cases where it may be important to argue for net negative or positive impacts if the antecedent conditions or management policies prior to beaver (re-)introduction have overriding priorities. For example, this may include beavers as an introduced species in the case of the former (net negative), and their potential role in river rehabilitation in the case of the latter (net positive), both of which are discussed in more detail below.

\subsection{Beavers as an introduced species}

In South America, $C$. canadensis was first introduced in the sub-antarctic ecoregions of Patagonia in 1946 (Anderson et al., 2009). This is beyond the known historical and Holocene range of beavers (Graells et al., 2015), meaning there is also an absence of natural predators and ecosystem adaptation, and officials have been engaged in active eradication programs since 2008 (Choi, 2008). Beavers have since spread along the eastern regions of Patagonia, but not yet to the more climatically extreme south and west (Anderson et al., 2006b; Graells et al., 2015), which is considered unlikely habitat for beavers due to its high relief and the dominance of unpalatable tree species (Anderson et al., 2009; Anderson et al., 2006b). Nonetheless, observations suggest beavers are actively expanding their range, including crossing the Strait of Magellan into mainland South America which has raised concerns about the prospect of future population expansions throughout the rest of the South American continent (Skewes et al., 2006a). In recently colonized catchments, beavers have modified 30 to $50 \%$ of formerly free-flowing stream reaches, including riparian zones consisting of either steppe vegetation or floodplain forests, lakes and bogs (Anderson et al., 2009; Pietrek and González-Roglich, 2015). Floodplain forests in particular have proven to be highly favored habitats, especially since they include abundant Nothofagus pumilio and Nothofagus betuloides which have become the preferred woody species browsed by beavers in the region (Anderson et al., 2006b). However, beavers have also been able to spread into the steppe vegetation landscapes which implies the importance of woody vegetation in habitat selection is lower than generally expected (Pietrek and González-Roglich, 2015). The net result is population numbers in Patagonia have grown to an estimated $\sim 100,000$ individuals (Choi, 2008).

In terms of impacts, beaver damming is flooding sub-Antarctic riparian forests and reducing canopy extent (Choi, 2008a). Vegetation succession in beaver ponds also follows a different trajectory compared to other disturbances common to the region such as forest clearings or wind-throw, and facilitate succession dominated by Nothofagus antarctica, which is the local pioneer species most adapted to high water content conditions (Martínez Pastur et al., 2006). The creation of beaver ponds and meadows has also been shown to advantage invasive bush and grass species (Anderson et al., 2009), and invasive mammals such as muskrats and minks which hunt native fauna (Crego et al., 2016). 
Interestingly, thus far there does not appear to be a significant difference between macro-invertebrate assemblages in the natural lentic habitats and those created by beavers in Patagonia (Anderson et al., 2014), suggesting the native lentic aquatic fauna have been able to expand their range. In any case, these findings are consistent with the broader ecological argument that introduced species can facilitate the expansion of additional introduced species (Anderson et al., 2009), and provides an important example of where it is possible to conclude that there are net negative ecological feedbacks associated with beaver impacts.

It is also worth noting that in Finland and areas of northwestern Russia, the beaver is also an introduced species to itself. Seven North American beavers (C. canadensis) were introduced in 1937 as part of ongoing efforts to re-introduce the nearly extinct Eurasian beaver ( $C$. fiber), which at the time were thought to be identical species (Parker et al., 2012). This is of considerable concern, since as noted by Parker et al. (2012), Gause's competitive exclusion principle dictates two species with identical niches cannot coexist indefinitely. Existing data suggests there are very few differences and near complete niche overlap between the species (Alakoski et al., 2019), except for the slightly larger litter size of $C$. canadensis, however the outcomes of direct contact are thus far inconclusive (Parker et al., 2012). There is therefore a very real chance that the invasive $C$. canadensis is able to displace $C$. fiber over the longer term and further expand into mainland Europe, thus strident eradication measures have been recommended (Parker et al., 2012), however it is unclear if any have yet been adopted.

\subsection{Beavers as ecosystem engineers and their role in river restoration and rehabilitation}

The global river restoration effort is a sizeable collective business, and in many cases is does not consider whether a site is within the historical range of beavers, or the implications for restoration strategy if they returned (Burchsted et al., 2010). There has been an interest in re-introducing beavers into formerly native habitats in Europe and North America since at least the 1950s, mainly for the biodiversity benefits (see section 6) (Stocker, 1985; Zahner et al., 2005). Since the 1990s beavers have also been increasingly recognized and described favourably as ecosystem engineers (Gurnell, 1998; Jones et al., 1996; Wright et al., 2002). In addition, the fact that beavers benefit from the ecosystem changes that they trigger (e.g. the pond as protection from predators, enhanced foraging habitat), and the large positive feedbacks they generate with the rest of the aquatic and terrestrial ecosystem, means they are now often labelled as a 'keystone species' (Mills et al., 1993). This designation as both a keystone species and ecosystem engineer mean beavers have become highly rated as a tool for river rehabilitation improved ecosystem biodiversity (Pollock et al., 2017), which is supported by the wide range of net positive impacts effect beavers can have (tables 1,4$)$. The clear benefits for river corridor ecosystem biodiversity in particular have led to the suggestion that river corridors and beaver modifications have co-evolved (sensu Corenblit et al., 2011) throughout the Holocene, and potentially even longer. This in turn implies that under natural conditions, ecosystem resilience to change is likely higher in streams with beaver impacts, which has useful implications for river management, especially where additional impacts of land-use and climate change need to be considered.

There is therefore a clear place for beavers in future landscape decisions concerning river corridors. Indeed, beavers have now entered, or are ready to enter, the lexicon of many restoration philosophies, most prominently: 'stage 0' (Cluer and Thorne, 2014), 'rewilding' (Law et al., 2017; Willby et al., 2018), 'nature based solutions' (Muller and Watling, 2016; Puttock et al., 2017; Westbrook et al., 2020), and 'ecosystem services' (Thompson et al., accepted), all of which are discussed in turn below. Although 
not synonymous, there is nonetheless considerable overlap between these concepts. 'Stage 0' river restoration aims to restore landscape processes that allow more 'natural' (i.e. pre-human disturbance) ecological functioning. In the context of unconfined, depositional valleys this specifically includes promoting multi-threaded channel systems with frequent floodplain inundation (Cluer and Thorne, 2014; Powers et al., 2019; Walter and Merritts, 2008), a goal which clearly dovetails with beaver driven impacts (see section 7), and acknowledges the considerable legacy of beaver ecosystem engineering on river corridors prior to their widespread eradication. Combining beavers and the geomorphic basis of stage 0 restoration efforts is particularly well suited to address the broader problem of historical channel incision, as the multithread channel system can reduce reach scale stream power and promote deposition (Pollock et al., 2014). In combination, these processes can lead to the lateral hydrological re-connection of the floodplain-channel system (Polvi and Wohl, 2013) and greatly reduces the sensitivity of riparian vegetation to rainfall variability in drier areas (Silverman et al., 2019). However, the continuing absence of beavers from many river systems targeted for restoration has led to the emergence of beaver dam analogue (BDA) construction as a complementary technique (Bouwes et al., 2016; Pollock et al., 2007; Pollock et al., 2014) that falls within the broader stage 0 approach. The goal with BDA construction is usually to 1) emulate the hydrological and geomorphic feedbacks induced by real beaver dams (see section 7) and their net positive benefits (see section 9.2) and 2) to attract extant beaver populations to colonize the targeted restoration reach (Pollock et al., 2017). Like many restoration efforts however, there is a paucity of information relating to the effectiveness of BDAs, though this is beginning to change (Bouwes et al., 2016). Nonetheless, more long term work is required to understand success in attracting beaver populations to take over as the 'stage 0 ' engineer, otherwise the continued maintenance of BDA efforts, and the broader feedbacks deriving from the 'perpetual succession' induced by beaver disturbance (see section 7.2), could be difficult to reach. The core goal behind the rewilding framework is the re-establishment of trophic ecosystem complexity (Bakker and Svenning, 2018), particularly top-down interactions promoted by larger wildlife species or their proxies (Svenning et al., 2016). Thus, beaver re-introduction is essentially a form of rewilding, and parts of this review have documented the trophic complexity they facilitate, particularly in aquatic and wetland meadow ecosystems (see sections 6,7 ). In addition, as an ecosystem engineer beavers may substantially improve the biodiversity restoration success many rewilding projects seek to achieve and reduce the need for management interventions (Law et al., 2017; Willby et al., 2018). The final restoration paradigms, namely 'nature based solutions' and 'ecosystem services' are both more targeted, with the former primarily used as a 'soft' engineering replacement for otherwise 'hard' engineering solutions, and the latter placing effect sizes of natural ecosystem and landscape processes in a broader 'cost-benefit' style economic context. The primary application of beaver impacts in the context of nature based solutions has been in terms of flooding, which in turn falls under the umbrella of 'natural flood management' (Lane, 2017), which has thus far been dominated by the construction of far leakier dams than those constructed by beavers (Muller and Watling 2016). The concept of ecosystem services can promote the economic benefits of specific beaver impacts such as water quality changes and flood protection measures (Thompson et al., accepted). However, as this review has emphasised, the effect sizes of many of the potential ecosystem services provided by beavers, such as flood and drought mitigation (see section 3), carbon sequestration (see section 7.2), and water quality (see section 5), are highly uncertain and context dependent (see section 10), thus extrapolating financial values for these services may be premature for widespread management and policy use. Nonetheless, as the knowledge and evidence base increases, the utility of this approach is certain to increase. In terms of distilling the place of beavers across all these restoration frameworks, it is clear 
from the knowledge collected in this review that there is a need to consider the profound spatial and temporal variation in the feedbacks created by beaver impacts both between and within river corridors, in all aspects of project planning and implementation. This variation is driven in large part, but not exclusively, by the context dependency of the site being considered, which is synthesized in more detail below (section 10).

\section{Putting beaver impacts in a holistic context}

Here we develop a holistic context for evaluating beaver impacts based on an inter-disciplinary synthesis stemming from the main findings of this review. This is centered on a conceptual model (Figure 24) that emphasizes these impacts cannot be divorced from the wider landscape context in which they occur. We first consider the spatial components of connectivity (lateral vs longitudinal connectivity), and then show how in combination with climate, these gradients can impact important process timescales (e.g. water and nutrient transport). Broadly, we consider valley slope and width as placing an important first order constraint on where and how beaver damming will influence a river corridor, which is demonstrated using four river valley scenarios (Figure 24).

The extent of beaver impacts on lateral connectivity will control, amongst other things, open water extents, flood attenuation capacity, sediment, carbon and nutrient storage, extent of anaerobic metabolism and biogeochemical interfaces, water residence times and nutrient fluxes, aquatic ecosystem productivity and biodiversity, riparian vegetation mosaics, and river channel pattern. Thus, the ability of beaver dams to influence the lateral hydrological connectivity between the channel and floodplain is a key impact from which many other hydrological, geomorphic, biogeochemical, and ecosystem impacts follow.

Valley slope and width will moderate the number of dams that can be built in a given reach, and thus determine the overall capacity for beavers to decrease longitudinal connectivity, but increase vertical exchanges, over a stretch of river corridor. This is because increasing the slope allows a higher density of dams per unit stream length, or a beaver dam cascade, and at lower slopes wider multi-channel systems also potentially allow a high density of dams to develop laterally across its network. Dam density defines the extent of disruption to longitudinal connectivity, as well as influencing water, sediment, carbon and nutrient storages, vertical hydraulic gradients controlling ground and surface water interaction and hyporheic exchange, hydraulic roughness, the size and number of lentic to lotic aquatic ecosystem transitions, fish migration, the extent of wood introduction to the river corridor, and the spatial constraints on meadow development.

In our framework, river corridors that are highly incised or contain negligible floodplain area represent systems in which there is little capacity for increases in the width of open water area, meaning beaver impacts on lateral connectivity will be comparatively low (Figure 24 A1-A2). However, these typically low-order and higher slope river systems represent cases where although changes to lateral connectivity may be low, the changes to longitudinal connectivity and vertical exchanges may be very high, especially relative to the conditions prior to beaver impact. The damming of low order river systems by beavers can create significant jumps in longitudinal hydraulic gradients, with sections of flatter water surfaces, ponds and wetlands, connected by short but abrupt increases in the hydraulic gradient (i.e. the dams themselves). This may greatly enhance longitudinal processes such as hyporheic exchange, and also create a mosaic of lentic ecosystem conditions and transitions within river corridors that would be highly unlikely to support them in the absence of beavers. 
As greater floodplain and channel space becomes available with increasing stream order and decreasing slope, the lateral connectivity associated with individual dams has the potential to increase (Figure $24 \mathrm{~B}-\mathrm{C}$ ). In many river corridors of the world, river-floodplain connectivity has been heavily reduced or lost due to incision and engineering modifications, leading to large losses in aquatic and terrestrial habitat and biodiversity (Schumm, 2005; Wohl, 2004; Wohl, 2005; Wohl and Beckman, 2014). These streams are likely to experience the greatest increases in lateral connectivity, open water extent, and habitat complexity through beaver damming activity, often resulting in distinctive beaver meadow development through the 'reverse' succession of vegetation assemblages.

The relative impact of beavers on river-floodplain connectivity will be lower when this lateral connectivity is already naturally high, such as in near-natural river systems in Patagonia with a high abundance of lakes and wetlands (Anderson et al., 2006a), in natural fen and peat ecosystems (Naiman et al., 1988) or in larger braided or anabranching rivers (Malison et al., 2014), where beavers mostly dam smaller tributaries or secondary channels and therefore a much small proportion of the overall flow is impacted by beaver damming (Figure $24 \mathrm{D}$ ). However, even in these cases, at a local scale the influence of beaver dams on the riparian processes and ecosystems can still be significant.

The climatic context will also exert considerable influence on the spatial and temporal scale of beaver impacts through its control on the supply of, and atmospheric demand for, water. If we hold the general valley geometry to be constant, then varying the climate context within each scenario in Figure $24(A-D)$ will lead to differential beaver impacts on the river corridor. For example, being able to increase the extent of open surface water and higher soil moisture through the construction of beaver dams will have increasingly large hydrological and ecosystem consequences as the surrounding climatic context moves to drier scenarios. This is because in very dry climates the proportion of water lost to evaporation from open water may increase, but concurrent water storage increases may allow increases to streamflow persistence downstream, and the creation of new lentic habitat and ecosystem refugia that would not otherwise exist. Thus, river corridors with temporary flow dynamics, either because they are low order systems (e.g.: steeper headwater channels), or because they are very dry, should experience very large relative changes to connectivity and residence times (hydrological and biogeochemical). In very cold climates, deeper beaver ponds with surficial ice cover may also provide new and important aquatic habitat refugia.

The final context to consider is temporal. As agents of shifting connectivity, ecosystem disturbance and succession, and increased gradients, process feedbacks associated with beaver damming will evolve over time within each of the spatial contexts described above. How long beavers can maintain their activity at a site depends on both top down (e.g. humans, predators, competitors) and bottom up (e.g. food resource) constraints, and will determine the persistence of water, carbon, nutrient, and ecosystem changes they have induced. Importantly, the population constraints, length of beaver occupation, and whether cycles of abandonment and re-occupation can be established, will all help determine how river corridor landscapes and ecosystems develop once beaver occupation ceases.

The legacy of beaver damming impacts for river corridor processes and ecosystems further downstream remains poorly understood and is critical to improve given the importance of river networks in the global water, carbon, and nutrient cycles. The ubiquitous increase in wood and particulate organic carbon to rivers following beaver damming (Anderson et al., 2009; Thompson et al. 2016) is an example in which beaver impacts can generate a significant downstream legacy for 
ecosystems, carbon cycling, sediment transport, and channel evolution (Levine and Meyer, 2019). Changes to water storage also have the potential to leave a downstream legacy on streamflow regimes and water resources. In addition, changes to riparian ecosystem structures and trophic complexity through the introduction of new lentic-lotic transitions and 'reverse' succession meadows will challenge traditional concepts of how these ecosystems should vary downstream along rivers.

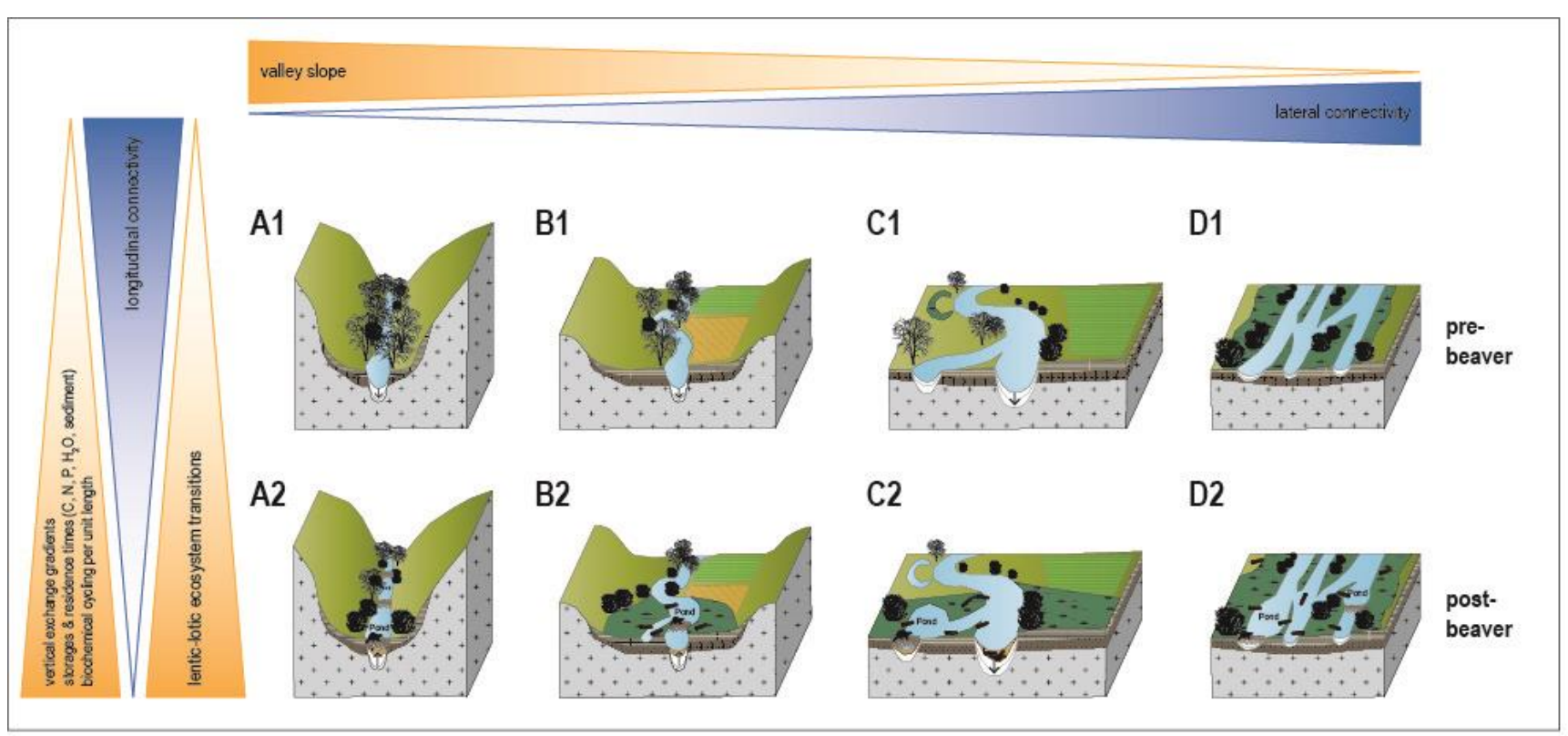

Figure 24: Conceptual model of how beavers increase river-floodplain (vertical) connectivity (1-2) and decrease longitudinal connectivity within changing river-floodplain dynamics and increasing catchment size $(A-D)$.

\section{Conclusion}

Beavers fundamentally alter river and floodplain landscapes and ecosystems by building dams, which can increase lateral and vertical, and decrease longitudinal hydrologic connectivity. This change in hydrological connectivity is the basis for all subsequent impacts, with the key process impacts summarized in Table 1. Longitudinal decreases in connectivity create ponds and wetlands, transitions between lentic to lotic ecosystems, increase vertical hydraulic exchange gradients, and biogeochemical cycling per unit stream length. Increased lateral connectivity will determine the extent of open water area and wetland and littoral zone habitats and induce 'reverse' succession in riparian vegetation assemblages. In combination, these changes in connectivity also promote increased storages of surface and subsurface water, carbon, nutrients, and sediment, and increase habitat complexity and biodiversity at the reach scale. The extent of these impacts depends on 1) the hydro-geomorphic landscape context, with the extent of floodplain inundation being a key driver of changes to hydrologic, geomorphic, biogeochemical, and ecosystem dynamics, and 2) the length of time beavers can sustain this disturbance at a given site. This large influence of beavers on river corridor processes and feedbacks is also fundamentally distinct from what would occur in their absence, and thus has profound implications for the future function and management of river systems as beaver populations continue to recover and expand. Nonetheless, considerable knowledge gaps and outstanding questions remain, which provides a rich and interdisciplinary future research agenda. 


\section{Acknowledgements}

2429

2430

2431

2432

2433

2434

2435

2436

2437

2438

2439

2440

2441

2442

2443

2444

2445

2446

2447

2448

2449

2450

2451

2452

2453

2454

2455

2456

2457

2458

2459

2460

2461

2462

2463

We are grateful to the many beavers of the world who have kept us busy. We wish to thank the many friends, colleagues, acquaintances, and chance meetings that inspired us to complete this review, too many to mention here. AL thanks the University of Lausanne for the 'Bourse Egalité' Fellowship, during which the foundation of this review was created. The review process has been lengthy, and we thank the patience of two different editors, and the constructive comments of four anonymous reviewers, all of which significantly improved the manuscript. Most importantly, we thank the many authors who have published all the wonderful hard work we are able to draw upon in compiling and synthesising this review.

\section{Figure Captions}

\section{Introduction}

Figure 1

Number of publications on beaver-ecosystem feedbacks in peer-review journals per country (USA: states). Data based on a search in Web of Science performed on 17.11.2016 using the keywords "beaver" and "castor" in the research fields Physical Geography, Environment, and Ecology. Present day beaver distribution data is based on the IUCN spatial dataset (downloaded at 21.11.2017) for both castor fiber and castor canadensis.

\section{Figure 2}

Landscape context of a typical beaver cascade (a) and beaver meadow (b). Beaver cascades are generally set in narrow, steeper valleys, while beaver meadows develop in wider, depositional valley bottoms. Grey lines are $5 \mathrm{~m}$ contour lines, white arrows point towards beaver ponds, and black arrows indicate valley width. Aerial imagery is based on drone derived orthophotos from Langwisenbach, Switzerland (a) and Jossa, Germany (b). Background imagery from Esri (Source: Esri, Maxar, GeoEye, Earthstar Geographics, CNES/Airbus DS, USDA, AeroGRID, IGN, and the GIS User Community).

\section{Figure 3}

Beaver pond examples across a wide spectrum of flow regimes. Arrows point to the location of beaver dams, lines help identify the orientation of old beaver dams, FD = flow direction. a) Large beaver pond just south of the Arctic Circle (Chena River, Fairbanks, Alaska, USA). A beaver lodge is located in the right side of the photo; $b$ ) Beaver pond complex along a headwater stream close to the elevation of the tree line (Homestake Creek, Colorado, USA); c) Beaver pond in a temperate headwater stream (Mederbach, Switzerland); d) Beaver dams along an intermittent stream (Arikaree River, eastern Colorado, USA). Here the beaver dams are primarily made of silt and clay, with some small wood branches; e) Beaver dam near Ushuaia, Argentina. Photos a, b, d taken by Ellen Wohl (Colorado State 
University), photo e) is a cropped version of a photo taken by llya Haykinson, distributed under Creative Common License CC BY-SA 1.0.

\section{Hydrology}

Figure 4

Conceptual models of the influence of beaver dams on surface and subsurface hydrology. Inset A) specifies different types of beaver dams and through flow, modified from Woo and Waddington, 1990. B) Conceptualization of hydrological feedbacks as a result of beaver dam construction on surface and groundwater flow paths and storages. Inset C) illustrates potential hyporheic exchange pathways, modified from White, 1990.

\section{Figure 5}

Beaver dam complexes create more spatially complex, and less advective flow networks in semi- or unconfined river-floodplain systems (from Green and Westbrook, 2009). Historical air photograph from Sanddorn Creek (British Columbia, CA) (scale approximately 1:10000). The aerial photographs of 1988 shows the stream before removal of eight beaver dams (marked with black lines and numbered from upstream to downstream), the photograph of 2004 after the removal of the beaver dams.

Figure 6

Changes in the area of open water due to beaver impacts (a) The long-term increase in open water surface area over time closely follows the number of active beaver lodges across a large area of Elk Island National Park, Alberta (Canada) (Hood and Bayley, 2008). (b) Average pond area per site over time, grouped by quasi-decadal cohorts (using aerial photography), on the wetland rich Kabetogama Peninsula, northern Minnesota, USA. See legend for cohort details. Modified from Johnston and Naiman (1990)(c) Number of ponds since beaver introduction (open squares) and the total water surface area (solid circles) in a small headwater agricultural stream in southern England (from Puttock et al. (2017)). (d) Strong seasonal changes in the water surface area of a shallow beaver pond and wetland on the coastal plain of Alabama, USA

Figure 7

Example of changing freeboard and water storage capacity upstream of a beaver dam, and the moderation of discharge downstream. Note the generally low but variable freeboard capacity (range $=\sim 30 \%$ of dam height) and overtopping during spring peak flows (modified from Devito and Dillon, 1993)

Figure 8

Flood attenuation illustrated through the comparison of inflowing (Qin) and outflowing discharge (Qout) in a headwater beaver pond cascade system in Belgium. The Qout hydrograph peaks are smaller and delayed compared to the Qin hydrograph, but Qout has higher discharge during recessions and low flow conditions. The dotted horizontal line indicates the highest measured discharge for the rating curve construction (1.2 m3 s-1). From Nyssen et al. (2011). 
Figure 9

Rise in river water levels due to beaver dam construction in a low-order stream in Germany (A), resulting in a rise in the shallow groundwater level in two distal piezometers (B) (modified from Zahner, 1997). Rise in water levels are apparent after the dashed vertical lines, which represents the timing of beaver dam construction. (C) Measured geometry of an idealized groundwater 'wedge' developed due to a rise in the groundwater table upstream and adjacent to a beaver dam in the Bridge River, Oregon (USA). Note the spatial dimensions in this figure are not drawn to scale. Modified from Lowry (1993).

Figure 10

Figure 10: Vertical hydraulic gradients (upstream - downstream) mediated by the downstream channel depth, across 74 separate beaver dams in Sweden (modified from Hartmann and Törnlöv (2006))

\section{Geomorphology}

Figure 11

Example of a sediment wedge preserved against a recently ( 1 day old) breached beaver dam (Langwisenbach, Switzerland). Note the generally massive stratigraphy and large concentrations of fine and coarse particulate organic matter in the fine sediment matrix.

Figure 12

Conceptual model of beaver dam influenced sedimentation patterns. a) Sediment wedge deposited on the upstream side of a beaver dam (BD) (WL = water level), b) deltaic sedimentation at the upstream end of the beaver pond; $c$ ) deposition and erosion in beaver ponds upstream of beaver dams during a variety of flow types: during normal flow (i); re-mobilisation of beaver pond sediments during highflow events and sediment deposition on floodplains respectively beaver meadows (ii); inset floodplain of former beaver pond deposits remain after drainage (iii); and d) variability of spatio-temporal pattern of in-channel beaver ponds $(\mathrm{i}-\mathrm{iii})$ results in a delay in overall sediment transport downstream. Flow direction is indicated by thick black arrows.

Figure 13

Channel widening and bank collapse following the breaching of several beaver dams during a summer storm in a river with multiple meadow complexes, between the begin of a the most upstream beaver meadow $(A)$ and downstream unmodified $(F)$ reaches $(\sim 3 \mathrm{~km})$. Arrows labelled FD indicate flow direction. B) Freshly drained beaver trapped sandy bedload (arrows). C) Beaver scratch marks (arrow) indicate they can over steepen pond and river banks, meaning bank collapse is more likely once water levels drop and soil pores are drained (D). E) More complex channel patterns (black arrows) develop upstream of dams in previous pond sediments (white arrow) immediately following dam failure. Note this sequence only documents the channel response immediately following dam failures, and not the subsequent recovery over a prolonged time period. 
Figure 14

Abandoned and breached beaver dams and huts (arrows) have been incorporated into the stream banks in a reach of the Jossa River in Germany, reinforcing bank stability and setting a narrow meander geometry.

\section{Biogeochemistry}

Figure 15

Conceptual model of changing biogeochemical conditions, pathways and fluxes potentially induced by beaver dams, from upstream to downstream.

Figure 16

Synthesis of literature findings on the direction of change following beaver impact for a) DOC ( $n=18)$, b) $\mathrm{NO}_{3}^{-}(n=19)$ c) $\mathrm{NH}_{4}{ }^{+}(\mathrm{n}=10)$ d) $\mathrm{PO}_{4}^{-}(\mathrm{n}=15)$ e) discharge $(\mathrm{n}=8)$, and f) suspended sediments $(\mathrm{n}=8)$. Of the 37 separate studies containing information on beaver water quality impacts, 14 (38\%) also examine sub-annual effects (seasonal, monthly, or event timescales). Based data from: (Błędzki et al., 2011; Burns and McDonnell, 1998; Cirmo and Driscoll, 1993; Correll et al., 2000; Dahm et al., 1987; Devito and Dillon, 1993; Dillon et al., 1991; Driscoll et al., 1998; Fuller and Peckarsky, 2011; Green and Westbrook, 2009; Hillman et al., 2004; Klotz, 1998; Klotz, 2010; Koschorreck et al., 2016; Kothawala et al., 2006; Law et al., 2016; Levanoni et al., 2015; Maret et al., 1987; Margolis et al., 2001; Muskopf, 2007; Naiman, 1982; Naiman et al., 1986; Puttock et al., 2017; Roy et al., 2009; Smith et al., 1991; Wegener et al., in press; Woo and Waddington, 1990)

\section{Figure 17}

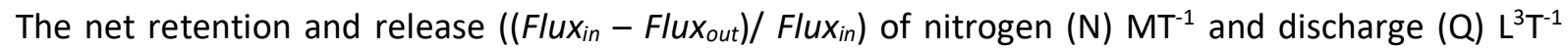
within a beaver pond and wetland on the coastal plain of southern Alabama, USA (Talladega wetland) (a). The same data is shown in (b) but with the single outlier month samples removed. The dashed grey line in (b) represents the 1:1 line. Deviations below the 1:1 line represent cases where the relative storage change in water $\left(\Delta S_{0} / Q_{\text {in }}\right.$, where $\left.\Delta S_{Q}=Q_{\text {in }}-Q_{\text {out }}\right)$ is greater than the relative storage change in nitrogen $\left(\Delta \mathrm{S}_{N} / \mathrm{N}_{\text {in }}\right.$, where $\left.\Delta \mathrm{S}_{\mathrm{N}}=\mathrm{N}_{\text {in }}-\mathrm{N}_{\text {out }}\right)$, and thus $\Delta \mathrm{S}_{\alpha} / \mathrm{Q}_{\text {in }}>\Delta \mathrm{S}_{N} / \mathrm{N}_{\text {in }}$, whereas deviations above the 1:1 line represent greater relative storage changes in nitrogen than water $\left(\Delta S_{N} / N_{\text {in }}>\Delta S_{0} / Q_{\text {in }}\right)$. Modified from Stanley and Ward (1997).

\section{Ecology}

Figure 18

Beaver dams and ponds create more diverse habitat and connect aquatic and riparian ecotones. Backwater ponds introduce lentic, littoral and wetland (characterized by unconfined surface flow, beaver meadows) habitat for invertebrates, amphibians, and fish in otherwise faster flowing rivers and dry floodplains. By permanently flooding some of the floodplain, beavers connect aquatic and terrestrial ecotones, and create breeding and feeding ground for many animals. 
Figure 19

Beaver induced tree mortality across the river corridor in Marthalen, Switzerland. Beaver dam construction in 2009 created a large wetland by 2012, with the mixed oak, ash and pine riparian forest experiencing total mortality in this reach within 5 years.

\section{Interconnections and feedbacks}

Figure 20

Cause and effect feedback loops that can be generated following beaver dam construction, digging, and gnawing (large yellow circles) in a connected river-floodplain system (Hydrology (blue), Geomorphology (brown), freshwater ecosystems (turquoise), and Biogeochemistry (red)). A link to Animal Ecology (purple) is also provided as an example case, but is not meant to be definitive. The figure indicates that conceptually, the cause of most beaver induced environmental changes in the aquatic and riparian ecosystem is caused by beaver dams being able to inundate the floodplain and pond the main channel.

\section{Figure 21}

Summary of shorter-term and longer-term processes and feedbacks in beaver meadows, with a visual example from the Jossa River in Germany. Within 3 months of damming, a large shallow wetland covered a large portion of the formerly agricultural floodplain (left aerial photo). After $\sim 20$ years, the floodplain has developed into a mix of ponds, wetlands, channels, and a mosaic of organic matter rich fen, sedge, reed, and juvenile willow vegetation patches (right photo, a drone-derived orthophoto and digital elevation model, giving a spatial impression). The arrow points towards the confluence between the two Jossa channels.

\section{Alternate stable states}

Figure 22

Potential alternate riparian trajectories of river corridors depending on weather beaver occupation can be sustained. If the site is abandoned, e.g. due to resource depletion or competitive exclusion (a), the subsequent trajectory depends on the valley hydro-geomorphic, and specifically whether channel stability and high water contents can be maintained, or whether incision and drying ensues (b). Numbers refer to example references for alternate stable states: ${ }^{1}$ Johnston and Naiman, 1990, ${ }^{2}$ Logofet et al., 2016, ${ }^{3}$ Baker et al., 2012; ${ }^{4}$ Fouty, 2018.

\section{Holistic context}

Figure 23 
Conceptual model of how beaver damming increases lateral and decreases longitudinal connectivity. This connectivity is initially hydrological, which then in turn influences geomorphic, biogeochemical and ecosystem connectivity. The horizontal transitions $(A-D)$ represent shifts in river valley (and to some extent climatic) contexts. These represent a transition in overall valley slope, along with an increase in the size of the main channel and extent of the valley and floodplain area. The transition from landscape context $B$ to $C$ represents an increase in the size of the main channel such that beavers are likely to be able to dam the main channel $(A-B)$ below this size, and unlikely to be able to dam the main channel $(C-D)$ above this size. An important feature of the landscape (and climatic) transitions is the increase in lateral connectivity from $A-D$, with the relative extent of this lateral connectivity enhanced by beaver damming $(1-2)$, especially as valley slope decreases.

The vertical transitions $(1-2)$ represent the change in each landscape context from pre- $(1)$ to post(2) beaver damming. An important consequence of the pre- to post-beaver damming transition across all landscape contexts is the decrease in longitudinal connectivity. Some key consequences of this are an increase in vertical hydrological exchange gradients, increases in the storage and residence times of water $\left(\mathrm{H}_{2} \mathrm{O}\right)$ carbon, nutrients ( $\mathrm{N}$ and $\mathrm{P}$ ) and sediment, and an increase in the biogeochemical cycling within the river reach (per unit length). In addition, each dam introduces new ponded water, and as the number of dams increases, so too does the number of transitions between lentic and lotic freshwater ecosystem habitats. With increasing river size and natural lateral connectivity (A-B), the potential influence of beaver dams on the lateral connectivity become smaller $(1-2)$.

\section{Bibliography}

Alakoski, R., Kauhala, K. and Selonen, V., 2019. Differences in habitat use between the native Eurasian beaver and the invasive North American beaver in Finland. Biological Invasions, 21(5): 16011613.

Andersen, D.C. and Shafroth, P.B., 2010. Beaver dams, hydrological thresholds, and controlled floods as a management tool in a desert riverine ecosystem, Bill Williams River, Arizona. Ecohydrology, 3(3): 325-338, DOI: 10.1002/eco.113.

Anderson, C.B., Griffith, C.R., Rosemond, A.D., Rozzi, R. and Dollenz, O., 2006a. The effects of invasive North American beavers on riparian plant communities in Cape Horn, Chile: Do exotic beavers engineer differently in sub-Antarctic ecosystems? Biological Conservation, 128(4): 467-474, DOI: http://dx.doi.org/10.1016/j.biocon.2005.10.011.

Anderson, C.B., Martinez-Pastur, G. and Lencinas, M.V., 2009. Do introduced North American beavers Castor canadensis engineer differently in southern South America? An overview with implications for restoration. Mammal Rev, 39, DOI: 10.1111/j.1365-2907.2008.00136.x.

Anderson, C.B., Rozzi, R., Torres-Mura, J.C., Mcgehee, S.M., Sherriffs, M.F., Schüttler, E. and Rosemond, A.D., 2006b. Exotic Vertebrate Fauna in the Remote and Pristine Sub-Antarctic Cape Horn Archipelago, Chile. Biodiversity \& Conservation, 15(10): 3295-3313, DOI: 10.1007/s10531-0050605-y.

Anderson, C.B., Vanessa Lencinas, M., Wallem, P.K., Valenzuela, A.E.J., Simanonok, M.P. and Martínez Pastur, G., 2014. Engineering by an invasive species alters landscape-level ecosystem function, 
but does not affect biodiversity in freshwater systems. Diversity and Distributions, 20(2): 214222, DOI: $10.1111 /$ ddi.12147.

Anderson, M.G. and Idso, S.B., 1987. Surface geometry and stomatal conductance effects on evaporation from aquatic macrophytes. Water Resources Research, 23(6): 1037-1042, DOI: 10.1029/WR023i006p01037.

Avery, E.L., 2002. Fish community and habitat responses in Northern Wisconsin brook trout stream 18 years after beaver dam removal.

BAFU, Bundesamt fuer Umwelt, 2016. Konzept Biber Schweiz. In: Ö. Abteilung Arten, Landschaften (Editor), online.

Bailey, D.R., Dittbrenner, B.J. and Yocom, K.P., 2019. Reintegrating the North American beaver (Castor canadensis) in the urban landscape. WIREs Water, 6(1): e1323.

Baker, B.W., Ducharme, H.C., Mitchell, D.C.S., Stanley, T.R. and Peinetti, H.R., 2005. Interaction of beaver and elk herbivory reduces standing crop of willow. Ecological Applications, 15(1): 110118, DOI: 10.1890/03-5237.

Baker, B.W., Peinetti, H.R., Coughenour, M.B. and Johnson, T.L., 2012. Competition favors elk over beaver in a riparian willow ecosystem. Ecosphere, 3(11): 1-15, DOI: 10.1890/ES12-00058.1.

Bakker, E.S. and Svenning, J.-C., 2018. Trophic rewilding: impact on ecosystems under global change. Philosophical Transactions of the Royal Society B: Biological Sciences, 373(1761): 20170432.

Barnes, D.M. and Mallik, A., 2001. Effects of beaver, Castor canadensis, herbivory on streamside vegetation in a Northern Ontario watershed. Canadian Field-Naturalist, 115: 9.

Barnes, W.J. and Dibble, E., 1988. The effects of beaver in riverbank forest succession. Canadian Journal of Botany, 66(1): 40-44.

Basey, J.M., 1999. Foraging Behavior of Beavers (Castor Canadensis), Plant Secondary Compounds, and Management Concerns. In: B. P.E. and D. R.M. (Editors), Beaver Protection, Management, and Utilization in Europe and North America. Springer, Boston, MA.

Basey, J.M. and Jenkins, S.H., 1995. Influences off predation risk and energy maximization on food selection by beavers (Castor canadensis). Canadian Journal of Zoology, 73(12): 2197-2208.

Basey, J.M., Jenkins, S.H. and Busher, P.E., 1988. Optimal central-place foraging by beavers: Tree-size selection in relation to defensive chemicals of quaking aspen. Oecologia, 76(2): 278-282.

Basey, J.M., Jenkins, S.H. and Miller, G.C., 1990. Food Selection by Beavers in Relation to Inducible Defenses of Populus tremuloides. Oikos, 59(1): 57-62.

Battin, T.J., Besemer, K., Bengtsson, M.M., Romani, A.M. and Packmann, A.I., 2016. The ecology and biogeochemistry of stream biofilms. Nat Rev Micro, 14(4): 251-263, DOI: 10.1038/nrmicro.2016.15.

Bätz, N., Colombini, P., Cherubini, P. and Lane, S.N., 2016. Groundwater controls on biogeomorphic succession and river channel morphodynamics. Journal of Geophysical Research: Earth Surface: n/a-n/a, DOI: 10.1002/2016JF004009.

BBC, 2017. Flood fighting beavers, https://www.bbc.co.uk/news/av/uk-england-devon39402944/flood-fighting-beavers.

Beedle, D., 1991. Physical dimensions and hydrologic effects of beaver ponds on Kuiu Island in southeast Alaska, Oregon State University, Corvallis USA.

Belovsky, G.E., 1984. Summer Diet Optimization by Beaver. The American Midland Naturalist, 111(2): 209-222.

Benke, A.C. and Wallace, J.B., 2003. Influence of wood on Invertabrate Communities in Streams and Rivers. In: A.M. Gurnell, S.V. Gregory and K.L. Boyer (Editors), The ecology and managment of wood in rivers. American Fisheries Society, Berthesda, Maryland, pp. 149-177.

Benz, S.A., Bayer, P. and Blum, P., 2017. Global patterns of shallow groundwater temperatures. Environmental Research Letters, 12(3): 034005.

Bergman, B.G. and Bump, J.K., 2015. Experimental evidence that the ecosystem effects of aquatic herbivory by moose and beaver may be contingent on water body type. Freshwater Biology, 60(8): 1635-1646, DOI: 10.1111/fwb.12595. 
Beschta, R.L. and Ripple, W.J., 2019. Can large carnivores change streams via a trophic cascade? Ecohydrology, 12(1): e2048.

Bhat, M.G., Huffaker, R.G. and Lenhart, S.M., 1993. Controlling Forest Damage by Dispersive Beaver Populations: Centralized Optimal Management Strategy. Ecological Applications, 3(3): 518530.

Bilyeu, D.M., Cooper, D.J. and Hobbs, N.T., 2008. Water tables constrain height recovers of willow on Yellowstone's northern range. Ecological Applications, 18(1): 80-92, DOI: 10.1890/07-0212.1.

Błędzki, L.A., Bubier, J.L., Moulton, L.A. and Kyker-Snowman, T.D., 2011. Downstream effects of beaver ponds on the water quality of New England first- and second-order streams. Ecohydrology, 4(5): 698-707, DOI: 10.1002/eco.163.

Bocking, E., Cooper, D.J. and Price, J., 2017. Using tree ring analysis to determine impacts of a road on a boreal peatland. Forest Ecology and Management, 404: 24-30.

Bouwes, N., Weber, N., Jordan, C.E., Saunders, W.C., Tattam, I.A., Volk, C., Wheaton, J.M. and Pollock, M.M., 2016. Ecosystem experiment reveals benefits of natural and simulated beaver dams to a threatened population of steelhead (Oncorhynchus mykiss). Scientific Reports, 6: 28581, DOI: $10.1038 /$ srep28581

Briggs, M.A., Lautz, L.K., Hare, D.K. and González-Pinzón, R., 2013. Relating hyporheic fluxes, residence times, and redox-sensitive biogeochemical processes upstream of beaver dams. Freshwater Science, 32(2): 622-641.

Briggs, M.A., Wang, C., Day-Lewis, F.D., Williams, K.H., Dong, W. and Lane, J.W., 2019. Return flows from beaver ponds enhance floodplain-to-river metals exchange in alluvial mountain catchments. Science of The Total Environment, 685: 357-369.

Brown, R.S., Hubert, W.A. and Daly, S.F., 2011. A Primer on Winter, Ice, and Fish: What Fisheries Biologists Should Know about Winter Ice Processes and Stream-Dwelling Fish. Fisheries, 36(1): 8-26.

Bubier, J.L., Moore, T.R. and Roulet, N.T., 1993. Methane Emissions from Wetlands in the Midboreal Region of Northern Ontario, Canada. Ecology, 74(8): 2240-2254.

Burchsted, D., Daniels, M., Thorson, R. and Vokoun, J., 2010. The River Discontinuum: Applying Beaver Modifications to Baseline Conditions for Restoration of Forested Headwaters. BioScience, 60(11): 908-922, DOI: 10.1525/bio.2010.60.11.7.

Burchsted, D. and Daniels, M.D., 2014. Classification of the alterations of beaver dams to headwater streams in northeastern Connecticut, U.S.A. Geomorphology, 205(0): 36-50, DOI: http://dx.doi.org/10.1016/j.geomorph.2012.12.029.

Burns, D.A. and McDonnell, J.J., 1998. Effects of a beaver pond on runoff processes: comparison of two headwater catchments. Journal of Hydrology, 205(3): 248-264, DOI: http://dx.doi.org/10.1016/S0022-1694(98)00081-X.

Butler, D.R. and Malanson, G.P., 1995. Sedimentation rates and patterns in beaver ponds in a mountain environment. Geomorphology, 13(1): 255-269, DOI: http://dx.doi.org/10.1016/0169555X(95)00031-Y.

Butler, D.R. and Malanson, G.P., 2005. The geomorphic influences of beaver dams and failures of beaver dams. Geomorphology, 71(1-2): 48-60, DOI: http://dx.doi.org/10.1016/j.geomorph.2004.08.016.

Byers, J.E., Cuddington, K., Jones, C.G., Talley, T.S., Hastings, A., Lambrinos, J.G., Crooks, J.A. and Wilson, W.G., 2006. Using ecosystem engineers to restore ecological systems. Trends in Ecology \& Evolution, 21(9): 493-500.

Bylak, A., Kukuła, K. and Mitka, J., 2014. Beaver impact on stream fish life histories: the role of landscape and local attributes. Canadian Journal of Fisheries and Aquatic Sciences, 71(11): 1603-1615. 
Catalán, N., Ortega, S.H., Gröntoft, H., Hilmarsson, T., Bertilsson, S., Wu, P., Levanoni, O., Bishop, K. and Bravo, A., 2016. Effects of beaver impoundments on dissolved organic matter quality and biodegradability in boreal riverine systems. Hydrobiologia: 1-14.

Chaubey, I. and Ward, G.M., 2006. Hydrologic Budget Analysis of a Small Natural Wetland in Southeast USA Journal of Environmental Informatics, 8(1): 10-21.

Choi, C., 2008. Tierra del Fuego: the beavers must die. Nature, 453(453): 968, DOI: 10.1038/453968a.

Cirmo, C.P. and Driscoll, C.T., 1993. Beaver pond biogeochemistry: acid neutralizing capacity generation in a headwater wetland. Wetlands, 13(4): 277-292.

Cluer, B. and Thorne, C., 2014. A stream evolution model integrating habitat and ecosystem benefits. River Research and Applications, 30(2): 135-154.

Cohen, M.J., Creed, I.F., Alexander, L., Basu, N.B., Calhoun, A.J.K., Craft, C., D’Amico, E., DeKeyser, E., Fowler, L., Golden, H.E., Jawitz, J.W., Kalla, P., Kirkman, L.K., Lane, C.R., Lang, M., Leibowitz, S.G., Lewis, D.B., Marton, J., McLaughlin, D.L., Mushet, D.M., Raanan-Kiperwas, H., Rains, M.C., Smith, L. and Walls, S.C., 2016. Do geographically isolated wetlands influence landscape functions? Proceedings of the National Academy of Sciences, 113(8): 1978-1986, DOI: 10.1073/pnas.1512650113.

Coleman, R.L. and Dahm, C.N., 1990. Stream Geomorphology: Effects on Periphyton Standing Crop and Primary Production. Journal of the North American Benthological Society, 9(4): 293-302, DOI: 10.2307/1467897.

Collen, P. and Gibson, R.J., 2000. The general ecology of beavers (Castor spp.), as related to their influence on stream ecosystems and riparian habitats, and the subsequent effects on fish - a review. Reviews in Fish Biology and Fisheries, 10(4): 439-461, DOI: 10.1023/a:1012262217012.

Conner, M.M., Saunders, W.C., Bouwes, N. and Jordan, C., 2016. Evaluating impacts using a BACl design, ratios, and a Bayesian approach with a focus on restoration. Environmental Monitoring and Assessment, 188(10): 555.

Cooke, R.U. and Reeves, R.W., 1976. Arroyos and environmental change in the American South-West. Oxford research studies in geography. Clarendon Press, Oxford, 213 pp.

Corenblit, D., Baas, A.C.W., Bornette, G., Darrozes, J., Delmotte, S., Francis, R.A., Gurnell, A.M., Julien, F., Naiman, R.J. and Steiger, J., 2011. Feedbacks between geomorphology and biota controlling Earth surface processes and landforms: A review of foundation concepts and current understandings. Earth-Science Reviews, 106(3-4): 307-331, DOI: http://dx.doi.org/10.1016/j.earscirev.2011.03.002.

Corenblit, D., Tabacchi, E., Steiger, J. and Gurnell, A.M., 2007. Reciprocal interactions and adjustments between fluvial landforms and vegetation dynamics in river corridors: A review of complementary approaches. Earth-Science Reviews, 84(1-2): 56-86, DOI: http://dx.doi.org/10.1016/j.earscirev.2007.05.004.

Correll, D.L., Jordan, T.E. and Weller, D.E., 2000. Beaver pond biogeochemical effects in the Maryland Coastal Plain. Biogeochemistry, 49(3): 217-239, DOI: 10.1023/a:1006330501887.

Crego, R.D., Jiménez, J.E. and Rozzi, R., 2016. A synergistic trio of invasive mammals? Facilitative interactions among beavers, muskrats, and mink at the southern end of the Americas. Biological Invasions, 18(7): 1923-1938, DOI: 10.1007/s10530-016-1135-0.

Cunjak, R.A. and Therrien J., 1998. Inter-stage survival of wild juvenile Atlantic salmon, Salmo salar L. Fisheries Management and Ecology, 5(3): 209-223, DOI: doi:10.1046/j.13652400.1998.00094.x.

Curran, J.C. and Cannatelli, K.M., 2014. The impact of beaver dams on the morphology of a river in the eastern United States with implications for river restoration. Earth Surface Processes and Landforms, 39(9): 1236-1244, DOI: 10.1002/esp.3576.

Cutting, K.A., Ferguson, J.M., Anderson, M.L., Cook, K., Davis, S.C. and Levine, R., 2018. Linking beaver dam affected flow dynamics to upstream passage of Arctic grayling. Ecology and Evolution, 8(24): 12905-12917. 
Dahm, C.N., Trotter, E.H. and Sedell, J.R., 1987. Role of anaerobic zones and processes in stream ecosystem productivity. Chemical Quality of Water and the Hydrologic Cycle: 157-178.

Dalbeck, L., 2012. Die Rückkehr des Biber - eine Erfolgsgeschichte des Artenschutz. Zeitschrift des Koelner Zoos, 55(4): 167-180.

Dalbeck, L., Janssen, J. and Luise Völsgen, S., 2014. Beavers increase habitat availability, heterogeneity and connectivity for common frogs. Amphibia-Reptilia, 35(3): 321-329, DOI: doi:http://dx.doi.org/10.1163/15685381-00002956.

Dalbeck, L., Lüscher, B. and Ohlhoff, D., 2007. Beaver ponds as habitat of amphibian communities in a central European highland. Amphibia-Reptilia, 28(4): 493-501, DOI: doi:http://dx.doi.org/10.1163/156853807782152561.

DeAnna, L. and Wohl, E., 2019. The persistence of beaver-induced geomorphic heterogeneity and organic carbon stock in river corridors. Earth Surface Processes and Landforms, 44(1): 342-353.

de Visscher, M., Nyssen, J., Pontzeele, J., Billi, P. and Frankl, A., 2014. Spatio-temporal sedimentation patterns in beaver ponds along the Chevral river, Ardennes, Belgium. Hydrological Processes, 28(4): 1602-1615, DOI: 10.1002/hyp.9702.

Demmer, R. and Beschta, R.L., 2008. Recent History (1988-2004) of Beaver Dams along Bridge Creek in Central Oregon. Northwest Science, 82(4): 309-318, DOI: 10.3955/0029-344X-82.4.309.

Devito, K.J. and Dillon, P.J., 1993. Importance of Runoff and Winter Anoxia to the P and N Dynamics of a Beaver Pond. Canadian Journal of Fisheries and Aquatic Sciences, 50(10): 2222-2234, DOI: 10.1139/f93-248.

Dillon, P.J., Molot, L.A. and Scheider, W.A., 1991. Phosphorus and Nitrogen Export from Forested Stream Catchments in Central Ontario. Journal of Environmental Quality, 20(4): 857-864, DOI: 10.2134/jeq1991.00472425002000040025x.

Dixon, S.J., Sear, D.A., Odoni, N.A., Sykes, T. and Lane, S.N., 2016. The effects of river restoration on catchment scale flood risk and flood hydrology. Earth Surface Processes and Landforms, 41(7): 997-1008, DOI: 10.1002/esp.3919.

Djoshkin, W.W. and Safanow, W.G., 1972. Die Biber der alten und neuen Welt, 2. KGWolf, Magdeburg, $168 \mathrm{pp}$.

Driscoll, C.T., Holsapple, J., Schofield, C.L. and Munson, R., 1998. The chemistry and transport of mercury in a small wetland in the Adirondack region of New York, USA. Biogeochemistry, 40(2): 137-146, DOI: 10.1023/a:1005989229089.

Dvořák, J., 2013. Diet preference of Eurasian Beaver (Castor Fiber L., 1758) in the environment of Oderské vrchy and its influence on the tree species composition of river bank stands. Acta Universitatis Agriculturae et Silviculturae Mendelianae Brunensis, 61: 1637-1643.

Ecke, F., Levanoni, O., Audet, J., Carlson, P., Eklöf, K., Hartman, G., McKie, B., Ledesma, J., Segersten, J., Truchy, A. and Futter, M., 2017. Meta-analysis of environmental effects of beaver in relation to artificial dams. Environmental Research Letters, 12(11): 113002.

Ehrman, T.P. and Lamberti, G.A., 1992. Hydraulic and Particulate Matter Retention in a 3rd-Order Indiana Stream. Journal of the North American Benthological Society, 11(4): 341-349.

Feng, K. and Molz, F.J., 1997. A 2-D, diffusion-based, wetland flow model. Journal of Hydrology, 196(1): 230-250, DOI: https://doi.org/10.1016/S0022-1694(96)03282-9.

Fairfax, E. and Small, E.E., 2018. Using remote sensing to assess the impact of beaver damming on riparian evapotranspiration in an arid landscape. Ecohydrology, 11(7): e1993.

Fairfax, E. and Whittle, A., Smokey the Beaver: beaver-dammed riparian corridors stay green during wildfire throughout the western USA. Ecological Applications, n/a(n/a): e2225.

Fogler, S.H., 2006. Elements of chemical reaction engineering. Prentice Hall Profesional.

Ford, T.E. and Naiman, R.J., 1988. Alteration of carbon cycling by beaver: methane evasion rates from boreal forest streams and rivers. Canadian Journal of Zoology, 66(2): 529-533, DOI: 10.1139/z88-076.

Fouty, S.C., 2018. Euro-American Beaver Trapping and Its LongTerm Impact on Drainage Network Form and Function, Water Abundance, Delivery, and System Stability, Department of Agriculture, Forest Service, Rocky Mountain Research Station, Fort Collins, CO: U.S. 
Francis, M.M., Naiman, R.J. and Melillo, J.M., 1985. Nitrogen fixation in subarctic streams influenced by beaver (Castor canadensis). Hydrobiologia, 121(3): 193-202.

Fryxell, J.M. and Doucet, C.M., 1993. Diet Choice and the Funcional Response of Beavers. Ecology, 74(5): 1298-1306.

Fuller, M.R. and Peckarsky, B.L., 2011. Does the morphology of beaver ponds alter downstream ecosystems? Hydrobiologia, 668(1): 35-48, DOI: 10.1007/s10750-011-0611-x.

Gable, T.D., Windels, S.K., Romanski, M.C. and Rosell, F., 2018. The forgotten prey of an iconic predator: a review of interactions between grey wolves Canis lupus and beavers Castor spp. Mammal Review, 48(2): 123-138.

Gibson, P.P. and Olden, J.D., 2014. Ecology, management, and conservation implications of North American beaver (Castor canadensis) in dryland streams. Aquatic Conservation: Marine and Freshwater Ecosystems, 24(3): 391-409, DOI: 10.1002/aqc.2432.

Giriat, D., Gorczyca, E. and Sobucki, M., 2016. Beaver ponds' impact on fluvial processes (Beskid Niski Mts., SE Poland). Science of The Total Environment, 544: 339-353, DOI: http://dx.doi.org/10.1016/i.scitotenv.2015.11.103.

Goldfarb, B., 2018. Eager. The surprising, secret life of beavers and why they matter., 1. Chelsea Green Publishing, Chelsea, 304 pp.

Graells, G., Corcoran, D. and Aravena, J.C., 2015. Invasion of North American beaver (Castor canadensis) in the province of Magallanes, Southern Chile: comparison between dating sites through interviews with the local community and dendrochronology. Revista Chilena de Historia Natural, 88(1): 3, DOI: 10.1186/s40693-015-0034-6.

Green, K.C. and Westbrook, C.J., 2009. Changes in riparian area structure, channel hydraulics, and sediment yield following loss of beaver dams. 2009.

Grover, A.M. and Baldassarre, G.A., 1995. Bird species richness within beaver ponds in south-central New York. Wetlands, 15(2): 108-118.

Grygoruk, M. and Nowak, M., 2014. Spatial and Temporal Variability of Channel Retention in a Lowland Temperate Forest Stream Settled by European Beaver (Castor fiber). Forests, 5(9): 2276-2288.

Gurnell, A.M., 1998. The hydrogeomorphological effects of beaver dam-building activity. Progress in Physical Geography, 22(2): 167-189, DOI: 10.1177/030913339802200202.

Haarberg, O. and Rosell, F., 2006. Selective foraging on woody plant species by the Eurasian beaver (Castor fiber) in Telemark, Norway. Journal of Zoology, 270(2): 201-208.

Hanson, W.D. and Campbell, R.S., 1963. The Effects of Pool Size and Beaver Activity on Distribution and Abundance of Warm-water Fishes in a North Missouri Stream. The American Midland Naturalist, 69(1): 136-149, DOI: 10.2307/2422849.

Hägglund, Å. and Sjöberg, G., 1999. Effects of beaver dams on the fish fauna of forest streams. Forest Ecology and Management, 115(2): 259-266.

Halley, D., Rosell, F. and Saveljev, A., 2012. Population and Distribution of Eurasian Beaver (Castor fiber). Baltic Forestry, 18(1): 168-175.

Halley, D.J. and Rosell, F., 2002. The beaver's reconquest of Eurasia: status, population development and management of a conservation success. Mammal Review, 32(3): 153-178.

Hanson, W.D. and Campbell, R.S., 1963. The Effects of Pool Size and Beaver Activity on Distribution and Abundance of Warm-water Fishes in a North Missouri Stream. The American Midland Naturalist, 69(1): 136-149.

Härkönen, S., 1999. Forest damage caused by the Canadian beaver (Castor canadensis) in South Savo, Finland. Silva Fennica 33(4): 648.

Harthun, M., 1998. Biber als Landschaftsgestalter. Einfluss des Bibers auf die Lebensgemeinschaft von Mittelgebirgsbächen. Maecenata Verlag, Muenchen, $199 \mathrm{pp}$.

Harthun, M., 2000. Einflüsse der Stauaktivität des Bibers (Castor fiber albicus) auf physikalische und chemische Parameter von Mittelgebirgs-Bächen (Hessen, Deutschland). Limnologica - Ecology and Management of Inland Waters, 30(1): 21-35, DOI: https://doi.org/10.1016/S00759511(00)80037-7. 
Hartman, G., 1994. Long-Term Population Development of a Reintroduced Beaver (Castor fiber) Population in Sweden. Conservation Biology, 8(3): 713-717.

Hartman, G., 1996. Habitat selection by European beaver (Castor fiber) colonizing a boreal landscape. Journal of Zoology, 240(2): 317-325.

Hartman, G. and Axelsson, A., 2004. Effect of watercourse characteristics on food-caching behaviour by European beaver, Castor fiber. Animal Behaviour, 67(4): 643-646.

Hartmann, G. and Törnlöv, S., 2006. Influence of watercourse depth and width on dam-building behaviour by Euasian beaver (Castor fiber). Journal of Zoology, 268: 127-131.

Hay, K.G., 2010. Succession of Beaver Ponds in Colorado 50 Years After Beaver Removal. The Journal of Wildlife Management, 74(8): 1732-1736.

Hester, E.T. and Doyle, M.W., 2008. In-stream geomorphic structures as drivers of hyporheic exchange. Water Resources Research, 44(3): n/a-n/a, DOI: 10.1029/2006WR005810.

Hill, A.R. and Duval, T.P., 2009. Beaver dams along an agricultural stream in southern Ontario, Canada: their impact on riparian zone hydrology and nitrogen chemistry. Hydrological Processes, 23(9): 1324-1336, DOI: 10.1002/hyp.7249.

Hillman, G.R., 1998. Flood wave attenuation by a wetland following a beaver dam failure on a second order boreal stream. Wetlands, 18(1): 21-34, DOI: 10.1007/bf03161439.

Hillman, G.R., Feng, J.C., Feng, C.C. and Wang, Y., 2004. Effects of catchment characteristics and disturbances on storage and export of dissolved organic carbon in a boreal headwater stream. Canadian Journal of Fisheries and Aquatic Sciences, 61(8): 1447-1460, DOI: 10.1139/f04-082.

Hinze, G., 1950. Der Biber. Koerperbau und Lebensweise, Verbreitung und Geschichte. Akademie Verlag, Berlin, $216 \mathrm{pp}$.

Hodkinson, I.D., 1975. Energy flow and organic matter decomposition in an abandoned beaver pond ecosystem. Oecologia, 21(2): 131-139.

Holgerson, M.A. and Raymond, P.A., 2016. Large contribution to inland water $\mathrm{CO} 2$ and $\mathrm{CH} 4$ emissions from very small ponds. Nature Geosci, 9(3): 222-226, DOI: 10.1038/ngeo2654

Hood, G.A. and Bayley, S.E., 2008a. Beaver (Castor canadensis) mitigate the effects of climate on the area of open water in boreal wetlands in western Canada. Biological Conservation, 141(2): 556567, DOI: http://dx.doi.org/10.1016/j.biocon.2007.12.003.

Hood, G.A. and Bayley, S.E., 2008b. The effects of high ungulate densities on foraging choices by beaver (Castor canadensis) in the mixed-wood boreal forest. Canadian Journal of Zoology, 86(6): 484496.

Hood, G.A. and Larson, D.G., 2014. Beaver-Created Habitat Heterogeneity Influences Aquatic Invertebrate Assemblages in Boreal Canada. Wetlands, 34(1): 19-29, DOI: 10.1007/s13157013-0476-z.

Hood, G.A. and Larson, D.G., 2015. Ecological engineering and aquatic connectivity: a new perspective from beaver-modified wetlands. Freshwater Biology, 60(1): 198-208, DOI: 10.1111/fwb.12487.

Hossack, B.R., Gould, W.R., Patla, D.A., Muths, E., Daley, R., Legg, K. and Corn, P.S., 2015. Trends in Rocky Mountain amphibians and the role of beaver as a keystone species. Biological Conservation, 187: 260-269, DOI: http://dx.doi.org/10.1016/j.biocon.2015.05.005.

Hyvönen, T. and Nummi, P., 2008. Habitat dynamics of beaver at two spatial scales. Wildlife Biology, 14(3): 302-308, 7.

Ives, R.L., 1942. The Beaver-Meadow Complex. Journal of Geomorphology, 5: 191-203.

Jakob, M., Clague, J.J. and Church, M., 2016. Rare and dangerous: Recognizing extra-ordinary events in stream channels. Canadian Water Resources Journal / Revue canadienne des ressources hydriques, 41(1-2): 161-173, DOI: 10.1080/07011784.2015.1028451.

James, C.D. and Lanman, R.B., 2012. Novel physical evidence that beaver historically were native to the Sierra Nevada. California Fish and Game, 98(2): 129-132.

Janiszewski, P., Strychalski, J. and Sz, K., 2017. The preferences of the european beaver castor fiber for trees and shrubs in riparian zones. Applied Ecology and Environmental Research, 15: 313-327.

Jenkins, S.H., 1975. Food selection by beavers. Oecologia, 21(2): 157-173. 
Jenkins, S.H., 1980. A Size-Distance Relation in Food Selection by Beavers. Ecology, 61(4): 740-746.

Jin, L., Siegel, D.I., Lautz, L.K. and Otz, M.H., 2009. Transient storage and downstream solute transport in nested stream reaches affected by beaver dams. Hydrological Processes, 23(17): 2438-2449, DOI: 10.1002/hyp.7359.

John, S. and Klein, A., 2004. Hydrogeomorphic effects of beaver dams on floodplain morphology: avulsion processes and sediment fluxes in upland valley floors (Spessart, Germany) [ Les effets hydro-géomorphologiques des barrages de castors sur la morphologie de la plaine alluviale : processus d'avulsions et flux sédimentaires des vallées intra-montagnardes (Spessart, Allemagne).]. Quaternaire: 219-231.

Johnston, C. and Naiman, R., 1990a. The use of a geographic information system to analyze long-term landscape alteration by beaver. Landscape Ecology, 4(1): 5-19, DOI: 10.1007/bf02573947.

Johnston, C.A., 2001. Wetland Soil and Landscape Alteration by Beavers. In: J.L. Richardson and M.J. Vepraskas (Editors), Wetland Soils. Genesis, Hydrology, Landscapes and Classification. CRC Press LLC, Boca Raton, FL, pp. 391-408.

Johnston, C.A., 2014. Beaver pond effects on carbon storage in soils. Geoderma, 213(0): 371-378, DOI: http://dx.doi.org/10.1016/j.geoderma.2013.08.025.

Johnston, C.A., 2015. Fate of 150 Year Old Beaver Ponds in the Laurentian Great Lakes Region. Wetlands, 35(5): 1013-1019.

Johnston, C.A., 2017. Beavers: Boreal Ecosystem Engineers. Springer International, Cham, 272 pp.

Johnston, C.A. and Naiman, R.J., 1990b. Aquatic Patch Creation in Relation to Beaver Population Trends. Ecology, 71(4): 1617-1621.

Johnson-Bice, S.M., Renik, K.M., Windels, S.K. and Hafs, A.W., 2018. A Review of Beaver-Salmonid Relationships and History of Management Actions in the Western Great Lakes (USA) Region. North American Journal of Fisheries Management, 38(6): 1203-1225.

Jones, C.G., Lawton, J.H. and Shachak, M., 1996. Organisms as Ecosystem Engineers, Ecosystem Management: Selected Readings. Springer New York, New York, NY, pp. 130-147.

Jones, K., Gilvear, D., Willby, N. and Gaywood, M., 2009. Willow (Salix spp.) and aspen (Populus tremula) regrowth after felling by the Eurasian beaver (Castor fiber): implications for riparian woodland conservation in Scotland. Aquatic Conservation: Marine and Freshwater Ecosystems, 19(1): 75-87.

Joyce M. Reddoch, A.H.R., 2005. Consequences of Beaver, Castor canadensis, Flooding on a Small Shore Fen in Southwestern Quebec. The Canadian Field-Naturalist, 119(3).

Junk, W.J., Bayley, P.B. and Sparks, R.E., 1989. The flood pulse concept in River-Floodplain Systems. In: D.P. Dodge (Editor), Proceedings of the International Large River Symposium. Can. Spec. Publ. Fish. Aquat. Sci.

Kauffman, M.J., Brodie, J.F. and Jules, E.S., 2010. Are wolves saving Yellowstone's aspen? A landscape-level test of a behaviorally mediated trophic cascade. Ecology, 91(9): 2742-2755.

Kalinin, A., Covino, T. and McGlynn, B., 2016. The influence of an in-network lake on the timing, form, and magnitude of downstream dissolved organic carbon and nutrient flux. Water Resources Research, 52(11): 8668-8684, DOI: 10.1002/2016WR019378.

Karran, D.J., Westbrook, C.J. and Bedard-Haughn, A., 2018. Beaver-mediated water table dynamics in a Rocky Mountain fen. Ecohydrology, 11(2): e1923.

Kemp, P.S., Worthington, T.A., Langford, T.E.L., Tree, A.R.J. and Gaywood, M.J., 2012. Qualitative and quantitative effects of reintroduced beavers on stream fish. Fish and Fisheries, 13(2): 158-181.

Kivinen, S., Nummi, P. and Kumpula, T., 2020. Beaver-induced spatiotemporal patch dynamics affect landscape-level environmental heterogeneity. Environmental Research Letters, 15(9): 094065.

Kling, G.W., Kipphut, G.W., Miller, M.M. and O'Brien, W.J., 2000. Integration of lakes and streams in a landscape perspective: the importance of material processing on spatial patterns and temporal coherence. Freshwater Biology, 43(3): 477-497, DOI: 10.1046/j.13652427.2000.00515.x. 
Klotz, R.L., 1998. Influence of beaver ponds on the phosphorus concentration of stream water. Canadian Journal of Fisheries and Aquatic Sciences, 55(5): 1228-1235, DOI: 10.1139/f97-318.

Klotz, R.L., 2010. Reduction of High Nitrate Concentrations in a Central New York State Stream Impounded by Beaver. Northeastern Naturalist, 17(3): 349-356.

Koschorreck, M., Herzsprung, P., Brands, E., Kirch, P.M. and Dalbeck, L., 2016. Minor effect of beaver dams on stream dissolved organic carbon in the catchment of a German drinking water reservoir. Limnologica - Ecology and Management of Inland Waters, 61: 36-43, DOI: https://doi.org/10.1016/j.limno.2016.09.005.

Kothawala, D.N., Evans, R.D. and Dillon, P.J., 2006. Changes in the molecular weight distribution of dissolved organic carbon within a Precambrian shield stream. Water Resources Research, 42(5): n/a-n/a, DOI: 10.1029/2005WR004441.

Kukuła, K. and Bylak, A., 2010. Ichthyofauna of a mountain stream dammed by beaver. Archives of Polish Fisheries, 18(1): 33 - 43.

Kramer, N., Wohl, E.E. and Harry, D.L., 2012. Using ground penetrating radar to 'unearth' buried beaver dams. Geology, 40(1): 43-46, DOI: 10.1130/g32682.1.

Kreutzweiser, D.P., Good, K.P. and Sutton, T.M., 2005. Large woody debris characteristics and contributions to pool formation in forest streams of the Boreal Shield. Canadian Journal of Forest Research, 35(5): 1213-1223.

Kroes, D.E. and Bason, C.W., 2015. Sediment-Trapping by Beaver Ponds in Streams of the Mid-Atlantic Piedmont and Coastal Plain, USA. Southeastern Naturalist, 14(3): 577-595, DOI: 10.1656/058.014.0309.

Laland, K.N. and Boogert, N.J., 2010. Niche construction, co-evolution and biodiversity. Ecological Economics, 69(4): 731-736, DOI: http://dx.doi.org/10.1016/j.ecolecon.2008.11.014.

Lane, S.N., 2017. Natural flood management. Wiley Interdisciplinary Reviews: Water, 4(3): e1211-n/a, DOI: 10.1002/wat2.1211.

Lautz, L.K., Siegel, D.I. and Bauer, R.L., 2006. Impact of debris dams on hyporheic interaction along a semi-arid stream. Hydrological Processes, 20(1): 183-196, DOI: 10.1002/hyp.5910.

Law, A., Gaywood, M.J., Jones, K.C., Ramsay, P. and Willby, N.J., 2017. Using ecosystem engineers as tools in habitat restoration and rewilding: beaver and wetlands. Science of The Total Environment, 605-606(Supplement C): 1021-1030.

Law, A., McLean, F. and Willby, N.J., 2016. Habitat engineering by beaver benefits aquatic biodiversity and ecosystem processes in agricultural streams. Freshwater Biology, 61(4): 486-499, DOI: 10.1111/fwb.12721.

Lazar, J.G., Addy, K., Gold, A.J., Groffman, P.M., McKinney, R.A. and Kellogg, D.Q., 2015. Beaver Ponds: Resurgent Nitrogen Sinks for Rural Watersheds in the Northeastern United States. Journal of Environmental Quality, 44(5): 1684-1693, DOI: 10.2134/jeq2014.12.0540.

Leidholt-Bruner, K., Hibbs, D. and Mccomb, W., 1992. Beaver Dam Locations and Their Effects on Distribution and Abundance of Coho Salmon Fry in Two Coastal Oregon Streams.

Lesica, P. and Miles, S., 2004. Beavers indirectly enhance the growth of Russian Olive and Tamarisk along eastern Montana rivers. Western North American Naturalist, 64(1): 93-100.

Levanoni, O., Bishop, K., McKie, B.G., Hartman, G., Eklöf, K. and Ecke, F., 2015. Impact of Beaver Pond Colonization History on Methylmercury Concentrations in Surface Water. Environmental Science \& Technology, 49(21): 12679-12687, DOI: 10.1021/acs.est.5b03146.

Levine, R. and Meyer, G.A., 2014. Beaver dams and channel sediment dynamics on Odell Creek, Centennial Valley, Montana, USA. Geomorphology, 205(0): 51-64, DOI: http://dx.doi.org/10.1016/i.geomorph.2013.04.035.

Levine, R. and Meyer, G.A., 2019. Beaver-generated disturbance extends beyond active dam sites to enhance stream morphodynamics and riparian plant recruitment. Scientific Reports, 9(1): 8124.

Little, A.M., Guntenspergen, G.R. and Allen, T.F.H., 2012. Wetland vegetation dynamics in response to beaver (Castor canadensis) activity at multiple scales. Écoscience, 19(3): 246-257, DOI: 10.2980/19-3-3498. 
Logofet, D.O., Evstigneev, O.I., Aleinikov, A.A. and Morozova, A.O., 2016. Succession caused by beaver (Castor fiber L.) life activity: II. a refined markov model. Biology Bulletin Reviews, 6(1): 39-56.

Lokteff, R.L., Roper, B.B. and Wheaton, J.M., 2013. Do Beaver Dams Impede the Movement of Trout? Transactions of the American Fisheries Society, 142(4): 1114-1125.

Lowry, M.M., 1993. Groundwater elevations and temperature adjacent to a beaver pond in central Oregon. Masters Thesis.

Macdonald, D.W., Tattersall, F.H., Brown, E.D. and Balharry, D., 1995. Reintroducing the European beaver to Britain: nostalgic meddling or restoring biodiversity? Mammal Rev, 25, DOI: 10.1111/j.1365-2907.1995.tb00443.x.

Macfarlane, W.W., Wheaton, J.M., Bouwes, N., Jensen, M.L., Gilbert, J.T., Hough-Snee, N. and Shivik, J.A., 2017. Modeling the capacity of riverscapes to support beaver dams. Geomorphology, DOI: http://dx.doi.org/10.1016/i.geomorph.2015.11.019.

Majerova, M., Neilson, B.T. and Roper, B.B., 2020. Beaver dam influences on streamflow hydraulic properties and thermal regimes. Science of The Total Environment, 718: 134853.

Majerova, M., Neilson, B.T., Schmadel, N.M., Wheaton, J.M. and Snow, C.J., 2015. Impacts of beaver dams on hydrologic and temperature regimes in a mountain stream. Hydrol. Earth Syst. Sci., 19(8): 3541-3556, DOI: 10.5194/hess-19-3541-2015.

Malison, R.L., Lorang, M.S., Whited, D.C. and Stanford, J.A., 2014. Beavers (Castor canadensis) influence habitat for juvenile salmon in a large Alaskan river floodplain. Freshwater Biology, 59(6): 1229-1246, DOI: 10.1111/fwb.12343.

Mann, C.J. and Wetzel, R.G., 1995. Dissolved organic carbon and its utilization in a riverine wetland ecosystem. Biogeochemistry, 31(2): 99-120, DOI: 10.1007/bf00000941.

Mann, C.J. and Wetzel, R.G., 2000. Hydrology of an impounded lotic wetland-wetland sediment characteristics. Wetlands, 20(1): 23-32, DOI: 10.1672/02775212(2000)020[0023:HOAILW]2.0.CO;2.

Maret, T.J., Parker, M. and Fannin, T.E., 1987. The effect of beaver ponds on the nonpoint source water quality of a stream in Southwestern Wyoming. Water Research, 21(3): 263-268, DOI: http://dx.doi.org/10.1016/0043-1354(87)90204-1.

Margolis, B.E., Castro, M.S. and Raesly, R.L., 2001. The impact of beaver impoundments on the water chemistry of two Appalachian streams. Canadian Journal of Fisheries and Aquatic Sciences, 58(11): 2271-2283.

Margolis, B.E., Raesly, R.L. and Shumway, D.L., 2001. The effects of beaver-created wetlands on the benthic macroinvertebrate assemblages of two appalachian streams. Wetlands, 21(4): 554, DOI: 10.1672/0277-5212(2001)021[0554:teobcw]2.0.co;2.

Marshall, K.N., Hobbs, N.T. and Cooper, D.J., 2013. Stream hydrology limits recovery of riparian ecosystems after wolf reintroduction. Proceedings of the Royal Society B: Biological Sciences, 280(1756), DOI: 10.1098/rspb.2012.2977.

Marshall, K.N., Cooper, D.J. and Hobbs, N.T., 2014. Interactions among herbivory, climate, topography and plant age shape riparian willow dynamics in northern Yellowstone National Park, USA. Journal of Ecology, 102(3): 667-677.

Martell, K.A., Foote, A.L. and Cumming, S.G., 2006. Riparian disturbance due to beavers (Castor canadensis) in Alberta's boreal mixedwood forests: Implications for forest management. Écoscience, 13(2): 164-171, DOI: 10.2980/i1195-6860-13-2-164.1.

Martínez Pastur, G., Lencinas, M.V., Escobar, J., Quiroga, P., Malmierca, L. and Lizarralde, M., 2006. Understorey succession in Nothofagus forests in Tierra del Fuego (Argentina) affected by Castor canadensis. Appl Veg Sci, 9, DOI: 10.1658/1402-2001(2006)9[143:usinfi]2.0.co;2.

McCaffery, M. and Eby, L., 2016. Beaver activity increases aquatic subsidies to terrestrial consumers. Freshwater Biology, 61(4): 518-532, DOI: 10.1111/fwb.12725.

McDowell, D.M. and Naiman, R.J., 1986. Structure and function of a benthic invertebrate stream community as influenced by beaver (Castor canadensis). Oecologia, 68(4): 481-489, DOI: $10.1007 /$ bf00378759. 
McGinley, M.A. and Whitham, T.G., 1985. Central place foraging by beavers (Castor canadensis): a test of foraging predictions and the impact of selective feeding on the growth form of cottonwoods (Populus fremontii). Oecologia, 66(4): 558-562.

McHale, M.R., Cirmo, C.P., Mitchell, M.J. and McDonnell, J.J., 2004. Wetland nitrogen dynamics in an Adirondack forested watershed. Hydrological Processes, 18(10): 1853-1870.

McMaster, R.T. and McMaster, N.D., 2001. Composition, structure, and dynamics of vegetation in fiftenn beaver-impacted wetlands in western Massachusetts. . Rhodora, 103(915): 293-320.

McMenamin, S.K., Hadly, E.A. and Wright, C.K., 2008. Climatic change and wetland desiccation cause amphibian decline in Yellowstone National Park. Proceedings of the National Academy of Sciences, 105(44): 16988-16993, DOI: 10.1073/pnas.0809090105.

McRae, G. and Edwards, C.J., 1994. Thermal Characteristics of Wisconsin Headwater Streams Occupied by Beaver: Implications for Brook Trout Habitat. Transactions of the American Fisheries Society, 123(4): 641-656.

Meentemeyer, R.K. and Butler, D.R., 1999. Hydrogeomorphic effects of beaver dams in Glacier National Park, Montana. Physical Geography, 20(5): 436-446, DOI: 10.1080/02723646.1999.10642688.

Meyer, G.A., Wells, S.G., Balling Jr, R.C. and Jull, A.J.T., 1992. Response of alluvial systems to fire and climate change in Yellowstone National Park. Nature, 357: 147, DOI: 10.1038/357147a0.

Meyer, G.A., Wells, S.G. and Timothy Jull, A.J., 1995. Fire and alluvial chronology in Yellowstone National Park: Climatic and intrinsic controls on Holocene geomorphic processes. GSA Bulletin, 107(10): 1211-1230, DOI: 10.1130/0016-7606(1995)107.

Middleton, A.D., Kauffman, M.J., McWhirter, D.E., Jimenez, M.D., Cook, R.C., Cook, J.G., Albeke, S.E., Sawyer, H. and White, P.J., 2013. Linking anti-predator behaviour to prey demography reveals limited risk effects of an actively hunting large carnivore. Ecology Letters, 16(8): 10231030.

Mika, S., Hoyle, J. and Kyle, G., 2010. Inside the 'Black Box' of River Restoration: Using Catchment History to Identify Disturbance and Response Mechanisms to Set Targets for Process-Based Restoration. Ecology and Society, 15.

Mills, L.S., Soul, xe, E., M. and Doak, D.F., 1993. The Keystone-Species Concept in Ecology and Conservation. BioScience, 43(4): 219-224, DOI: 10.2307/1312122.

Mitchell, C.C. and Niering, W.A., 1993. Vegetation Change in a Topogenic Bog Following Beaver Flooding. Bulletin of the Torrey Botanical Club, 120(2): 136-147, DOI: 10.2307/2996943.

Mitchell, S.C. and Cunjak, R.A., 2007. Stream flow, salmon and beaver dams: roles in the structuring of stream fish communities within an anadromous salmon dominated stream. Journal of Animal Ecology, 76(6): 1062-1074, DOI: doi:10.1111/j.1365-2656.2007.01286.x.

Moen, R., Pastor, J. and Cohen, Y., 1990. Effects of beaver and moose on the vegetation of Isle Royale National Park. Alces, 26: 51-63.

Moore, P.D., 1988. The dam busters. Nature, 334(6180): 295-295.

Morgan, L.H., 1868. The American Beaver and his works. J.B. Lippincott \& Co., Philadelphia, USA.

Morrison, A., Westbrook, C.J. and Bedard-Haughn, A., 2015. Distribution of Canadian Rocky Mountain Wetlands Impacted by Beaver. Wetlands, 35(1): 95-104, DOI: 10.1007/s13157-014-0595-1.

Mortenson, S.G., Weisberg, P.J. and Ralston, B.E., 2008. Do beavers promote the invasion of non-native Tamarix in the Grand Canyon riparian zone? Wetlands, 28(3): 666-675, DOI: 10.1672/07-142.1.

Muller, G. and Watling, J., 2016. The engineering in beaver dams, River Flow 2016, St Louis.

Müller-Schwarze, D., 2011. The Beaver. Its Life and Impact. Cornell University Press, Ithaka, NY.

Muskopf, S., 2007. The effect of beaver (castor canadensis) dam removal on total phosphorus concetration in Taylor Creek and wetland, south Lake Tahoe, California, Humboldt State University, Arcata, CA 95521, 27 pp.

Naiman, R.J., 1982. Characteristics of Sediment and Organic Carbon Export from Pristine Boreal Forest Watersheds. Canadian Journal of Fisheries and Aquatic Sciences, 39(12): 1699-1718, DOI: 10.1139/f82-226. 
Naiman, R.J., Johnston, C.A. and Kelley, J.C., 1988. Alteration of North American Streams by Beaver. BioScience, 38(11): 753-762, DOI: 10.2307/1310784.

Naiman, R.J. and Melillo, J.M., 1984. Nitrogen budget of a subarctic stream altered by beaver (Castor canadensis). Oecologia, 62(2): 150-155, DOI: 10.1007/bf00379007.

Naiman, R.J., Melillo, J.M. and Hobbie, J.E., 1986. Ecosystem Alteation of Boreal Forest Streams by Beaver (Castor Canadensis). Ecology, 67(5): 1254-1269, DOI: 10.2307/1938681.

Naiman, R.J., Pinay, G., Johnston, C.A. and Pastor, J., 1994. Beaver Influences on the Long-Term Biogeochemical Characteristics of Boreal Forest Drainage Networks. Ecology, 75(4): 905-921, DOI: $10.2307 / 1939415$.

Naiman, R.J. and Rogers, K.H., 1997. Large Animals and System-Level Characteristics in River Corridors. BioScience, 47(8): 521-529.

Nash, J., 1957. The form of the instantaneous unit hydrograph. International Association of Scientific Hydrology, Publ, 3: 114-121.

Neumayer, M., Teschemacher, S., Schloemer, S., Zahner, V. and Rieger, W., 2020. Hydraulic Modeling of Beaver Dams and Evaluation of Their Impacts on Flood Events. Water, 12(1): 300.

Nickelson, T.E., Rodgers, J.D., Johnson, S.L. and Solazzi, M.F., 1992. Seasonal Changes in Habitat Use by Juvenile Coho Salmon (Oncorhynchus kisutch) in Oregon Coastal Streams. Canadian Journal of Fisheries and Aquatic Sciences, 49(4): 783-789, DOI: 10.1139/f92-088.

Nisbet, E.G., 1989. Some northern sources of atmospheric methane: production, history, and future implications. Canadian Journal of Earth Sciences, 26(8): 1603-1611, DOI: 10.1139/e89-136.

Nolet, B.A., Hoekstra, A. and Ottenheim, M.M., 1994. Selective foraging on woody species by the beaver Castor fiber, and its impact on a riparian willow forest. Biological Conservation, 70(2): 117-128.

Nowinski, J.D., Cardenas, M.B. and Lightbody, A.F., 2011. Evolution of hydraulic conductivity in the floodplain of a meandering river due to hyporheic transport of fine materials. Geophysical Research Letters, 38(1): n/a-n/a, DOI: 10.1029/2010GL045819.

Nummi, P., 1989. Simulated effects of the beaver on vegetation, invertebrates and ducks. Annales Zoologici Fennici, 26(1): 43-52.

Nummi, P. and Kuuluvainen, T., 2013. Forest disturbance by an ecosystem engineer: beaver in boreal forest landscapes.

Nummi, P. and Holopainen, S., 2014. Whole-community facilitation by beaver: ecosystem engineer increases waterbird diversity. Aquatic Conservation: Marine and Freshwater Ecosystems, 24(5): 623-633, DOI: 10.1002/aqc.2437.

Nummi, P., Vehkaoja, M., Pumpanen, J. and Ojala, A., 2018. Beavers affect carbon biogeochemistry: both short-term and long-term processes are involved. Mammal Review, 48(4): 298-311.

Nyssen, J., Pontzeele, J. and Billi, P., 2011. Effect of beaver dams on the hydrology of small mountain streams: Example from the Chevral in the Ourthe Orientale basin, Ardennes, Belgium. Journal of Hydrology, 402(1-2): 92-102, DOI: http://dx.doi.org/10.1016/j.jhydrol.2011.03.008.

Palmer, M.A., Bernhardt, E.S., Allan, J.D., Lake, P.S., Alexander, G., Brooks, S., Carr, J., Clayton, S., Dahm, C.N., Follstad Shah, J., Galat, D.L., Loss, S.G., Goodwin, P., Hart, D.D., Hassett, B., Jenkinson, R., Kondolf, G.M., Lave, R., Meyer, J.L., O'Donnell, T.K., Pagano, L. and Sudduth, E., 2005. Standards for ecologically successful river restoration. Journal of Applied Ecology, 42(2): 208217, DOI: 10.1111/j.1365-2664.2005.01004.x.

Parker, H., Nummi, P., Hartman, G. and Rosell, F., 2012. Invasive North American beaver in Eurasia: a review of potential consequences and a strategy for eradication. Wildlife Biology, 18(4): 354$365,12$.

Parker, J.D., Caudill, C.C. and Hay, M.E., 2007. Beaver herbivory on aquatic plants. Oecologia, 151(4): 616-625.

Pastor, J. and Naiman, R.J., 1992. Selective Foraging and Ecosystem Processes in Boreal Forests. The American Naturalist, 139(4): 690-705.

Pastor, J., Naiman, R.J., Dewey, B. and McInnes, P., 1988. Moose, Microbes, and the Boreal Forest. BioScience, 38(11): 770-777. 
Persico, L. and Meyer, G., 2009. Holocene beaver damming, fluvial geomorphology, and climate in Yellowstone National Park, Wyoming. Quaternary Research, 71(3): 340-353, DOI: http://dx.doi.org/10.1016/j.yqres.2008.09.007.

Persico, L. and Meyer, G., 2013. Natural and historical variability in fluvial processes, beaver activity, and climate in the Greater Yellowstone Ecosystem. Earth Surface Processes and Landforms, 38(7): 728-750, DOI: 10.1002/esp.3349.

Pinkowski, B., 1983. Foraging Behavior of Beavers (Castor canadensis) in North Dakota. Journal of Mammalogy, 64(2): 312-314.

Pinto, B.P., Santos, M.J.S. and Rosell, F.R., 2009. Habitat selection of the Eurasian beaver (Castor fiber) near its carrying capacity: an example from Norway. Canadian Journal of Zoology, 87(4): 317-325.

Pietrek, A.G. and González-Roglich, M., 2015. Post-establishment changes in habitat selection by an invasive species: beavers in the Patagonian steppe. Biological Invasions, 17(11): 3225-3235, DOI: 10.1007/s10530-015-0948-6.

Pollock, M., Naiman, R., Erickson, H., Johnston, C., Pastoro, J. and Pinay, G., 1995. Beaver as Engineers: Influences on Biotic and Abiotic Characteristics of Drainage Basins, pp. 117-126.

Pollock, M.M., Beechie, T.J. and Jordan, C.E., 2007. Geomorphic changes upstream of beaver dams in Bridge Creek, an incised stream channel in the interior Columbia River basin, eastern Oregon. Earth Surface Processes and Landforms, 32(8): 1174-1185, DOI: 10.1002/esp.1553.

Pollock, M.M., Beechie, T.J., Wheaton, J.M., Jordan, C.E., Bouwes, N., Weber, N. and Volk, C., 2014. Using Beaver Dams to Restore Incised Stream Ecosystems. BioScience, 64(4): 279-290, DOI: 10.1093/biosci/biu036.

Pollock, M.M., Heim, M. and Werner, D., 2003. Hydrologic and geomorphic effects of beaver dams and their influence on fishes, American Fisheries Society Symposium, pp. 213-233.

Polvi, L.E. and Wohl, E., 2012. The beaver meadow complex revisited - the role of beavers in postglacial floodplain development. Earth Surface Processes and Landforms, 37(3): 332-346, DOI: 10.1002/esp.2261.

Polvi, L.E. and Wohl, E., 2013. Biotic Drivers of Stream Planform: Implications for Understanding the Past and Restoring the Future. BioScience, 63(6): 439-452, DOI: 10.1525/bio.2013.63.6.6.

Powers, P.D., Helstab, M. and Niezgoda, S.L., 2019. A process-based approach to restoring depositional river valleys to Stage 0 , an anastomosing channel network. River Research and Applications, 35(1): 3-13.

Puttock, A., Graham, H.A., Cunliffe, A.M., Elliott, M. and Brazier, R.E., 2017. Eurasian beaver activity increases water storage, attenuates flow and mitigates diffuse pollution from intensivelymanaged grasslands. Science of The Total Environment, 576: 430-443, DOI: https://doi.org/10.1016/j.scitotenv.2016.10.122.

Puttock, A., Graham, H. A., Carless, D., Brazier, R. E. , in press. Sediment and Nutrient Storage in a Beaver Engineered Wetland. Earth Surf. Process. Landforms, DOI: 10.1002/esp.4398.

Raffel, T.R., Smith, N., Cortright, C. and Gatz, A.J., 2009. Central Place Foraging by Beavers in a Complex Lake Habitat. The American Midland Naturalist, 162(1): 62-73, 12.

Ray, A.M., Rebertus, A.J. and Ray, H.L., 2001. Macrophyte succession in Minnesota beaver ponds. Canadian Journal of Botany, 79(4): 487-499.

Reddy, K.R. and DeLaune, R.D., 2008. Biogeochemistry of wetlands: science and applications. CRC Press, Boca Raton, FL.

Redin, A. and Sjöberg, G., 2013. Effects of beaver dams on invertebrate drift in forest streams. Sumarski List, 137: 597-607.

Regnier, P., Friedlingstein, P., Ciais, P., Mackenzie, F.T., Gruber, N., Janssens, I.A., Laruelle, G.G., Lauerwald, R., Luyssaert, S., Andersson, A.J., Arndt, S., Arnosti, C., Borges, A.V., Dale, A.W., Gallego-Sala, A., Godderis, Y., Goossens, N., Hartmann, J., Heinze, C., Ilyina, T., Joos, F., LaRowe, D.E., Leifeld, J., Meysman, F.J.R., Munhoven, G., Raymond, P.A., Spahni, R., 
Suntharalingam, P. and Thullner, M., 2013. Anthropogenic perturbation of the carbon fluxes from land to ocean. Nature Geosci, 6(8): 597-607, DOI: 10.1038/ngeo1830

Remillard, M.M., Gruendling, G.K. and D.J., B., 1987. Disturbance by Beaver (Castor canadensis Kuhl) and Increased Landscape Heterogeneity. In: M.G. Turner (Editor), Landscape Heterogeneity and Disturbance. Springer, New York, NY.

Robinson, C.T., Schweizer, P., Larsen, A., Schubert, C.J. and Siebers, A.R., 2020. Beaver effects on macroinvertebrate assemblages in two streams with contrasting morphology. Science of The Total Environment, 722: 137899.

Roden, E.E. and Edmonds, J.W., 1997. Phosphate mobilization in iron-rich anaerobic sediments: microbial $\mathrm{Fe}(\mathrm{III})$ oxide reduction versus iron-sulfide formation. Archiv fuer Hydrobiologie, 139(3): 347-378.

Rolauffs, P., Hering, D. and Lohse, S., 2001. Composition, invertebrate community and productivity of a beaver dam in comparison to other stream habitat types. Hydrobiologia, 459(1): 201-212.

Rosell, F., BozsÉR, O., Collen, P. and Parker, H., 2005. Ecological impact of beavers Castor fiber and Castor canadensis and their ability to modify ecosystems. Mammal Review, 35(3-4): 248-276, DOI: 10.1111/j.1365-2907.2005.00067.x.

Roulet, N.T., Crill, P.M., Comer, N.T., Dove, A. and Boubonniere, R.A., 1997. CO2 and CH4 flux between a boreal beaver pond and the atmosphere. Journal of Geophysical Research: Atmospheres, 102(D24): 29313-29319, DOI: 10.1029/97JD01237.

Roy, V., Amyot, M. and Carignan, R., 2009. Beaver Ponds Increase Methylmercury Concentrations in Canadian Shield Streams along Vegetation and Pond-Age Gradients. Environmental Science \& Technology, 43(15): 5605-5611, DOI: 10.1021/es901193x.

Rudemann, R. and Schoonmaker, W., 1938. Beaver-dams as geologic agents. Science, 88(2292): 523525.

Rutten, M.G., 1967. Flat-bottomed glacial valleys, braided rivers and the beaver. Geologie en Mijnbouw, 46: 356-360.

Saunders, D.L. and Kalff, J., 2001. Nitrogen retention in wetlands, lakes and rivers. Hydrobiologia, 443(1): 205-212, DOI: 10.1023/a:1017506914063.

Schloemer, S., 2014. Der Einfluss des europaeischen Bibers (Castor fiber) auf Mittelgebirgsbaeche der Nordeifel (NRW) am Beispiel der Libellenfauna (Odonata). In: A. Nietzsche (Editor), Ergebnisse der Nationalen Bibertagung, Dessau-Rosslau, pp. 25-29.

Schlosser, I.J., 1995. Dispersal, Boundary Processes, and Trophic-Level Interactions in Streams Adjacent to Beaver Ponds. Ecology, 76(3): 908-925.

Schlosser, I.J. and Kallemeyn, L.W., 2000. Spatial variation in fish assemblages across a beaverinfluenced successional landscape. Ecology, 81(5): 1371-1382.

Schumm, S.A., 2005. River Variability and Complexity. Cambridge University Press, Cambridge, 220 pp.

Severud, W.J., 2013. Seasonal Variation in Assimilated Diets of American Beavers. The American Midland Naturalist, 169(1): 30-42, 13.

Sigourney, D.B., Letcher, B.H. and Cunjak, R.A., 2006. Influence of Beaver Activity on Summer Growth and Condition of Age-2 Atlantic Salmon Parr. Transactions of the American Fisheries Society, 135(4): 1068-1075.

Silverman, N.L., Allred, B.W., Donnelly, J.P., Chapman, T.B., Maestas, J.D., Wheaton, J.M., White, J. and Naugle, D.E., 2019. Low-tech riparian and wet meadow restoration increases vegetation productivity and resilience across semiarid rangelands. Restoration Ecology, 27(2): 269-278.

Skewes, O., Gonzalez, F., Olave, R., Ávila, A., Vargas, V. and Paulsen, P., 2006a. Abundance and distribution of American beaver, Castor canadensis (Kuhl 1820), in Tierra del Fuego and Navarino islands, Chile. Eur J Wildl Res, 52, DOI: 10.1007/s10344-006-0038-2.

Skewes, O., Gonzalez, F., Olave, R., Ávila, A., Vargas, V., Paulsen, P. and König, H.E., 2006b. Abundance and distribution of American beaver, Castor canadensis (Kuhl 1820), in Tierra del Fuego and 
Navarino islands, Chile. European Journal of Wildlife Research, 52(4): 292-296, DOI: 10.1007/s10344-006-0038-2.

Smith, M.E., Driscoll, C.T., Wyskowski, B.J., Brooks, C.M. and Cosentini, C.C., 1991. Modification of stream ecosystem structure and function by beaver (Castor canadensis) in the Adirondack Mountains, New York. Canadian Journal of Zoology, 69(1): 55-61, DOI: 10.1139/z91-009.

Smith, A., Tetzlaff, D., Gelbrecht, J., Kleine, L. and Soulsby, C., 2020. Riparian wetland rehabilitation and beaver re-colonization impacts on hydrological processes and water quality in a lowland agricultural catchment. Science of The Total Environment, 699: 134302.

Smith, J.M. and Mather, M.E., 2013. Beaver dams maintain fish biodiversity by increasing habitat heterogeneity throughout a low-gradient stream network. Freshwater Biology, 58(7): 15231538.

Snodgrass, J.W., 1997. Temporal and Spatial Dynamics of Beaver-Created Patches as Influenced by Management Practices in a South-Eastern North American Landscape. Journal of Applied Ecology, 34(4): 1043-1056, DOI: 10.2307/2405293.

Snodgrass, J.W. and Meffe, G.K., 1998. Influence of beavers on stream fish assemblages: Effects of pond age and watershed position. Ecology, 79(3): 928-942.

Songster-Alpin, M.S. and Klotz, R.L., 1995. A comparison of electron transport system activity in stream and beaver pond sediments. Canadian Journal of Fisheries and Aquatic Sciences, 52(6): 13181326, DOI: 10.1139/f95-128.

Stabler, D.F., 1985. Increasing summer flow in small streams through management of riparian areas and adjacent vegetation: A synthesis. RR Johnson, CD Ziebell, DR Patton, PF Ffolliott, and RH Hamre (technical coordinators), Riparian ecosystems and their management: Reconciling conflicting uses. United States Department of Agriculture, Forest Service, General Technical Report RM-120: 206-210.

Stanley, E.H., Johnson, M.D. and Ward, A.K., 2003. Evaluating the influence of macrophytes on algal and bacterial production in multiple habitats of a freshwater wetland. Limnology and Oceanography, 48(3): 1101-1111, DOI: doi:10.4319/lo.2003.48.3.1101.

Stanley, E.H. and Ward, A.K., 1997. Inorganic Nitrogen Regimes in an Alabama Wetland. Journal of the North American Benthological Society, 16(4): 820-832, DOI: 10.2307/1468174.

Stewardson, M.J., Datry, T., Lamouroux, N., Pella, H., Thommeret, N., Valette, L. and Grant, S.B., 2016. Variation in reach-scale hydraulic conductivity of streambeds. Geomorphology, 259: 70-80, DOI: https://doi.org/10.1016/j.geomorph.2016.02.001.

Stocker, G., 1985. Biber (Castor fiber L.) in der Schweiz, Swiss Federal Institute of Forestry Research, Teufen.

Sturtevant, B.R., 1998. A model of wetland vegetation dynamics in simulated beaver impoundments. Ecological Modelling, 112(2): 195-225.

Suding, K.N., Gross, K.L. and Houseman, G.R., 2004. Alternative states and positive feedbacks in restoration ecology. Trends in Ecology \& Evolution, 19(1): 46-53, DOI: http://dx.doi.org/10.1016/j.tree.2003.10.005.

Sutfin, N.A., Wohl, E.E. and Dwire, K.A., 2016. Banking carbon: a review of organic carbon storage and physical factors influencing retention in floodplains and riparian ecosystems. Earth Surface Processes and Landforms, 41(1): 38-60.

Suzuki, N. and McComb, W.C., 1998. Habitat Classification Models for Beaver (Castor canadensis) in the Streams of the Central Oregon Coast Range. NorthWest Science, 72(2): 102-110.

Svendsen, G.E., 1980. Seasonal Change in Feeding Patterns of Beaver in Southeastern Ohio. The Journal of Wildlife Management, 44(1): 285-290.

Svenning, J.-C., Pedersen, P.B.M., Donlan, C.J., Ejrnæs, R., Faurby, S., Galetti, M., Hansen, D.M., Sandel, B., Sandom, C.J., Terborgh, J.W. and Vera, F.W.M., 2016. Science for a wilder Anthropocene: Synthesis and future directions for trophic rewilding research. Proceedings of the National Academy of Sciences, 113(4): 898-906. 
Taylor, B.R., Maclnnis, C. and Floyd, T.A., 2010. Influence of rainfall and beaver dams on upstream movement of spawning Atlantic salmon in a restored brook in Nova scotia, Canada. River Research and Applications, 26(2): 183-193, DOI: doi:10.1002/rra.1252.

Tercek, M.T., Stottlemyer, R. and Renkin, R., 2010. Bottom-Up Factors Influencing Riparian Willow Recovery in Yellowstone National Park, 70. BIOONE, 387-399, 13 pp.

Terwilliger, J. and Pastor, J., 1999. Small Mammals, Ectomycorrhizae, and Conifer Succession in Beaver Meadows. Oikos, 85(1): 83-94.

Thompson, S., Vehkaoja, M., Pellikka, J. and Nummi, P., accepted: Ecosystem services provided by beavers Castor spp. Mammal Review, $\mathrm{n} / \mathrm{a}(\mathrm{n} / \mathrm{a})$.

Thorp, J.H. and Delong, M.D., 1994. The Riverine Productivity Model: An Heuristic View of Carbon Sources and Organic Processing in Large River Ecosystems. Oikos, 70(2): 305-308, DOI: $10.2307 / 3545642$.

Triska, F.J., Jackman, A.P., Duff, J.H. and Avanzino, R.J., 2000. Subchannel flow velocity and dispersion beneath a relict beaver dam, Shingobee River, Minnesota, USA: implications for nutrient cycling. SIL Proceedings, 1922-2010, 27(1): 463-467, DOI: 10.1080/03680770.1998.11901274.

Ulevičius, A., Kisielytè, N. and Marius, J., 2011. Habitat use and selectivity by beavers (Castor fiber) in anthropogenic landscape. Ekologija, 57.

Ulloa, E.y.A., C. y Ardón, M. y Murcia, S. y Valenzuela, A., 2012. Organic matter characterization and decomposition dynamics in sub-Antarctic streams impacted by invasive beavers. Latin American Journal of Aquatic Research, 40(4): 881-892.

Vannote, R.L., Minshall, G.W., Cummins, K.W., Sedell, J.R. and Cushing, C.E., 1980. The River Continuum Concept. Canadian Journal of Fisheries and Aquatic Sciences, 37(1): 130-137, DOI: 10.1139/f80-017.

Vaux, W.G., 1968. Intragravel flow and interchange of water in a streambed. Fishery Bulletin, 66(3): $479-489$.

Vehkaoja, M., Nummi, P., Rask, M., Tulonen, T. and Arvola, L., 2015. Spatiotemporal dynamics of boreal landscapes with ecosystem engineers: beavers influence the biogeochemistry of small lakes. Biogeochemistry, 124(1): 405-415, DOI: 10.1007/s10533-015-0105-4.

Veraart, A.J., Nolet, B.A., Rosell, F. and de Vries, P.P., 2006. Simulated winter browsing may lead to induced susceptibility of willows to beavers in spring. Canadian Journal of Zoology, 84(12): 1733-1742.

Virbickas, T., Stakènas, S. and Steponènas, A., 2015. Impact of Beaver Dams on Abundance and Distribution of Anadromous Salmonids in Two Lowland Streams in Lithuania. PLoS ONE, 10(4): e0123107, DOI: 10.1371/journal.pone.0123107.

Walter, R.C. and Merritts, D.J., 2008. Natural Streams and the Legacy of Water-Powered Mills. Science, 319(5861): 299-304.

Wang, X., Shaw, E.L., Westbrook, C.J. and Bedard-Haughn, A., 2018. Beaver Dams Induce Hyporheic and Biogeochemical Changes in Riparian Areas in a Mountain Peatland. Wetlands, 38(5): 10171032.

Ward, G.M. and Chaubey, I., 2000. Diurnal variability of stage in a wetland pond in the southeastern United States. SIL Proceedings, 1922-2010, 27(3): 1703-1706, DOI: 10.1080/03680770.1998.11901532.

Ward, J.V. and Stanford, J.A., 1995. The serial discontinuity concept: Extending the model to floodplain rivers. Regulated Rivers: Research \& Management, 10(2-4): 159-168, DOI: doi:10.1002/rrr.3450100211.

Webb, R.H. and Leake, S.A., 2006. Ground-water surface-water interactions and long-term change in riverine riparian vegetation in the southwestern United States. Journal of Hydrology, 320(34): 302-323, DOI: http://dx.doi.org/10.1016/i.jhydrol.2005.07.022. 
Weber, N., Bouwes, N., Pollock, M.M., Volk, C., Wheaton, J.M., Wathen, G., Wirtz, J. and Jordan, C.E., 2017. Alteration of stream temperature by natural and artificial beaver dams. PLOS ONE, 12(5): e0176313.

Wegener, P., Covino, T. and Wohl, E., 2017. Beaver-mediated lateral hydrologic connectivity, fluvial carbon and nutrient flux, and aquatic ecosystem metabolism. Water Resources Research, 53(6): 4606-4623, DOI: doi:10.1002/2016WR019790.

Wegener, P., Covino, T. and Wohl, E., in press. Beaver-mediated lateral hydrologic connectivity, fluvial carbon and nutrient flux, and aquatic ecosystem metabolism. Water Resources Research.

Westbrook, C.J., Cooper, D.J. and Baker, B.W., 2006. Beaver dams and overbank floods influence groundwater-surface water interactions of a Rocky Mountain riparian area. Water Resources Research, 42(6), DOI: 10.1029/2005WR004560.

Westbrook, C.J., Cooper, D.J. and Baker, B.W., 2011. Beaver assisted river valley formation. River Research and Applications, 27(2): 247-256, DOI: 10.1002/rra.1359.

Westbrook, C.J., Cooper, D.J. and Butler, D.R., 2013. Beaver Hydrology and Geomorphology. In: J.F. Shroder (Editor), Treatise on Geomorphology. Ecogeomorphology. Elsevier, Amsterdam, pp. 293-306.

Westbrook, C.J., Ronnquist, A. and Bedard-Haughn, A., 2020. Hydrological functioning of a beaver dam sequence and regional dam persistence during an extreme rainstorm. Hydrological Processes, 34(18): 3726-3737.

Wetzel, R.G., 2001. Limnology. Lake and River Ecosystems., 3. Elsever Academic Press, San Diego, 1005 pp.

Weyhenmeyer, C.E., 1999. Methane emissions from beaver ponds: Rates, patterns, and transport mechanisms. Global Biogeochemical Cycles, 13(4): 1079-1090.

Wheaton, J., Bennett, S., Bouwes, N., Camp, R., Maestas, J. and Shahverdian, S., 2019. Chapter 2 Principles of Low-Tech Process-Based Restoration.

White, D.S., 1990. Biological relationships to convective flow patterns within stream beds. Hydrobiologia, 196(2): 149-158, DOI: 10.1007/bf00006106.

Whitfield, C.J., Baulch, H.M., Chun, K.P. and Westbrook, C.J., 2015. Beaver-mediated methane emission: The effects of population growth in Eurasia and the Americas. AMBIO, 44(1): 7-15, DOI: 10.1007/s13280-014-0575-y.

Willby, N.J., Law, A., Levanoni, O., Foster, G. and Ecke, F., 2018. Rewilding wetlands: beaver as agents of within-habitat heterogeneity and the responses of contrasting biota. Philosophical Transactions of the Royal Society B: Biological Sciences, 373(1761): 20170444.

Wohl, E., 2004. Disconnected Rivers. Linking rivers to landscapes. Yale University Press, New Haven \& London, $301 \mathrm{pp}$.

Wohl, E., 2005. Compromised Rivers: Understanding Historical Human Impacts on Rivers in the Context of Restoration. Ecology and Society, 10(2).

Wohl, E., Dwire, K., Sutfin, N., Polvi, L. and Bazan, R., 2012. Mechanisms of carbon storage in mountainous headwater rivers. Nat Commun, 3: 1263.

Wohl, E., 2013. Landscape-scale carbon storage associated with beaver dams. Geophysical Research Letters, 40(14): 3631-3636, DOI: 10.1002/grl.50710.

Wohl, E. and Beckman, N.D., 2014. Leaky rivers: Implications of the loss of longitudinal fluvial disconnectivity in headwater streams. Geomorphology, 205(0): 27-35, DOI: http://dx.doi.org/10.1016/j.geomorph.2011.10.022.

Wohl, E., Lane, S.N. and Wilcox, A., in review. The Science and Practice of River Restoration. Earth Surface Processes and Landforms.

Wohl, E. and Scott, D.N., 2016. Wood and sediment storage and dynamics in river corridors. Earth Surface Processes and Landforms: n/a-n/a, DOI: 10.1002/esp.3909.

Wohl, E., 2019. Saving the Dammed. Why we need beaver-modified ecosystems. Oxford University Press, Oxford, $164 \mathrm{pp}$. 
Wolf, E.C., Cooper, D.J. and Hobbs, N.T., 2007. Hydrologic regime and herbivory stabilize an alternative state in Yellowstone National Park. Ecological Applications, 17(6): 1572-1587, DOI: 10.1890/06-2042.1.

Woo, M.-k. and Waddington, J.M., 1990. Effects of Beaver Dams on Subarctic Wetland Hydrology. Arctic, 43(3): 223-230.

Wright, J.P., Jones, C.G. and Flecker, A.S., 2002. An ecosystem engineer, the beaver, increases species richness at the landscape scale. Oecologia, 132(1): 96-101, DOI: 10.1007/s00442-002-0929-1.

Wróbel, M. and Krysztofiak-Kaniewska, A., 2020. Long-term dynamics of and potential management strategies for the beaver (Castor fiber) population in Poland. The European Zoological Journal, 87(1): 116-121.

Yavitt, J.B., Lang, G.E. and Sexstone, A.J., 1990. Methane fluxes in wetland and forest soils, beaver ponds, and low-order streams of a temperate forest ecosystem. Journal of Geophysical Research: Atmospheres, 95(D13): 22463-22474, DOI: 10.1029/JD095iD13p22463.

Yavitt, J.B., Angell, L.L., Fahey, T.J., Cirmo, C.P. and Driscoll, C.T., 1992. Methane fluxes, concentrations, and production in two Adirondack beaver impoundments. Limnology and Oceanography, 37(5): 1057-1066.

Yavitt, J.B. and Fahey, T.J., 1994. Beaver impoundments in temperate forests as sources of atmospheric CO2. Geophysical Research Letters, 21(11): 995-998.

Zahner, V., 1997. Einfluss des Bibers auf gewaessernahe Waelder. Aubreitung der Population sowie Ansaetze zur Integration des Bibers in die Forstplanung und Waldbewirtschaftung in Bayern. UTZ Wissenschaft, Muenchen, 321 pp.

Zahner, V., Schmidbauer, M. and Schwab, G., 2005. Der Biber. Die Rueckkehr des Burgherren, 2. Buch und Kunstverlag Oberpfalz, Amberg, 136 pp. Zahner, V., Lorz, C. and Schloemer, S., 2018. Die Wirkung des Europäischen Bibers (Castor fiber) auf den natürlichen Wasserrückhalt an ausgewählten Fließgewässern Bayerns, Hochschule Weihenstephan-Triesdorf, Weihenstephan.

Zavyalov, N.A., 2014. Beavers (Castor fiber and Castor canadensis), the founders of Habitats and Phytophages Biology Bulletin Reviews, 4(2): 157-180.

\section{Tables}

Table 1: Beaver impact summaries on landscape and ecosystem processes

\begin{tabular}{|c|c|c|c|}
\hline Topic & Impact summary & Select references & Section \\
\hline \multicolumn{4}{|c|}{ Hydrology } \\
\hline $\begin{array}{l}\text { Water storage and } \\
\text { open water extent }\end{array}$ & $\begin{array}{l}\text { Increase in surface and } \\
\text { groundwater storage; Valley } \\
\text { geometry and flow regime } \\
\text { determine extent of open water } \\
\text { increase; Combined impacts of } \\
\text { multiple dams in a river reach } \\
\text { distinct from the sum of all } \\
\text { individual dams }\end{array}$ & $\begin{array}{l}\text { Hood and Bayley, 2008; } \\
\text { Johnston and Naiman, } \\
\text { 1990; Morrison et al., 2015; } \\
\text { Puttock et al., } 2017 \\
\text { Westbrook et al., 2006; } \\
\text { Woo and Waddington, } \\
1990\end{array}$ & $3.1,3.2$ \\
\hline $\begin{array}{l}\text { Evaporation and } \\
\text { discharge }\end{array}$ & $\begin{array}{l}\text { Evapotranspiration losses may } \\
\text { increase; discharge may decrease } \\
\text { at the annual scales, but impacts } \\
\text { on seasonal distribution unclear }\end{array}$ & $\begin{array}{l}\text { Burns and McDonnell, } \\
\text { 1998; Correll et al., 2000; } \\
\text { Fairfax and Small, 2018; } \\
\text { Woo and Waddington, } \\
1990\end{array}$ & 3.2 \\
\hline
\end{tabular}




\begin{tabular}{|c|c|c|c|}
\hline Flow regimes & $\begin{array}{l}\text { Potential attenuation of smaller } \\
\text { floods, unclear for larger floods, } \\
\text { highly context dependent (e.g. } \\
\text { floodplain diversion capacity); } \\
\text { Unclear impacts on low flows } \\
\text { (baseflow) but may increase in } \\
\text { some cases, }\end{array}$ & $\begin{array}{l}\text { Neumayer et al., 2020; } \\
\text { Nyssen et al., 2011; Puttock } \\
\text { et al., 2017; Stabler,1985 }\end{array}$ & $3.3,3.4$ \\
\hline $\begin{array}{l}\text { Groundwater-surface } \\
\text { water interactions }\end{array}$ & $\begin{array}{l}\text { Enhanced hyporheic exchange; } \\
\text { upstream of dams; Potential for } \\
\text { gaining conditions downstream of } \\
\text { dams }\end{array}$ & $\begin{array}{l}\text { Lautz et al., 2006; } \\
\text { Westbrook et al., 2006; } \\
\text { White, } 1990\end{array}$ & $3.5,3.6$ \\
\hline $\begin{array}{l}\text { Water residence } \\
\text { times }\end{array}$ & $\begin{array}{l}\text { Large increase in water residence } \\
\text { times and flow pathways }\end{array}$ & $\begin{array}{l}\text { Devito and Dillon, 1993; } \\
\text { Majerova et al., } 2015\end{array}$ & 3.7 \\
\hline Water temperature & $\begin{array}{l}\text { Overall, though variable, increase } \\
\text { in pond and downstream water } \\
\text { temperatures; Potential buffering } \\
\text { of diel temperature variation }\end{array}$ & $\begin{array}{l}\text { Avery, 2002; Majerova et } \\
\text { al., 2015; Weber et al., } \\
2017\end{array}$ & 3.8 \\
\hline \multicolumn{4}{|c|}{ Geomorphology } \\
\hline $\begin{array}{l}\text { Sediment transport } \\
\text { and deposition }\end{array}$ & $\begin{array}{l}\text { Increased short and long-term } \\
\text { sediment storage; delay in } \\
\text { downstream sediment transport; } \\
\text { increase in reach-scale sediment } \\
\text { residence times; increased } \\
\text { deposition upstream of dams as } \\
\text { sediment wedges or deltas; high } \\
\text { short-term beaver pond } \\
\text { sedimentation rates }\end{array}$ & $\begin{array}{l}\text { Butler and Malanson, 1995; } \\
\text { de Visscher et al., 2014; } \\
\text { Giriat et al., 2016; Harthun, } \\
\text { 1998; John and Klein, 2004; } \\
\text { Nyssen et al., 2011; Persico } \\
\text { and Meyer, 2009, Pollock et } \\
\text { al. 2003, Polvi and Wohl, } \\
2012\end{array}$ & 4.1 \\
\hline Erosion & $\begin{array}{l}\text { Beaver dam breaches can yield } \\
\text { high sediment transport and } \\
\text { initiate knickpoint incision; } \\
\text { Beavers can excavate floodplain } \\
\text { channels and promote lateral } \\
\text { hydrological connectivity; } \\
\text { burrowing activity and riparian } \\
\text { vegetation removal can destabilise } \\
\text { banks and increase bank erosion }\end{array}$ & $\begin{array}{l}\text { Butler and Malanson, } \\
2005 \text {; Burchsted et al., } \\
\text { 2010; Burchsted and } \\
\text { Daniels, } 2014 \text {; Demmer } \\
\text { and Beschta, } 2008 \text {; Hinze, } \\
\text { 1950, Hood and Larson, } \\
\text { 2015; Jakob et al., 2016; } \\
\text { Meentemeyer and Butler, } \\
\text { 1999; Polvi and Wohl, } 2013\end{array}$ & 4.2 \\
\hline $\begin{array}{l}\text { Channel planform } \\
\text { change and long-term } \\
\text { valley formation }\end{array}$ & $\begin{array}{l}\text { Breached or abandoned dams can } \\
\text { stabilise channel banks and set } \\
\text { meander geometry; beaver } \\
\text { wetland and meadow } \\
\text { development can drive long term } \\
\text { floodplain aggradation; long term } \\
\text { sedimentation rates much lower } \\
\text { than short term rates }\end{array}$ & $\begin{array}{l}\text { Fouty, } 2018 \text {; Ives, 1942; } \\
\text { John and Klein, 2004; } \\
\text { Johnston and Naiman, } \\
\text { 1990; Kramer et al., 2012; } \\
\text { Naiman et al., 1988; Persico } \\
\text { and Meyer, 2009; Polvi and } \\
\text { Wohl, 2012; Polvi and } \\
\text { Wohl, 2013; Rudemann and } \\
\text { Schoonmaker, 1938; } \\
\text { Rutten, 1967; Westbrook et } \\
\text { al., 2011 }\end{array}$ & $4.3,4.4$ \\
\hline \multicolumn{4}{|c|}{ Biogeochemistry and water quality } \\
\hline $\begin{array}{l}\text { Biogeochemical } \\
\text { pathways }\end{array}$ & $\begin{array}{l}\text { Expansion of anaerobic interfaces } \\
\text { and biogeochemical pathways }\end{array}$ & $\begin{array}{l}\text { Cirmo and Driscoll, 1993; } \\
\text { Dahm et al., } 1987\end{array}$ & 5.1 \\
\hline
\end{tabular}




\begin{tabular}{|c|c|c|c|}
\hline Carbon & $\begin{array}{l}\text { Increase in organic carbon storage; } \\
\text { increase in atmospheric fluxes } \\
\left(\mathrm{CO}_{2}, \mathrm{CH}_{4}\right) \text {, and dissolved organic } \\
\text { and inorganic carbon } \\
\text { concentrations downstream of } \\
\text { beaver systems. }\end{array}$ & $\begin{array}{l}\text { Lazar et al., 2015; Naiman } \\
\text { et al., 1986; Nummi et al., } \\
\text { 2018; Weyhenmeyer, 1999; } \\
\text { Wohl et al., } 2012\end{array}$ & 5.2 \\
\hline Nitrogen & $\begin{array}{l}\text { Increase in organic nitrogen } \\
\text { storage; increase in denitrification } \\
\text { ( } \mathrm{N}_{2} \text { losses), but not necessarily } \\
\mathrm{N}_{2} \mathrm{O} \text {; increased likelihood of } \mathrm{NO}_{3}^{-} \\
\text {retention and } \mathrm{NH}_{4}^{+} \text {enhancement } \\
\text { downstream of beaver systems }\end{array}$ & $\begin{array}{l}\text { Błędzki et al., 2011; Devito } \\
\text { and Dillon, 1993; Lazar et } \\
\text { al., 2015; Lazar et al., 2014; } \\
\text { Naiman and Melillo, } 1984\end{array}$ & 5.3 \\
\hline Phosphorus & $\begin{array}{l}\text { Phosphorus storage may increase } \\
\text { with increased sediment storage; } \\
\text { No consistent pattern in } \\
\text { downstream } \mathrm{PO}_{4}{ }^{3-} \text { export }\end{array}$ & $\begin{array}{l}\text { Devito and Dillon, 1993; } \\
\text { Fuller et al., 2015; Klotz, } \\
\text { 1998; Maret et al., } 1987\end{array}$ & 5.4 \\
\hline $\begin{array}{l}\text { Additional } \\
\text { contaminants }\end{array}$ & $\begin{array}{l}\text { Enhancement of Fe concentrations } \\
\text { and cycling. Potential increase in } \\
\text { methyl-mercury with implications } \\
\text { for downstream ecosystems }\end{array}$ & $\begin{array}{l}\text { Ciro and Driscoll, 1993; } \\
\text { Ecke et al., 2017; Levanoni } \\
\text { et al., 2015; Painter et al., } \\
\text { 2015; Roy et al., 2009a }\end{array}$ & 5.5 \\
\hline Source vs sink & $\begin{array}{l}\text { Pond / wetland storage relative to } \\
\text { inflowing water and nutrient } \\
\text { concentrations determine net } \\
\text { retention or export behaviour }\end{array}$ & $\begin{array}{l}\text { DeVito and Dillon, 1993; } \\
\text { Stanley and Ward, 1997; } \\
\text { Wegener et al., } 2017\end{array}$ & 5.6 \\
\hline \multicolumn{4}{|c|}{ Ecosystems } \\
\hline $\begin{array}{l}\text { Lentic - lotic } \\
\text { transitions and } \\
\text { primary production }\end{array}$ & $\begin{array}{l}\text { Damming creates mix of lentic and } \\
\text { lotic conditions; lentic zones have } \\
\text { higher productivity; } \\
\text { diversity in hydro-geomorphic } \\
\text { conditions leads to mosaic of } \\
\text { ecosystem habitat, also aided by } \\
\text { wood introduction; as agent of } \\
\text { disturbance, beavers disrupt the } \\
\text { river ecosystem continuum }\end{array}$ & $\begin{array}{l}\text { Burchstead et al., 2010; } \\
\text { Gibson and Olden, 2014b; } \\
\text { Hodkinson, 1975; Johnston } \\
\text { and Naiman, 1990; Law et } \\
\text { al., 2016; Naiman et al., } \\
\text { 1998; Margolis et al., 2001; } \\
\text { Snodgrass, } 1997\end{array}$ & 6.1 \\
\hline $\begin{array}{l}\text { Macro-invertebrates } \\
\text { and fish }\end{array}$ & $\begin{array}{l}\text { Likely net increase in reach scale } \\
\text { macro-invertebrate assemblage } \\
\text { diversity; restriction of fish } \\
\text { mobility dependent on dam, } \\
\text { discharge, species, and life stage; } \\
\text { increase in fish assemblage } \\
\text { diversity; increased water } \\
\text { temperatures can negatively } \\
\text { impact cold-water fish species }\end{array}$ & $\begin{array}{l}\text { Benke and Wallace, 2003; } \\
\text { Bouwes et al., 2016 ; Collen } \\
\text { and Gibson, 2000; Cunjak } \\
\text { and Therrien, 1998; } \\
\text { Dalbeck et al., 2014; } \\
\text { Johnson-Bice et al., 2018; } \\
\text { Kemp et al., 2012; Law et } \\
\text { al., 2016; Malison et al., } \\
\text { 2014;; Mitchell and Cunjak, } \\
\text { 2007; Schlosser, 1995; } \\
\text { Schlosser and Kallemeyn } \\
2000\end{array}$ & $6.2,6.3$ \\
\hline Vegetation & $\begin{array}{l}\text { Reduction in tree species through } \\
\text { water inundation, felling, } \\
\text { browsing; disturbance creates } \\
\text { 'reverse' succession in meadow } \\
\text { vegetation; long-term impact }\end{array}$ & $\begin{array}{l}\text { Barnes and Dibble, 2011; } \\
\text { Basey et al., 1988; Johnson } \\
\text { and Naiman, 1990; Kivinen } \\
\text { et al., 2020; Logofet et al., } \\
\text { 2016; Naiman et al. 1988; }\end{array}$ & 6.5 \\
\hline
\end{tabular}




\begin{tabular}{|c|c|c|c|}
\hline & $\begin{array}{l}\text { depends on frequency and length } \\
\text { of disturbance; net increase in } \\
\text { landscape scale vegetation } \\
\text { assemblage diversity; may } \\
\text { facilitate invasive species }\end{array}$ & $\begin{array}{l}\text { Nummi and Kuuluvainen, } \\
\text { 2013; Martell et al., 2006; } \\
\text { McMaster and McMaster, } \\
\text { 2001; Pastor et al., } 1988\end{array}$ & \\
\hline \multicolumn{4}{|c|}{ Feedbacks and management } \\
\hline Short-term feedbacks & $\begin{array}{l}\text { Inundation extent, as constrained } \\
\text { by hydro-geomorphic conditions, } \\
\text { is critical initial impact driving } \\
\text { changes to landscape and } \\
\text { ecosystem processes through } \\
\text { changing connectivity, storages, } \\
\text { and fluxes }\end{array}$ & See previous sections & 7.1 \\
\hline Long-term feedbacks & $\begin{array}{l}\text { Mosaic of aquatic and terrestrial } \\
\text { habitats (e.g. beaver meadow) } \\
\text { created in state of 'perpetual' } \\
\text { succession, so long as disturbance } \\
\text { can be maintained; likely increase } \\
\text { in long-term carbon sequestration } \\
\text { but magnitude uncertain }\end{array}$ & $\begin{array}{l}\text { Naiman et al. 1988; Naiman } \\
\text { et al., 1994; Westbrook et } \\
\text { al., 2011; Rudemann and } \\
\text { Schoonmaker, 1938; Wohl, } \\
2013\end{array}$ & 7.2 \\
\hline $\begin{array}{l}\text { River corridor } \\
\text { alternate stable states }\end{array}$ & $\begin{array}{l}\text { Resource depletion may occur } \\
\text { through over-exploitation or } \\
\text { competitive exclusion (e.g. with } \\
\text { elk); landscape trajectory to } \\
\text { alternate stable states following } \\
\text { abandonment depends on the } \\
\text { valley hydro-geomorphic context } \\
\text { driving water retention }\end{array}$ & $\begin{array}{l}\text { Baker et al., 2005; Baker et } \\
\text { al., } 2012 \text {; Hood and Bayley, } \\
\text { 2008b; Johnston and } \\
\text { Naiman, 1990a; Wolf et al., } \\
2007\end{array}$ & 8 \\
\hline Natural landscapes & $\begin{array}{l}\text { Landscape carrying capacity } \\
\text { involves both bottom-up and top- } \\
\text { down feedbacks, not just potential } \\
\text { habitat; Population trajectories } \\
\text { across climatic and human } \\
\text { interaction gradients highly } \\
\text { uncertain but need urgent } \\
\text { consideration in management and } \\
\text { policy making; Beavers are also an } \\
\text { invasive species in South America, } \\
\text { and to themselves in parts of } \\
\text { Finland + Russia }\end{array}$ & $\begin{array}{l}\text { Anderson et al., 2009; } \\
\text { Bailey et al., 2019; Halley } \\
\text { and Rosell, 2002; Hartman, } \\
\text { 1994; Hartman and } \\
\text { Axelsson, 2004; Parker et } \\
\text { al., 2012; Pinto et al., } 2009\end{array}$ & $9.1,9.3$ \\
\hline $\begin{array}{l}\text { Role of beavers in } \\
\text { stream management } \\
\text { and rehabilitation }\end{array}$ & $\begin{array}{l}\text { Beavers impacts may be in sync } \\
\text { with many river restoration efforts } \\
\text { and approaches, including 'stage } \\
\text { 0' (which can include beaver dam } \\
\text { analogues), rewilding, nature } \\
\text { based solutions, and ecosystem } \\
\text { services; as an ecosystem engineer } \\
\text { beavers may help improve } \\
\text { restoration success }\end{array}$ & $\begin{array}{l}\text { Bouwes et al., 2016; } \\
\text { Burchsted et al., 2010; Law } \\
\text { et al. 2017; Pollock et al., } \\
\text { 2017; Thompson et al., } \\
\text { accepted; Willby et al., } \\
2018\end{array}$ & 9.4 \\
\hline
\end{tabular}


Table 2 : Beaver pond sediment volumes

\begin{tabular}{|c|c|c|c|c|c|c|c|c|}
\hline $\begin{array}{l}\text { Locatio } \\
n\end{array}$ & $\begin{array}{c}\text { Environm } \\
\text { ental } \\
\text { context }\end{array}$ & $\begin{array}{c}\text { Aver } \\
\text { age } \\
\text { volu } \\
\text { me } \\
\left(\mathrm{m}^{3}\right) \\
\end{array}$ & $\begin{array}{l}\text { Volum } \\
\text { e } \\
\text { range }\end{array}$ & $\begin{array}{l}\text { Rate } \\
(\mathrm{cm} \\
\left.\mathrm{yr}^{-1}\right)\end{array}$ & $\begin{array}{l}\text { No. } \\
\text { of } \\
\text { pon } \\
\text { ds }\end{array}$ & Method & $\begin{array}{l}\text { Constraints on } \\
\text { rate estimates }\end{array}$ & $\begin{array}{l}\text { Referen } \\
\text { ce }\end{array}$ \\
\hline USA & $\begin{array}{l}\text { ponds, } \\
\text { high- to } \\
\text { low } \\
\text { mountain } \\
\text { range }\end{array}$ & 945 & $\begin{array}{c}11- \\
5084\end{array}$ & $2-28$ & 8 & $\begin{array}{l}\text { Cores within } \\
\text { drained } \\
\text { beaver } \\
\text { deposits }\end{array}$ & $\begin{array}{l}\text { Small number } \\
\text { and locations } \\
\text { of cores, error } \\
\text { range not } \\
\text { provided. }\end{array}$ & $\begin{array}{l}\text { Butler } \\
\text { and } \\
\text { Malans } \\
\text { on, } \\
1995\end{array}$ \\
\hline USA & $\begin{array}{l}\text { ponds, } \\
\text { high } \\
\text { mountain } \\
\text { s, 1st } \\
\text { order } \\
\text { streams } \\
\text { only }\end{array}$ & 111 & $9-267$ & $\begin{array}{l}15- \\
25\end{array}$ & 10 & $\begin{array}{l}\text { Systematic } \\
\text { grid-based } \\
\text { coring of } \\
\text { beaver ponds }\end{array}$ & $\mathrm{n} / \mathrm{a}$ & $\begin{array}{c}\text { Meente } \\
\text { meyer } \\
\text { and } \\
\text { Butler, } \\
1999\end{array}$ \\
\hline USA & $\begin{array}{l}\text { pond, } \\
\text { mountain } \\
\text { ous }\end{array}$ & 750 & & 1 & 1 & $\begin{array}{c}\text { Sediment } \\
\text { depth from } \\
\text { drained } \\
\text { beaver ponds }\end{array}$ & $\begin{array}{l}\text { Small number } \\
\text { of ponds }\end{array}$ & $\begin{array}{c}\text { Westbr } \\
\text { ook et } \\
\text { al., } \\
2011\end{array}$ \\
\hline USA & $\begin{array}{c}\text { ponds, } \\
\text { lake delta }\end{array}$ & 3069 & $\begin{array}{l}876- \\
6355\end{array}$ & $\mathrm{n} / \mathrm{a}$ & 10 & $\begin{array}{c}\text { No sediment } \\
\text { depth } \\
\text { measurement } \\
\mathrm{s}\end{array}$ & $\begin{array}{c}\text { Sediment } \\
\text { depth } \\
\text { estimated } \\
\text { using empirical } \\
\text { equation with } \\
\text { unclear } \\
\text { applicability }\end{array}$ & $\begin{array}{l}\text { Butler, } \\
2012\end{array}$ \\
\hline USA & $\begin{array}{l}\text { ponds, } \\
\text { low } \\
\text { gradient } \\
\text { fan }\end{array}$ & 92 & $48-182$ & $\mathrm{n} / \mathrm{a}$ & 6 & $\begin{array}{l}\text { Sediment } \\
\text { depth from } \\
\text { drained } \\
\text { beaver ponds } \\
\text { / wetlands }\end{array}$ & $\mathrm{n} / \mathrm{a}$ & $\begin{array}{l}\text { Levine } \\
\text { and } \\
\text { Meyer, } \\
2014\end{array}$ \\
\hline USA & $\begin{array}{l}\text { ponds, } \\
\text { mountain } \\
\text { ous }\end{array}$ & 554 & & $\begin{array}{c}45- \\
0.75\end{array}$ & 13 & $\begin{array}{l}\text { Systematic } \\
\text { grid-based } \\
\text { coring of } \\
\text { beaver ponds }\end{array}$ & $\begin{array}{c}\text { Landscape } \\
\text { context } \\
\text { unclear: in- } \\
\text { channel/floodp } \\
\text { lain ponds }\end{array}$ & $\begin{array}{l}\text { Pollock } \\
\text { et al., } \\
2007\end{array}$ \\
\hline Canada & $\begin{array}{l}\text { ponds, } \\
\text { mountain } \\
\text { ous, } \\
\text { valley- } \\
\text { spanning } \\
\text { dams }\end{array}$ & 387 & $98-842$ & 3.7 & 8 & $\begin{array}{c}\text { Regression } \\
\text { model based } \\
\text { on other sites }\end{array}$ & $\begin{array}{c}\text { no } \\
\text { measurements }\end{array}$ & $\begin{array}{l}\text { Green } \\
\text { and } \\
\text { Westbr } \\
\text { ook, } \\
2009\end{array}$ \\
\hline
\end{tabular}




\begin{tabular}{|c|c|c|c|c|c|c|c|c|}
\hline Canada & $\begin{array}{c}\text { pond, } \\
\text { lowlands }\end{array}$ & $\mathrm{n} / \mathrm{a}$ & $\mathrm{n} / \mathrm{a}$ & $\begin{array}{l}0.2- \\
0.6\end{array}$ & 1 & $\begin{array}{l}\text { Cores within } \\
\text { pond deposits }\end{array}$ & $\begin{array}{l}\text { Single pond, } \\
\text { coring strategy } \\
\text { unclear }\end{array}$ & $\begin{array}{c}\text { Devito } \\
\text { and } \\
\text { Dillon, } \\
1993\end{array}$ \\
\hline $\begin{array}{c}\text { German } \\
y\end{array}$ & $\begin{array}{l}\text { ponds, } \\
\text { mountain } \\
\text { ous }\end{array}$ & 223 & $33-516$ & 8 & 5 & $\begin{array}{l}\text { Systematic } \\
\text { grid-based } \\
\text { coring of } \\
\text { beaver ponds }\end{array}$ & $\begin{array}{c}\text { Landscape } \\
\text { context } \\
\text { unclear: in- } \\
\text { channel/floodp } \\
\text { lain ponds }\end{array}$ & $\begin{array}{l}\text { John } \\
\text { and } \\
\text { Klein, } \\
2004\end{array}$ \\
\hline Belgium & $\begin{array}{l}\text { ponds, } \\
\text { mountain } \\
\text { ous }\end{array}$ & 57.16 & $\begin{array}{l}0.94- \\
9.35\end{array}$ & 3.6 & 10 & $\begin{array}{c}\text { Systematic } \\
\text { grid-based } \\
\text { coring of } \\
\text { beaver ponds }\end{array}$ & $\mathrm{n} / \mathrm{a}$ & $\begin{array}{c}\text { de } \\
\text { Visscher } \\
\text { et al., } \\
2014\end{array}$ \\
\hline Poland & $\begin{array}{l}\text { ponds, } \\
\text { mountain } \\
\text { ous }\end{array}$ & $\mathrm{n} / \mathrm{a}$ & $\mathrm{n} / \mathrm{a}$ & 14 & 5 & $\begin{array}{l}\text { Coring of } \\
\text { beaver pond } \\
\text { deposit }\end{array}$ & $\begin{array}{l}\text { sampling } \\
\text { strategy not } \\
\text { described }\end{array}$ & $\begin{array}{c}\text { Giriat et } \\
\text { al., } \\
2016\end{array}$ \\
\hline England & $\begin{array}{l}\text { ponds, } \\
\text { fen, 1st } \\
\text { order } \\
\text { stream }\end{array}$ & $\begin{array}{c}381.8 \\
7\end{array}$ & $\begin{array}{l}7.33- \\
59.51\end{array}$ & 5.4 & 13 & $\begin{array}{c}\text { Systematic } \\
\text { grid-based } \\
\text { coring of } \\
\text { beaver ponds }\end{array}$ & $\mathrm{n} / \mathrm{a}$ & $\begin{array}{l}\text { Puttock } \\
\text { et al., } \\
2019\end{array}$ \\
\hline
\end{tabular}

Table 3. Thought experiment on the impact of an increasing number of beaver dams on the time needed for $50 \%$ of the water or sediment tracer outflow distribution $\left(t_{50}\right)$ to be released from the system, assuming different transfer delays of water $(\tau)$ and sediment $\left(\tau_{\text {sed }}\right)$ between dams.

\begin{tabular}{lll}
\hline$t_{50}$ Scenario & Water & Sediment \\
& $(\tau=1)$ & $\left(\tau_{\text {sed }}=100\right)$ \\
\hline 2 dams & 2.2 days & 168 days $(0.46 \mathrm{yrs})$ \\
5 dams & 4.2 days & 467 days $(1.3 \mathrm{yrs})$ \\
10 dams & 9.2 days & 968 days $(2.6 \mathrm{yrs})$
\end{tabular}


Table 4: Illustrative examples of net positive or negative interpretations of beaver related impacts, each made in isolation but stemming from the same underlying process feedback

Underlying feedback ${ }^{1}$

\begin{tabular}{|c|c|c|}
\hline $\begin{array}{l}\text { Increase in ground and surface } \\
\text { water storage }\end{array}$ & $\begin{array}{l}\text { - Potential increase in } \\
\text { baseflow }\end{array}$ & - Increase in evaporation \\
\hline $\begin{array}{l}\text { Increase in water inundation } \\
\text { area and floodplain } \\
\text { connectivity }\end{array}$ & $\begin{array}{l}\text { - Additional space for flood } \\
\text { management (but overall } \\
\text { impact on attenuation } \\
\text { uncertain or highly site } \\
\text { specific) }\end{array}$ & $\begin{array}{l}\text { - Increased chance of land } \\
\text { - } \text { use conflict } \\
\text { - } \quad \text { Loss of woody vegetation } \\
\text { - Potential dam failure }\end{array}$ \\
\hline $\begin{array}{l}\text { Increase in floodplain and } \\
\text { channel sediment deposition, } \\
\text { floodplain channel digging and } \\
\text { the creation of a multi-thread } \\
\text { channel system }\end{array}$ & 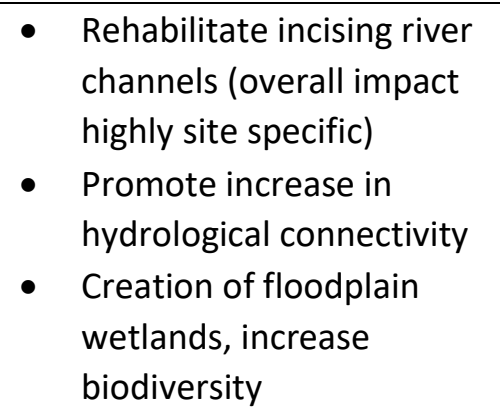 & $\begin{array}{l}\text { - Increase in land-use } \\
\text { conflicts } \\
\text { - Loss of cultural } \\
\text { landscapes }\end{array}$ \\
\hline $\begin{array}{l}\text { Increase in wetland habitat } \\
\text { and extent of anaerobic } \\
\text { interfaces }\end{array}$ & $\begin{array}{ll}\text { - } & \text { Reduction in } \mathrm{NO}_{3}^{-} \text {loads } \\
\text { - } & \text { Increased carbon storage } \\
\text { - } & \text { Increased net primary } \\
& \text { production, carbon } \\
\text { storage and cycling }\end{array}$ & $\begin{array}{ll}\text { - Increased } \mathrm{CO}_{2} \text { and } \mathrm{CH}_{4} \\
\text { emissions } \\
\text { - } \\
\text { Potential increase in } \\
\text { methyl mercury loads and } \\
\text { ecosystem uptake } \\
\text { - Increase in dissolved } \\
\text { organic carbon } \\
\text { concentrations } \\
\text { downstream adding to } \\
\text { water treatment loads }\end{array}$ \\
\hline $\begin{array}{l}\text { Creation of lotic to lentic } \\
\text { habitat transitions }\end{array}$ & $\begin{array}{l}\text { - Increase in overall aquatic } \\
\text { and terrestrial ecosystem } \\
\text { biodiversity } \\
\text { - Increase in lateral habitat } \\
\text { exchange }\end{array}$ & $\begin{array}{l}\text { Potential impacts on fish } \\
\text { migration } \\
\text { - Potential increase in } \\
\text { thermal stress for cold- } \\
\text { water species } \\
\text { - Disturbance can facilitate } \\
\text { introduced species }\end{array}$ \\
\hline
\end{tabular}

${ }^{1}$ See the relevant sections for more detailed discussions on these feedbacks

${ }^{2}$ In many regions of Western Europe river valleys have been actively managed as agricultural landscapes, in some cases since the Neolithic period, and in most regions since the medieval period. The policies to maintain and protect these cultivated river valleys often describes them as cultural landscapes 